\title{
Studies on neurodevelopmental issues in children
}

Citation for published version (APA):

Feron, F. J. M. (2007). Studies on neurodevelopmental issues in children. [Doctoral Thesis, Maastricht University]. Datawyse / Universitaire Pers Maastricht. https://doi.org/10.26481/dis.20070209ff

Document status and date:

Published: 01/01/2007

DOI:

10.26481/dis.20070209ff

Document Version:

Publisher's PDF, also known as Version of record

\section{Please check the document version of this publication:}

- A submitted manuscript is the version of the article upon submission and before peer-review. There can be important differences between the submitted version and the official published version of record.

People interested in the research are advised to contact the author for the final version of the publication, or visit the DOI to the publisher's website.

- The final author version and the galley proof are versions of the publication after peer review.

- The final published version features the final layout of the paper including the volume, issue and page numbers.

Link to publication

\footnotetext{
General rights rights.

- You may freely distribute the URL identifying the publication in the public portal. please follow below link for the End User Agreement:

www.umlib.nl/taverne-license

Take down policy

If you believe that this document breaches copyright please contact us at:

repository@maastrichtuniversity.nl

providing details and we will investigate your claim.
}

Copyright and moral rights for the publications made accessible in the public portal are retained by the authors and/or other copyright owners and it is a condition of accessing publications that users recognise and abide by the legal requirements associated with these

- Users may download and print one copy of any publication from the public portal for the purpose of private study or research.

- You may not further distribute the material or use it for any profit-making activity or commercial gain

If the publication is distributed under the terms of Article $25 \mathrm{fa}$ of the Dutch Copyright Act, indicated by the "Taverne" license above, 
STUDIES ON NEURODEVELOPMENTAL ISSUES IN CHILDREN 
(C) Frans Feron, Maastricht 2007

Cover design: @ Veronique Willems - Maastricht Layout: Frans Feron

Production: Datawyse / Universitaire Pers Maastricht

ISBN-13: 978-90-9021521-1

All rights reserved. Illustrations and brief excerpts from this publication may be used for scientific and educational purpose provided that the source is acknowledged. 


\title{
Studies on Neurodevelopmental Issues in Children
}

\author{
PROEFSCHRIFT
}

ter verkrijging van de graad van doctor aan de Universiteit Maastricht, op gezag van de Rector Magnificus, Prof.mr. G.P.M.F. Mols

volgens het besluit van het College van Decanen,

in het openbaar te verdedigen op vrijdag 9 februari 2007 om 14.00 uur

door

Franciscus Joseph Maria Feron 
Promotores

Prof.dr. J.S.H. Vles

Prof.dr. J. Jolles

\section{Copromotor}

Dr. J.G.M. Hendriksen

\section{Beoordelingscommissie}

Prof.dr. J. Troost (Voorzitter)

Prof.dr. A.P. Aldenkamp (Epilepsiecentrum Kempenhaeghe)

Prof.dr. A.M. Korebrits

Prof.dr. H. Swaab-Barneveld (Universiteit Leiden)

Prof.dr. L.J.I. Zimmermann 
Voor Josien, Erik, Martijn en Jolien 


\section{CONTENTS}

Chapter 2 Acid-base status at birth, spontaneous motor behavior at term and 3 months and neurodevelopmental outcome at age 4 years in full-term infants

Chapter 3 Acid-base status at birth and neurocognitive outcome at preschool age

Chapter 4 The effect of clonidine and methylphenidate in children with Attention Deficit Hyperactivity Disorder: a comparison of neuropsychological and behavioral effects in 37 children

Chapter 5 Methylphenidate down-regulates the dopamine receptor and transporter system in children with Attention Deficit Hyperactivity Disorder (ADHD)

Chapter 6 Dopamine Transporter in Attention-Deficit Hyperactivity Disorder normalizes after cessation of methylphenidate

Chapter 7 Status epilepticus in a child with cerebral palsy and ADHD: a proconvulsant effect of Clonidine?

Chapter 8 Transmural consultation hour for AHDH at the Youth Health Care Department: A collaboration model in the south of the province of Limburg, the Netherlands

Chapter 9 Concluding remarks

Summary

Samenvatting

Dankwoord 
CHAPTER 1

\section{Background and outline of the thesis}


The present thesis is a compilation of several studies on neurodevelopmental issues in children. Issues to be discussed, concern the age range from birth to school age, with a main focus on perinatal asphyxia and attention deficit hyperactivity disorder. These issues will be introduced in this chapter within the wider context of the Youth Health Care, which was the starting point of all the studies. Brain-behavior relations are supposed to be the most important theoretical frameworks in children with neurodevelopmental disorders. As such Child Neurology and Child Neuropsychology are closely allied disciplines, which are brought together with Youth Health Care in a field of action for the studies in this thesis.

\subsection{BACKGROUND: NEURODEVELOPMENTAL ISSUES AND HEALTH IN CHILDREN}

Childhood is characterized by rapid developmental changes that affect physical health, behavioral functioning, cognition and health care needs. As children develop and grow older, their health care utilization changes, as well as the preventive care they require. Early detection and diagnosis of developmental disorders, behavioral problems, emotional problems and learning disabilities are main objectives in current youth health care in order to achieve early and timely therapeutic interventions. Neurodevelopment in a child is a continuous dynamic process occurring from conception to maturity. Neurodevelopment signifies maturation of the brain in relation to the maturation of other organs and systems within the context of biological, social and environmental influences, resulting in development of perceptual and motor capacities, speech- and language acquisition, intellectual abilities, emotional functioning, social skills and behavior. Brain-behavior related developmental disorders do have notable impact, not only on children and their parents, but also on society because of an increased risk of addiction, involvement in accidents, antisocial and criminal behavior. Societal consequences in this respect include the need for provisions for special education, health care, youth welfare work, child protection on the one hand and providing measures against juvenile delinquency and drug addiction on the other.

\subsection{PREVALENCE RATES OF NEURODEVELOPMENTAL DISORDERS}

Registrations in youth health care indicate that behavioral, emotional and educational problems are highly prevalent among children in the Netherlands (prevalence $25 \%$ to $30 \%)[1,2]$. The number of children suffering from long-term physical disorders is also considerable (12\% to $14 \%)$, especially among children of primary school age $[3,4]$. 
Attention-problems with hyperactivity are aspects of behavioral functioning that currently receive great notice in the scientific literature. These problems, especially in relation to school performance, are also of great interest to youth health care physicians. The prevalence of attention-deficit hyperactivity disorder among Dutch children is $3 \%$ to $5 \%$. Developmental coordination disorders (DCD) are noticed in about $5 \%$ to $10 \%$ of the children. Boys outnumber girls by three to one in displaying the symptoms of DCD. Problems in reading and spelling occur in $4 \%$ tot $8 \%$ of the children. Dyscalculia is seen in $3 \%$ to $6 \%$ of the school population [5].

Attention-deficit hyperactivity disorders have a research history of more than 100 years. In research, behavioral functioning most often is used to measure outcome, but outcome measures related to school and learning perspective have not yet been used very often. In this thesis we primarily use the school and learning perspective of ADHD.

ADHD is a neurodevelopmental disorder in children, which makes them unable to inhibit motor or emotional responses to an event. This results in the core symptoms of the DSM-IV classification, i.e. attention deficit and/or hyperactivity/impulsivity. These chronic difficulties with inattentions and/or impulsivity and hyperactivity are called the "holy trinity" of ADHD (Barkley, 2006) [6]. ADHD rarely occurs in isolation: often there are associated problems (Barkley, 2006) [6]. According to Barkley there is a great variation in the prevalence rates of learning disabilities associated with ADHD. They vary from $8-39 \%$ for reading disability, $12-26 \%$ for spelling disorder, and $12-33 \%$ for math disability. The prevalence of associated problems with motor development is even higher and estimated around 50\%. ADHD diagnosis in children has a high comorbidity for other psychiatric diagnoses, including oppositional defiant disorder, conduct disorder, mood disorders, anxiety disorders, and learning disorders $[6,7,8]$. Furthermore, children with ADHD are at high risk for associated with functional problems, including school failure, parental conflicts, poor peer relationships, delinquent and/or antisocial behavior, traffic accidents, injuries, smoking and substance abuse $[6,7,8]$.

\subsection{STUDIES ON NEURODEVELOPMENTAL ISSUES: GENERAL OBJECTIVE OF THE THESIS}

Research into neurodevelopmental issues in children in the field of the youth health care is not quite common. However, research into brain-behavioral relations and neurodevelopment in children does have large potentialities using the infrastructure of youth health care, especially regarding longitudinal cohort studies.

The present thesis contemplates to contribute in the knowledge on neurodevelopmental issues in children and to elucidate the added value of interdisciplinary co-operation within the context of research and care in the domain of 
neurodevelopmental disorders in children. Therefore, the general objective of this thesis is to emphasize the connection between neurodevelopmental research and youth health care.

In 2000, the Dutch Health Council wrote an extensive report on diagnosis and treatment of ADHD [9], with reference to the Maastricht working method [9: page 108]. In this report the role of the youth health care is clearly described, in particular early detection of ADHD in children and timely referral on the one hand and monitoring and follow up of therapeutic interventions on the other. The Dutch Health Council formulated several recommendations related to diagnosis and treatment of ADHD. Youth health care services play a key role in the network of numerous professionals and institutions concerning early detection, referral and prompting interventions. Furthermore, youth health care can provide low-threshold assistance in parenting and family support. The studies on neurodevelopmental issues in this thesis concerning ADHD are in line with the following recommendations of the National Health Council:

- Research is urgently needed to gather both quantitative and qualitative data on optimizing medical treatment, concerning indication of medical treatment and response on medication treatment respectively to gain an insight in reasons to stop medication.

- Intensive and long-term monitoring of the effect of methylphenidate is required in order to obtain information about the implications of prolonged use and long-term effects of methylphenidate.

- Knowledge about a child's family circumstances and school environment should be taken in account when considering the diagnosis of ADHD, making use of information from more than one source. On this point youth health care can provide preliminary information in consultation with parents and teachers.

\subsection{NEURODEVELOPMENTAL ISSUES IN CHILDREN: GENERAL SETTINGS FOR RESEARCH}

In order to make research into the above-mentioned objectives operational, a special setting is required in which the identification of neurodevelopmental disorders, diagnosis, treatment and monitoring are brought together in a multidisciplinary working arrangement. The Youth Health Care service in Maastricht, the University Hospital in Maastricht (department of Child Neurology), the University of Maastricht (department of Psychiatry and Neuropsychology) and the Child Rehabilitation Center Franciscusoord, have a tradition of more than a decade with respect to longitudinal research aimed at detecting the developmental profile of children with ADHD: the Study of Attention Disorders Maastricht (SAM). The SAM-study is a large-scale 
multidisciplinary study of attention deficit disorders in Maastricht and as such an example of efficacy of a collaborative research program in this domain, which resulted in several theses $[10,11,12]$ and numerous international publications. Over and above that, the SAM-study provides the unique opportunity for longitudinal follow-up of two large cohorts of children suffering from attention disorders, behavioral disorders and healthy control children from 5 till 18 years of age. For a detailed description of the SAM-study: see Kroes et al., 2001; Kalff et al., 2001; 2002 $[13,14,15]$.

As a result of the collaboration between the youth health care service and the academic partners in the SAM-study, two new instruments were developed for application in the assessment of children aged 5-6 years for early and timely detection of symptoms in motor performance and behavior suspect for the development of ADHD: the Maastricht Motor Test (MMT) respectively the Precursors of ADHD Questionnaire (PAQ) $[16,17,18,19]$. Moreover, in the SAM-study the socialdemographic variances and developmental profile of children with ADHD were further investigated, leading to a better understanding of behavioral problems in school-aged children and intervention strategies $[20,21,22,23,24,25]$.

In Maastricht, the Youth Health Care service, Child Neurology and Child Neuropsychology, work together in early detection, diagnosis and treatment of children with neurodevelopmental disorders. The Maastricht concept of collaboration in health care is unique in the Netherlands. This model has recently been presented at a national conference on ADHD (Vles, Hendriksen, Feron: ADHD and its consequences for school career. Amsterdam, October 2005). In figure 1.1, a Venn diagram visualizes this concept. The three circles represent the three disciplines Youth Health Care, Child Neurology and Child Neuropsychology, with their main target of interest, respectively general child health care, maturation of the brain and development of cognition. The overlap of the circles is represented first by the socalled structure of brain, for instance the neurobiological substrate of ADHD in the striatum (putamen and caudate nucleus) in children with ADHD. Another field of overlap is the function of the brain as represented by information processing capacities. Furthermore the learning problems and stagnation in school performances, as this area of overlap is the main reason for multi-disciplinary assessment and represents also the main field of evaluation. An extensive study of the Maastricht research group has recently been submitted, analyzing the outcome data of 495 children being referred to the outpatient clinic for learning disabilities (Hendriksen, Keulers, Feron et al., submitted) [26].

Finally, the threefold overlap concerns neurodevelopmental issues in children, being the main topics of this thesis. 


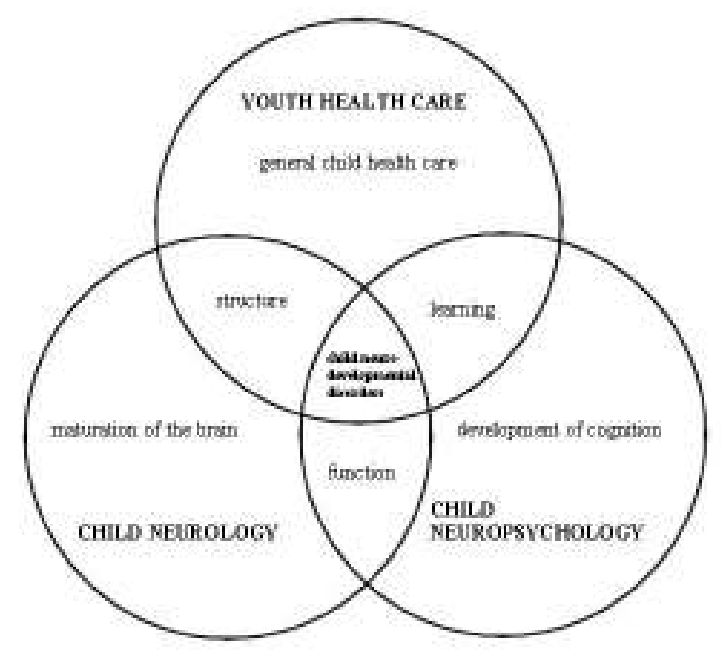

Figure 1.1: Maastricht concept: a collaboration model of Youth Health Care, Child Neurology and Child Neuropsychology visualized by a Venn diagram.

In the following section a short introduction is given on preventive youth health care in the Netherlands. The organization, regular tasks and working methods of youth health care are described, in order to explain the place of youth health care within the health care chain and its prominent entry for data-collection in respect of longitudinal cohort studies.

\subsection{PREVENTIVE YOUTH HEALTH CARE: AN INTRODUCTION}

In the Netherlands, services for child health care and preventive youth health care were initiated more than 100 years ago. Preventive Youth Health Care (YHC) was historically divided into three parts: (1) perinatal health care (maternity home help); (2) pre-school health care for infants and children aged 0-4 years, provided by youth health care physicians and nurses working in Mother and Child Health Care (MCHC), a division of the home care organizations; and (3) school health care, preventive youth health care for the age of 4-19 years old, provided by the Youth Health Care divisions of the Regional Public Health Services (GGD).

Pre-school health care and school health care are nowadays integrated into one youth health care system for all children from birth to 19 years. The Public Health Collective Prevention Act (Wet Collectieve Preventie Volksgezondheid - WCPV) provides a basic package of tasks for the youth health care $[27,28]$. This basic 
package of tasks focuses on the prevention and the active early detection of illnesses and health risks that disrupt normal physical, mental and social development in children $[27,28]$. In accordance with the Collective Prevention Act, youth health care activities also include publicly funded preventive programs: national vaccination program, periodical systemic medical assessments, preventive screening for specific physical abnormalities, consultation hours, health education and health promotion programs. As part of the youth health care system, all children living in the Netherlands receive free preventive medical assessments, from birth through adolescence. These assessments consist of an interview concerning any possible physical and psychosocial or developmental problems, a general physical examination and several standardized screening procedures. Based on the outcome of a medical assessment, youth health care physicians make a decision whether there is any need for counseling, follow-up, diagnostic work-up or referral.

During the early years, youth health care also includes parental counseling in nutrition, disease prevention and child development. Partly because the general health situation of Dutch children and young people is considered to be good, the attention of the youth health care among school-aged children has shifted from preventing somatic diseases to the early detection of vulnerable children and high risk groups. In particular, the youth health care has focused gradually on early diagnosis of developmental disorders, behavioral problems, emotional problems and learning disabilities.

Within the health care chain, preventive youth health care works not only by reacting to a demand for care, but also pro-active. There is an increasing need of direct anticipation on children and youngsters who are at risk in their health, growth and development. The simple fact that children may experience various physical and developmental problems, whereas their parents refrain from visiting a doctor or from asking for medical assistance, underlines the importance of a health care system primarily targeted at children and youngsters themselves.

In youth health care, longitudinal data acquisition in youth starts at birth, gathering data on prenatal, perinatal and postnatal development of newborns. Virtually every Dutch child attends the youth health care services for periodical medical assessments from early infancy through adolescence age. During every preventive systemic medical assessment, the balance between risk factors and protective factors in relation to child development is evaluated. As a result of the medical assessments, youth health care physicians are used to collect a wide range of heath screening data and findings in an attempt to predict children at risk of developing psychosocial problems, behavioral problems or learning disabilities.

At school age, the medical assessments are closely linked to the educational system, as appears from the use of the word "school doctor" in Dutch. Careful monitoring of health, growth and development at different ages provides the opportunity to produce extensive longitudinal data and epidemiological analysis of data on different levels. 
From birth to 19 years, health is monitored in repeated systemic medical assessments, completed with further information being provided by the parents or by the older children themselves through questionnaires. All these data are kept in individual files, providing a longitudinal database. Consequently, following individual children over a long period youth health care pre-eminently provides potentialities for retrospective cohort studies, cross-sectional studies and prospective longitudinal studies. The main topics in youth health care seen in an age-dependent perspective are represented in table 1.1 .

\begin{tabular}{|c|c|c|c|c|c|c|}
\hline & birth & $0-1$ years & $1-4$ years & 4- 6 years & $6-12$ years & $12-19$ years \\
\hline Pre-/peri-/postnatal complications & +++ & \pm & \pm & \pm & - & - \\
\hline Congenital defects & ++ & + & \pm & \pm & - & - \\
\hline Social Class \& Family Functioning & + & ++ & ++ & ++ & + & + \\
\hline Nutrition / malnutrition & + & +++ & ++ & + & + & + \\
\hline Growth & + & \multicolumn{5}{|c|}{ at each visit } \\
\hline Immunizations & - & + & + & - & + & - \\
\hline General physical examination & + & \multicolumn{5}{|c|}{ at each visit } \\
\hline Vision \& Hearing & + & \multicolumn{5}{|c|}{ at each visit } \\
\hline Motor development & + & $\begin{array}{c}+ \\
\text { V. Wiechen }\end{array}$ & $\begin{array}{c}++ \\
\text { V. Wiechen }\end{array}$ & $\begin{array}{c}++ \\
(\mathrm{MMT})\end{array}$ & + & \pm \\
\hline Language development & - & \pm & ++ & +++ & + & - \\
\hline Emotional \& Social development & - & + & ++ & $\begin{array}{c}++ \\
(\mathrm{CBCL} ; \mathrm{TRF})\end{array}$ & $\stackrel{+}{+}$ & $\stackrel{+}{+}$ \\
\hline Behavioral problems & - & - & + & $\stackrel{+}{+}$ & $\stackrel{+}{+}$ & $\begin{array}{c}+ \\
+ \\
(\mathrm{CBCL} ; \mathrm{TRF} ; \mathrm{YSR})\end{array}$ \\
\hline $\begin{array}{l}\text { Problems with inattention, } \\
\text { hyperactivity and impulsivity }\end{array}$ & - & - & \pm & $\begin{array}{c}+ \\
(\mathrm{PAQ})\end{array}$ & $\begin{array}{c}++ \\
(\mathrm{CBCL} ; \mathrm{TRF})\end{array}$ & $\stackrel{+}{+}$ \\
\hline Learning disabilities & - & - & - & \pm & +++ & + \\
\hline Child abuse \& neglect & - & +++ & ++ & ++ & + & + \\
\hline Overweight \& obesity & - & + & + & + & + & + \\
\hline Addiction (alcohol-drugs-nicotine) & - & - & - & - & \pm & ++ \\
\hline
\end{tabular}

$+++=$ high level of interest in medical assessments; $++=$ above average level of interest in medical assessments: $+=$ routine level of interest in medical assessments; $\pm=$ low or indirect level of interest in medical assessments; Abbreviations: V. Wiechen = Van Wiechen classification of psychomotor development [29]; MMT = Maastricht Motor Test (if indicated) [16,17]; PAQ = Precursors of ADHD Questionnaire (in Dutch: VVA) (if indicated) $[18,19]$; $\mathrm{CBCL}=$ Child Behavior Check List (if indicated) [30,31]; TRF = Teachers Report Form (if indicated) [32,33]; YSR = Youth Self Report (if indicated) [34,35]

The 'Van Wiechen' classification of psychomotor development is an age-dependent assessment of motor behavior, speech, communication and social skills [29]. The 'Van Wiechen' classification indicates age-dependent skills that $90 \%$ of the children of an average population should be able to perform. An underperformance in one of the above-mentioned domains of the developmental scale is considered to indicate disturbed development. Youth health care physicians use the 'Van Wiechen' 
classification of psychomotor development for routine medical assessment in children aged 1 to 48 months.

The Maastricht Motor Test (MMT) is a valid and reliable instrument to assess quantitative and qualitative aspects of motor development in 5 to 6 year old children, covering static balance, dynamic balance, ball skills, and diadochokinesis and manual dexterity $[16,17]$. In youth health care the MMT is used in medical assessments only if indicated. The PAQ, Precursors of ADHD Questionnaire, is a Dutch questionnaire for parents of pre-school children to detect precursors of ADHD. This questionnaire has been proven to be valid and reliable $[18,19]$. The PAQ consists of 23 items that yield scores on four subscales: Socially inadequate behavior, Impulsivity, Hyperactivity and Attention deficit problems $[18,19]$. In youth health care the PAQ is used in medical assessments only if indicated.

If indicated, behavioral functioning of the children can be measured by means of the Dutch version of the Child Behavior Checklist (CBCL), the Teacher's Report Form (TRF) and/or the Youth Self Report (YSR). The CBCL is a parent-reported measure of child behavior problems. This questionnaire yields T-scores for a total problemscale, two broadband scales (i.e., externalizing and internalizing behavior problems) and nine narrowband scales (i.e., withdrawal, physical complaints, anxiety/depression, social problems, thought problems, attention problems, delinquent behavior, aggressive behavior, and sexual problems) [30,31]. The Teacher's Report Form (TRF) obtains teacher's reports of children's academic performance, adaptive functioning, and behavioral/emotional problems [32,33]. Teachers rate the children's academic performance in each subject on a five-point scale ranging from 1 (far below grade level) to 5 (far above grade level). Cognitive and achievement test scores for the child, if available, can also be provided on the form. For adaptive functioning, teachers use a seven-point scale to compare the child to typical pupils for how hard he/she is working, how appropriately he/she is behaving, how much he/she is learning, and how happy he/she is. The Youth Self Report (YSR) provides selfratings for 20 competence and problem items paralleling those of the Child Behavior Checklist (CBCL). The YSR also includes open-ended responses to items covering physical problems, concerns, and strengths [34,35]. Youths aged 11 to 18 years rate themselves for how true each item is now or was within the past six months, using the same three-point response scale as the $\mathrm{CBCL}$ and TRF. Brugman and colleagues (2001) argued that youth health care services are capable in identifying and managing psychosocial problems in children, when using additional questionnaires are used like the Behavioral Child Check List (CBCL) [1].

\subsection{OUTLINE AND AIMS OF THE STUDIES}

This thesis attempts to explore the importance of the connection between neurodevelopmental research and the setting of youth health care. In the light of this 
general intention, this thesis is focused on the following specific objectives within the domain of neurodevelopment in children:

- To assess the relationship between acid-base status at birth and short-term and long-term neurodevelopmental outcome, in terms of general movements at birth respectively at age of 3 months, mental and motor development at age of 9 months respectively 18 months, and neurological, cognitive and behavioral functioning at age of 4 years.

- To determine effects of medication treatment in children with ADHD in terms of information processing and behavioral functioning.

- To monitor medication treatment in children with ADHD, focusing on the neurobiological substrate of ADHD in relation to neurodevelopmental outcome.

- To indicate the practical implications of the multidimensional aspects of neurodevelopmental issues.

The present thesis consists of two studies on predictive value of acid-base status at birth on later cognitive development at pre-school age. As such it concentrates on the first four years of development and the possible role of acidosis for development of later attention problems and cognition. Subsequently, three studies are presented on the effects of medication in a group of school-aged children with ADHD. The specific aim of these three studies is to demonstrate the influence of medication on the brain mechanism of ADHD respectively on learning and behavioral outcome: the neurobiological substratum of ADHD is discussed. A case study on the risks of medication for ADHD in a child with cerebral palsy is also included. Finally, the multidimensional aspects of neurodevelopmental issues are discussed in an article where Youth Health Care, Child Neurology and Child Neuropsychology are brought together. The neurodevelopmental perspective in this thesis is therefore both on the structure, function and learning (figure 1.1).

Following the introduction (chapter 1), a longitudinal study on the relation between the parameters acid-base status at birth, spontaneous motor behavior and neurodevelopmental outcome is described in chapter 2: Acid-base status at birth, spontaneous motor behavior at term and 3 months and neurodevelopmental outcome at age 4 years four years in full-term infants. Quality and quantity of general movements were assessed in full-term infants at birth and at the age of three months. At the age of four years in a group of 44 children outcome on motor, cognitive and behavioral functioning was measured, with a main focus on evaluation of neuromotor behavior. The results of this study are discussed from a clinical point of view, especially with concern to the prognosis for development in children with a history of perinatal acidosis of different degree.

The objective of the study presented in chapter 3 was to further investigate the relationship between acid-base status at birth and long-term neurocognitive and behavioral outcome using an extended sample size: Acid-base status at birth and 
neurocognitive outcome at preschool age. Based on analysis of data collected at the age of nine months, 18 months and four years, a group of 66 children was prospectively evaluated, with special reference to information processing capacities at the age of four years. In particular this study was focused on the values of initial umbilical artery $\mathrm{pH}$ and base excess as predictors of neurocognitive and behavioral outcome at early school age as well as possible gender differences.

Chapter 4 reports on a prospective study on the effects of medication treatment in children with ADHD, comparing clonidine to methylphenidate medication: The effect of clonidine and methylphenidate in children with Attention-Deficit $I$ Hyperactivity Disorder: a comparison of neuropsychological and behavioral effects in 37 children. Information processing and behavioral functioning were systematically assessed before and eight weeks after medication was started. The results of medication monitoring comparing clonidine to methylphenidate showed significant different effects as well as similar effects on information processing and inhibition control in behavior. The added value of neuropsychological assessment in clinical practice is demonstrated.

Using single-photon emission computed tomography (SPECT), imaging of brain dopamine transporter and receptor activity was studied in six boys with ADHD to monitor methylphenidate treatment. The results of this study are reported in chapter 5: Methylphenidate down-regulates the dopamine receptor and transporter system in children with Attention-Deficit / Hyperactivity Disorder (ADHD). Imaging by SPECT was performed before starting treatment with methylphenidate and SPECT was repeated after three months. An extensive neuropsychological assessment was also performed before and three months after treatment. The results on SPECT were studied in relation to baseline and follow-up neuropsychological findings.

Chapter 6 deals with the potential long-term effects of chronic methylphenidate treatment: Dopamine Transporter in ADHD normalizes after cessation of methylphenidate. Single-photon emission computed tomography (SPECT) was used to investigate possible long-term alterations in the cerebral dopamine system after cessation of treatment with methylphenidate in five children with ADHD.

In chapter 7 a case report is described in order to discuss the role of clonidine: Status Epilepticus in a child with Cerebral Palsy and ADHD: a proconvulsant effect of Clonidine? Within the spectrum of pharmacological interventions for the management of ADHD in school-aged children the role of clonidine is changing. Recent data related to the probable proconvulsant role of clonidine are discussed, focusing on the role of the alpha-2-adrenoreceptors.

In chapter 8 experiences on a transmural consultation hour for AHDH are reported: Transmural consultation at the Youth Health Care Department. A collaboration model in the south of the province of Limburg, the Netherlands.

Finally, in chapter 9 the findings as presented in the preceding chapters are combined and discussed: A neurodevelopmental model in a learning 
environment - Concluding remarks. Implications for further research and recommendations on future course of action are presented in this chapter. 


\section{REFERENCES}

[1] Brugman E, Reijneveld SA, Verhulst FC, Verloove-Vanhorick SP. Identification and management of psychosocial problems by preventive child health care. Arch Pediatr Adolesc Med 2001; 155: 462-469.

[2] Verhulst FC, van der Ende J, Rietbergen A. Ten-year time trends of psychopathology in Dutch children and adolescents: no evidence for strong trends. Acta Psychiatr Scand 1997b ; 96: 7-13.

[3] SCP-publication 2005. Invitational conference "Vroegtijdige signalering van problemen bij 0-12 jarigen". Social and Cultural Planning Office of the Netherlands, Den Haag 2005, ISBN 903770234 I.

[4] Zeijl E. Children in the Netherlands. Social and Cultural Planning Office of the Netherlands, Den Haag 2005, ISBN 9037702090.

[5] Braams T. Dyscalculie: een verzamelnaam voor uiteenlopende rekenstoornissen. Tijdschr $\vee$ Remedial Teaching, 2000; 4: 6-11.

[6] Barkley RA. Attention-Deficit Hyperactivity Disorder, a handbook for diagnosis and treatment. Third edition. New York: The Guilford Press, 2006.

[7] Biederman J. Attention-Deficit/Hyperactivity Disorder: A selective overview. Biol Psychiatry 2005; 57: 1215-1220.

[8] Biederman J, Faraone SV. Attention-deficit hyperactivity disorder. Lancet 2005; 366: 237-248.

[9] Health Council of the Netherlands: Diagnosis and treatment of ADHD. Health Council of the Netherlands: The Hague, 2000; publication no. 2000/24.

[10] Kroes M. Early motor, psychosocial and behavioural characteristics of Attention-Deficit/Hyperactivity disorder. Thesis, Maastricht University, Maastricht, 2002.

[11] Kalff AC. Neurocognitive performance and demographic variables in children at risk of AttentionDeficit/Hyperactivity Disorder. Thesis, Maastricht University, Maastricht, 2002.

[12] Hurks PPM. The influence of environment, behavior and attention deficits on cognitive development in school-aged children. Thesis, Maastricht University, Maastricht, 2003.

[13] Kroes M, Kalff AC, Kessels AGH, Steyaert J, Feron FJM, Van Someren AJWGM, Hurks PPM, Hendriksen JGM, Van Zeben TMCB, Rozendaal N, Crolla IFAM, Troost J, Jolles J, Vles JSH. Child psychiatric diagnoses in a population of Dutch schoolchildren aged 6 to 8 years. J Am Academy of Child and Adolescent Psychiatry, 2001; 40(12): 1401-1409.

[14] Kalff AC, Kroes M, Vles JSH, Hendriksen JGM, Feron FJM, Steyaert J, Van Zeben TMCB, Jolles J, van Os J. Neighbourhood-level and individual-level SES effects on child problem behaviour: A multilevel analysis. Journal of Epidemiological Community Health, 2001; 55: 246-250.

[15] Kalff AC, Hendriksen JGM, Kroes M, Vles JSH, Steyaert J, Feron FJM, Van Zeben TMCB, Jolles J. Neurocognitive performance of 5- and 6-year-old children who met criteria for Attention Deficit/Hyperactivity Disorder at 18 months follow-up: Results from a prospective population study. Journal of Abnormal Child Psychology, 2002; 30: 589-598.

[16] Kroes M, Kessels GH, Kalff AC, Feron FJM, Vissers YL, Jolles J, Vles JSH. Quality of movement as predictor of Attention Deficit/Hyperactivity Disorder: results from a prospective population study in 5and 6-year-old children, Dev Med Child Neurol. 2002; 44: 753-760.

[17] Vles JSH, Kroes M, Feron FJM. Maastrichtse Motoriek Test [Manual of the Maastricht Motor test]. Leiden: PITS, 2004.

[18] Hendriksen JGM, Steyaert J, Kroes M, Vles JSH. VVA: Vragenlijst Voorlopers ADHD [PAQ: Precursors of ADHD Questionnaire]. Dutch questionnaire; Manual. Leiden: PITS 2002.

[19] Kroes M, Hendriksen JGM, Steyaert J, Kalff AC, Feron FJM, van Zeben-van der Aa TMCB, Jolles J, Troost J, Vles JSH. De Vragenlijst Voorlopers ADHD: Ontwikkeling en enkele psychometrische kenmerken [Precursors of ADHD Questionnaire: development and some psychometric features]. Kind en Adolescent, 2000; 22, 22-35.

[20] Kalff AC, Kroes M., Vles JSH, Bosma H., Feron FJM, Hendriksen JGM, Steyaert J., van Zeben TM, Crolla IF, Jolles J. Factors affecting the relation between parental education as well as occupation and problem behaviour in Dutch 5- to 6-year-old children. Soc Psychiatry and Psychiatric Epidemiology 2001; 36: 324-331. 
[21] Kroes M, Kalff AC, Steyaert J, Kessels AGH, Feron FJM, v.Someren AJWGM, Hurks PPM, Hendriksen JGM, v.Zeben TM, Rozendaal N, Crolla IF, Troost J, Jolles J, Vles JSH. Child psychiatric diagnoses in a population of Dutch school children aged 6 to 8 years. J Am Acad Child Adolesc Psychiatry 2001; 40: 1401-1409.

[22] Kalff AC, Kroes M, Vles JSH, Hendriksen JGM, Feron FJM, Steyaert J, Zeben, TMCB van, Jolles J, Os $\mathrm{J}$ van. Neighbourhood level and individual level SES effects on child problem behaviour: a multilevel analysis. J Epidemiol Community Health. 2001; 55: 246-250.

[23] Kroes M, Kalff AC, Steyaert J, Kessels AGH, Feron FJM, Hendriksen JGM, van Zeben TMCB, Jolles J, Troost J, Vles JSH. A longitudinal community study: do psychosocial risk factors and CBCL scores at 5 years of age predict psychiatric diagnoses at a later age? J Am Acad Child Adolesc Psychiatry. 2002; 41: 955-963.

[24] Kalff AC, Hendriksen JGM, Kroes M, Vles JSH, Steyaert J, Feron FJM, van Zeben TMCB, Jolles J. Neurocognitive performance of 5- and 6-year-old children who met criteria for attention deficit/hyperactivity disorder at 18 months follow-up: results from a prospective population study. Journal of Abnormal Child Psychology 2002; 30: 589-598.

[25] Wassenberg R, Feron FJM, Kessels AGH, Hendriksen JGM, Kalff AC, Kroes M, Hurks PPM, Beeren M, Jolles J, Vles JSH. Relation between cognitive and motor performance in 5- to 6-year-old children: results from a large-scale cross-sectional study. Child Development 2005; 76: 1092-1103.

[26] Hendriksen JGM, Keulers EHH, Feron FJM, Wassenberg R, Jolles J, Vles JSH. Subtypes of learning disabilities: neuropsychological and behavioral functioning of 495 children referred for multidisciplinary assessment (submitted for publication).

[27] Dutch Ministry of Health, Welfare and Sport (VWS). Living longer in good health, also a question of healthy lifestyle-Netherlands Health-Care Prevention Policy. Publication nr. 19. July 2004. Internet: www.minvws.nl.

[28] Dutch Ministry of Health, Welfare and Sport (VWS). Basic package of tasks for the Youth Health Care 0-19 years. (Publication in Duch: Basistakenpakket Jeugdgezondheidszorg 0-19 jaar). March 2002. Internet: www.minvws.nl

[29] Brouwers-De Jong EA, Burgmeijer RJF, Laurent de Angula MS. Ontwikkelingsonderzoek op het consultatiebureau. Handboek bij het vernieuwde Van Wiechenonderzoek. [Revised Manual of the Van Wiechen Classification of psychomotor development] Second edition. Assen: Van Gorcum, 2000.

[30] Achenbach TM. Manual for the Child Behavior Checklist / 4-18 and 1991 profile. Burlington University of Vermont Department of Psychiatry, 1991.

[31] Verhulst FC, Koot JM, Van der Ende J. Handleiding voor de CBCL (Child Behavior Checklist) [Manual for the CBCL]. Afd. Kinder- en Jeugdpsychiatrie, Sophia Kinderziekenhuis / Academisch Ziekenhuis Rotterdam / Erasmus Universiteit Rotterdam, the Netherlands, 1996.

[32] Achenbach, T. M. (1991). Manual of the Teacher's Report Form and 1991 profile. Burlington, VT: University of Vermont, Department of Psychiatry.

[33] Verhulst FC, Van der Ende J, Koot HM. Handleiding voor de Teacher's Report Form (TRF) [Manual for the TRF]. Afd. Kinder- en Jeugdpsychiatrie, Sophia Kinderziekenhuis / Academisch Ziekenhuis Rotterdam / Erasmus Universiteit Rotterdam, the Netherlands, 1997.

[34] Achenbach, T. (1991). Manual for the Youth Self-Report \& 1991 profile. Burlington, VT: University of Vermont Department of Psychiatry.

[35] Verhulst FC, Van der Ende J, Koot HM. Handleiding voor de Youth Self-Report (YSR) [Manual for the YSR] Afd. Kinder- en Jeugdpsychiatrie, Sophia Kinderziekenhuis / Academisch Ziekenhuis Rotterdam / Erasmus Universiteit Rotterdam, the Netherlands, 1997. 
CHAPTER 2
Acid-base status at birth, spontaneous motor behavior at term and 3 months and neurodevelopmental outcome at age 4 years in full-term infants 


\section{ABSTRACT}

Objective: The aim of the study was to assess the relationship between acid base status and quality and quantity of General Movements (GMs) at birth and quality of GMs at age three months and motor, cognitive and behavioral functioning at the age of four years.

Methods: From a cohort of 84 term children with different umbilical artery $\mathrm{pH}$ without severe neonatal neurological abnormalities, GMs were assessed at term and at three months. At the age of four years, 44 children were assessed by means of the Movement Assessment Battery for Children (Movement-ABC), Neurological Examination for Toddlers of Hempel, Kaufman Assessment Battery for Children information processing (Kaufman $A B C$ ), Visuomotor Integration (VMI), the Child Behavior Checklist (CBCL) and Precursors ADHD Questionnaire (PAQ).

Results: We found no relationship between $\mathrm{pH}$ or GM-quality and quantity at term or GM-quality at 3 months and scores on most of the items of the Movement-ABC, cognitive and behavioral outcome. However, neonatal $\mathrm{pH}$ value and GM-quality at 3 months were related to some extend to the presence of subtle signs of neuromotor dysfunction as measured by the Hempel test.

Conclusions: In a sample of infants with a large variation in umbilical artery $\mathrm{pH}$ and without severe neonatal neurological abnormalities, acid-base status at birth and quality of GMs at three months of age is not predictive for motor milestone achievement, cognitive and behavioral functioning at four years, but these parameters are related to a less optimal condition of the nervous system. The latter finding has, however, limited clinical significance. 


\subsection{INTRODUCTION}

There is an ongoing discussion in literature on the issue which examination in early infancy is the most sensitive indicator of brain damage and which infant examination predicts later outcome most precisely. It has been suggested that the qualitative assessment of General Movements (GMs) at the age of three months is a sensitive indicator of brain damage/brain dysfunction with a high predictive value $[1,2,3]$. It has been stated that a qualitative assessment of GMs in early infancy has a better predictive value than the neurological examination at this age [4,5]. The predictive value of the quantity of GMs lacks reliability of diagnostic and prognostic value $[6,7,8,9]$. It is assumed that evaluation of spontaneous motor behavior is a method to evaluate the functional integrity of the brain. The advantage of this method is that it can be performed without interference or manipulation of the newborn. Other studies indicate that cranial ultrasound and MRI are methods of choice to diagnose structural injury and to predict functional outcome $[10,11]$. Ultrasound has the advantage that it can be performed at the bedside, is non-invasive and can be repeated whenever indicated. MRI allows a precise structural localization of the lesions. Other means of assessing brain injury related to outcome include evoked response techniques and continuous cerebral function monitoring and their potential value is probably great. Which of the above-mentioned methods is actually in use, seems to be primarily based on local interest and local facilities. It is accepted that umbilical arterial $\mathrm{pH}$ is a short-term indicator of the acid-base status of the fetus $[12,13]$.

The literature is inconclusive on the value of the acid-base status for predicting outcome. Astrup and co-workers were unable to determine a definite level of tissue acidosis associated with electrical failure in primate brain [14]. Points of discussion are the cut-off between high-risk and low-risk values and the number and type of sequelae $[15,16,17,18]$. In neurology, observation of the patient is one of the basic tools in order to come to a diagnosis and in obstetric practice determination of umbilical artery $\mathrm{pH}$ is a routine action.

The aim of this longitudinal study of term infants, in which umbilical artery $\mathrm{pH}$, quality and quantity of GMs and motor and cognitive function at four years of age are related to each other, is to determine the predictive value of these two clinical tools: umbilical artery $\mathrm{pH}$ and observation of GMs.

More specifically we addressed the following questions:

- Is there a relation between umbilical artery $\mathrm{pH}$ of term infants with normal birth weight on the one hand and neurological, cognitive and behavioral functioning at the age of four years on the other hand?

- Is there a relation between the quality of GMs at term and at the age of three months and neurological, cognitive and behavioral functioning at the age of four years? 
- Is there a relation between the quantity of GMs at term and neurological, cognitive and behavioral functioning at the age of four years?

\subsection{PARTICIPANTS AND METHODS}

The infants were enrolled in the study after obtaining informed consent from then parents. The Medical Ethics Committee of our Hospital approved the study. If the infants fulfilled the inclusion or exclusion criteria, parents were approached to participate. Two hospitals, the academic hospital in Maastricht and the general hospital in Kerkrade, cooperated in this study. The inclusion criteria consisted of: known umbilical artery $\mathrm{pH}$, born at postmenstrual age of 37-42 weeks, with a birth weight between the $2.3^{\text {rd }}$ and $97.7^{\text {th }}$ percentiles of Kloosterman intra-uterine growth curves [20] and born in vertex position, and a stay in the hospital at least three days after birth (which is an optimal age for video-recording GMs. Excluded from the study were children with hypoxia-ischemia other than caused by perinatal adverse conditions as measured from umbilical artery $\mathrm{pH}$. Consequently, children were excluded in case of meconium aspiration, respiratory distress, infections or born after complicated pregnancy, malformations (e.g., diaphragmatic hernia, lissencephalia) and reported use of medication, alcohol or drugs during pregnancy, based on maternal information. Furthermore, the children with abnormal $\mathrm{pH}$ values caused by metabolic disorders were excluded. The clinical criteria used for hypoxic-ischemic encephalopathy were based on the neurological syndrome that accompanies hypoxic-ischemic encephalopathies [14]. No routine MRI or US of the brain were carried out. Only infants with a pH below 7.10 had a cranial US between the tenth and fourteenth day after birth to assess parenchymal echogenicity, effacement of cortical sulci and cavitations as indicators of hypoxic-ischemic brain lesion. In the absence of these findings, cranial ultrasounds were classified as normal. The strict in- and exclusion criteria were chosen to get a population where $\mathrm{pH}$ would be a major factor-determining outcome, without the confounding effect of other birth complications or associated structural brain abnormalities. Out of a birth cohort of 1000 children, born between February 1994 and November 1996 and fulfilling the above-described selection criteria, 84 children were included, 43 boys and 41 girls, 32 infants with $\mathrm{pH}<7.10$ and 52 infants with $\mathrm{pH} \geq 7.10$ [19]. Pre- and perinatal condition of the 16 infants not participating in the study did not differ from the 84 who were included. Birth weight of the children with $\mathrm{pH}<7.1$ was $3130 \pm 569 \mathrm{~g}$ (median \pm SD), birth weight of children with $\mathrm{pH} \geq 7.10$ and $\mathrm{pH}<7.20$ was $3405 \pm 479 \mathrm{~g}$ and birth weight of children with $\mathrm{pH} \geq 7.20$ was $3520 \pm 347 \mathrm{~g}$. To analyze $\mathrm{pH}$, arterial umbilical blood $(2 \mathrm{ml}$ ) was drawn form a double clamped segment of the umbilical cord into a heparinized syringe. Blood gas determination was then performed on an AVL 995 analyzer or a Ciba Corning 278 blood gas system within 15 min after 
collection and corrected for $37^{\circ} \mathrm{C}$. Umbilical artery $\mathrm{pH}$ was used as selection criterion in this study.

For the evaluation of the quality and quantity of GMs, spontaneous motor behavior at term was recorded on video by a fellow in neurology $(\mathrm{MvH}$, trained by JSHV). All infants were video recorded between the third and eighth postnatal day. They lay under a radiant warmer a constant temperature of $36.5^{\circ} \mathrm{C}$. At the beginning of the observation session, the head was held in the midline until no lateral pressure was felt. Each recording lasted three hours. Most of the observation sessions started one hour before a feed. During observation sessions, neonates were not sedated, needed no ventilatory support, nor did they have infusion lines.

The quality of GMs at three months (12 weeks \pm 1 week) was recorded on videos of one hour. During all these recording sessions, infants were placed in supine position, wearing only a loose diaper and body vest. They lay in a box or on a carpet on the floor. The infants were observed from above, which is the optimal position to score General Movements. A time code was superimposed on the tape. In case of prolonged crying, recordings were interrupted and later resumed in order to obtain similar observation sessions for all infants. From each video, three GMs were selected. General Movements with a minimal duration of 20 seconds [21,22] were selected from the video recordings for analysis. General Movements during crying, sucking, hiccups and manipulation were excluded from analysis.

The final judgment of the quality of GMs was made on the basis of these three GMs. Four different qualities of GMs were distinguished: two forms of normal (N) GMs (normal-optimal and normal-suboptimal) and two forms of abnormal GMs (mildly abnormal (MA) and definitely abnormal (DA) (Table 2.1).

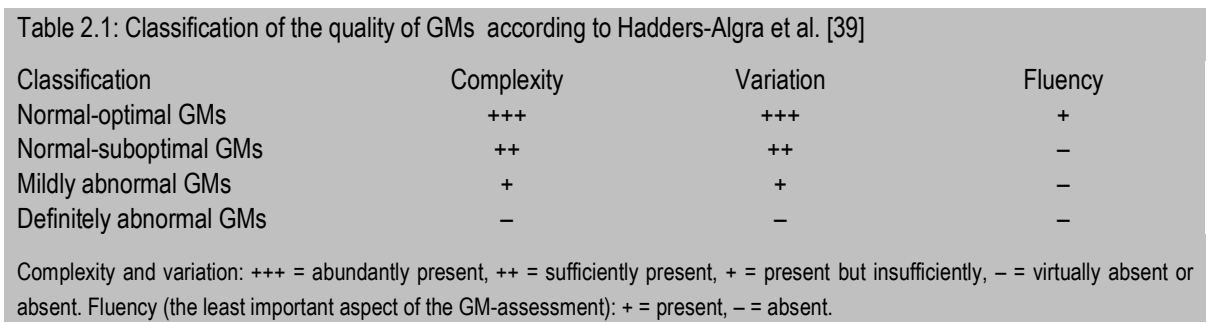

The quality of each GM was assessed separately. This means that a child could obtain one of the nine possible combinations of scores. The combinations $\mathrm{N}-\mathrm{N}-\mathrm{N}$, MA-N-N, MA-MA-N were classified as normal; the combinations DA-DA-DA, MA-DADA, and MA-MA-DA were scored as definitely abnormal. All other combinations were scored as mildly abnormal. Two observers (JSHV, child neurologist, and MHA, developmental neurologist) scored the GMs. Interobserver agreement on the classification of the quality of GMs into three categories was determined on the basis of a random sample of videos by the two observers (JSHV and MHA) who were unaware of the child's history and outcome. Interscorer agreement was good 
(Cohen's Kappa > 0.8). The obtained overall scores were related to outcome at the age of four years and the umbilical artery $\mathrm{pH}$. The quantity of GMs at term age was determined on the basis of the percentage of observation time during which GMs were observed.

At 4 years (mean 51.0 months; range $47-61$ months), 44 of the 84 children participated in the study: 20 girls and 24 boys: 21 children with $\mathrm{pH}<7.10$ and 23 children with $\mathrm{pH} \geq 7.10$. At age 4 years 11 children had moved to an unknown address, parents of six children refused to participate and files of 23 children were lost. All 44 children had a neuromotor examination, and 38 had a neuropsychological examination. Because the literature is rather arbitrary in defining perinatal acidemia (umbilical cord arterial blood $\mathrm{pH}<7.0$ to scalp $\mathrm{pH}$ of 7.2 ) two analyses were carried out: in the first one we trichotomized the group of infants using two different cut off points of umbilical arterial $\mathrm{pH}<7.0$ and $\geq 7.1$; in the second analysis we dichotomized $\mathrm{pH}$ at $<7.1$.

At the age of 4 years an experienced physiotherapist (JW) assessed quantitative motor functioning with the Movement-ABC test and qualitative motor functioning with the Hempel test. The Movement-ABC test (M-ABC) is a standardized motor test for children between 4 and 12 years old. It has been proved to be a valid and reliable instrument $[23,24]$. The test provides a separate measure of manual dexterity, ball skills and static and dynamic balance. The best total score is 0 and the worst is 40 . A score of 0 to 9 is a normal score, 9.5 to 16 a suspect and more than 16 an abnormal score. The Hempel test $[25,26]$ is a valid, reliable and standardized observation technique for spontaneous qualitative motor behavior of children from $1 \frac{1}{2}$ to 4 years old, developed in the Netherlands. The child is observed during reaching and grasping, sitting, crawling, standing and walking, and the following aspects are scored in discrete scales: fine and gross motor behavior, posture, coordination of trunk and extremities, fluency and adequacy of mobility, indications for developmental delay, muscle tone, reflexes and responses. Two persons carried out the test. An experienced physiotherapist (JW) took care of the 68 items dealing with spontaneous motor behavior. A child neurologist (JSHV) scored 24 more classical neurological items of the test, such as the tendon reflexes, hearing, visual acuity, and head circumference. Additionally, the child neurologist evaluated as part of the standard neurological examination oculomotor function, motor coordination and sensory functions. The results of the Hempel tests were analyzed by scoring each item on a 2, 3, 4 or 5-point scale, where a score of 0 was the optimal score. The sum of the scores was the total score. Subscores were made according to Hempel [26]. An experienced child-neuropsychologist (JGMH) carried out cognitive and behavioral examination at the age of 4 years. The battery consisted of the following instruments: the Kaufman Assessment Battery for Children (Kaufman ABC) [27], Visuo Motor Integration Test (VMI) [28], the Child Behavior Checklist (CBCL) [29] and Precursors 
ADHD Questionnaire (PAQ) [30] respectively. The Kaufman test measures two strategies of information processing: simultaneous processing in which information has to be processed at once, and sequential processing in which information has to be processed step by step. The Beery Developmental test of Visual Motor Integration is a widely used paper-pencil, design-copying test. The test presents a developmental sequence of geometric forms that show an increased complexity with age.

The CBCL is a questionnaire measuring problem behavior of the child. With this questionnaire, a distinction can be made in a scale for internalizing (e.g., anxiety) and one for externalizing behavior (e.g., aggressive behavior). The PAQ is a questionnaire to assess behavior problems and the risk for later ADHD problems. One of the parents, usually the mother, completed the CBCL and PAQ.

\subsubsection{Statistical analysis}

The outcome of the children on the scores of the various tests, such as the total score and the subscores of the Movement $A B C$, the optimality scores of the Hempel test and the scores of the neuropsychological and behavioral tests, were evaluated with non-parametric statistics by comparing groups with specific infancy characteristics. Medians of sub scores and total scores were used.

We used two dichotomies for defining low $\mathrm{pH}$ value, and overall GM-classification. The relation between GMs and outcome was studied in two different ways: first, while taking the three different qualities (normal, mildly abnormal, definitely abnormal) into account, second, by dichotomizing quality into two classes: normal versus mildly and definitely abnormal. Here the non-parametric tests Mann Whitney $U$ and Kruskal Wallis were used. In addition Spearman correlations were used to assess the relationships between $\mathrm{pH}$-value and the qualitative and quantitative parameters of the GMs and outcome scores. The statistical analyses were performed with SPSS 11.0. $P$-values $<0.05$ were considered to be statistically significant (two-tailed testing).

\subsection{RESULTS}

\subsubsection{Findings during early infancy}

At term in 19 infants GMs were considered to be normal (8 normal-optimal and 11 normal-suboptimal), in 12 infants as mildly abnormal and in 13 children as definitely abnormal. At the age of three months 33 children had normal GMs (21 normaloptimal and 12 normal-suboptimal), 8 mildly abnormal and 3 definitely abnormal GMs. Like what has been previously reported, GM-quality was not stable from term age till 3 months. Eleven of the 19 infants with normal GMs at term had normal GMs 
at the age of three months, 5 had mildly abnormal and 3 had abnormal GMs. All 12 infants with mildly abnormal GMs at term had normal movements at 3 months. Eleven of the 13 infants with definitely abnormal GMs at term had normal GMs at 3 months and two infants showed mildly abnormal movements. From the three infants with definitely abnormal GMs at 3 months, one infant had normal GMs at term, a pH of 7.25, a normal M-ABC (score=4) and an optimal Hempel score (score $=0$ ). The two other infants had normal and mildly abnormal GMs at term; they had a $\mathrm{pH}<7.0$ ( $\mathrm{pH}$ was 6.79 and 6.96), a suspect M-ABC score (score 12 and 9.5) and a Hempel score or 10 and 8 , respectively.

The analysis of the quantity of GMs in rate per hour at term revealed that the rate of occurrence of GMs was 0 to $31.3 \%$. The children with a lower $\mathrm{pH}(<7.0)$ showed the lowest rates of GMs per hour and also a small range; at a $\mathrm{pH} \geq 7.0$ the range of the percentage of the observation in which GMs were observed varied from 0 to $31.1 \%$. There was no significant correlation between $\mathrm{pH}$ and the quantity of GMs, and no correlation between $\mathrm{pH}$ and quality of $\mathrm{GMs}$ at term and at 3 months (Spearman correlation).

\subsection{2 $\mathrm{pH}$ value and outcome at the age of 4 years}

At the age of 4 years, one child showed a severe dyskinetic movement disorder and therefore was not able to perform the Movement-ABC test. Another child showed a severe coordination disorder. These two children had suffered from severe acidemia $(\mathrm{pH}<6.85$; $\mathrm{BE}<-30)$. Both children had abnormal GMs at term and mildly abnormal GMs at the age of three months. From these two children, the child who performed the Movement-ABC had an abnormal score. Six other children had an abnormal Movement-ABC score, eight children had a score that was classified as suspect and 28 children had a normal score. There was no significant correlation between $\mathrm{pH}$ and Movement $\mathrm{ABC}$; however, there was a significant correlation between $\mathrm{pH}$ and most of the subscores of the Hempel examination (Spearman correlation $-0.31 \leftrightarrow-0.39$ ), except for the subscore of arm/hand function, fluency of movements and neurodevelopment. The statistically significant correlations between $\mathrm{pH}$ and the Hempel scores are illustrated in Figure1. $\mathrm{pH}$ was not related to the outcome on the neurobehavioral scores.

When $\mathrm{pH}$ values were divided into three groups with cutoff points at 7.0 and $7.1, \mathrm{pH}$ was marginally related to neuromotor behavior at 4 years. The M-ABC score for manual dexterity of the children with $\mathrm{pH}<7.0$ was significantly higher than the manual dexterity score of children in the other groups. The subscore 'coordination of extremities' of the Hempel test was significantly lower in the group of children with $\mathrm{pH}$ $\geq 7.1$ (Table 2.2). When dichotomizing umbilical artery $\mathrm{pH}(\mathrm{pH} \geq 7.1$ and $\mathrm{pH}<7.1)$, no relation was found between $\mathrm{pH}$ and outcomes measured by the $\mathrm{M}-\mathrm{ABC}$. However, $\mathrm{pH}$ was significantly related to the total score and to various subscores of the Hempel test: quality of trunk / head / leg function, posture, coordination of the trunk and coordination of the extremities were better in the children with a higher $\mathrm{pH}$ value 
(Table 2.3). No relation was found between $\mathrm{pH}$ values and outcomes on the cognitive and behavioral tests (Tables 2.4 and 2.5).

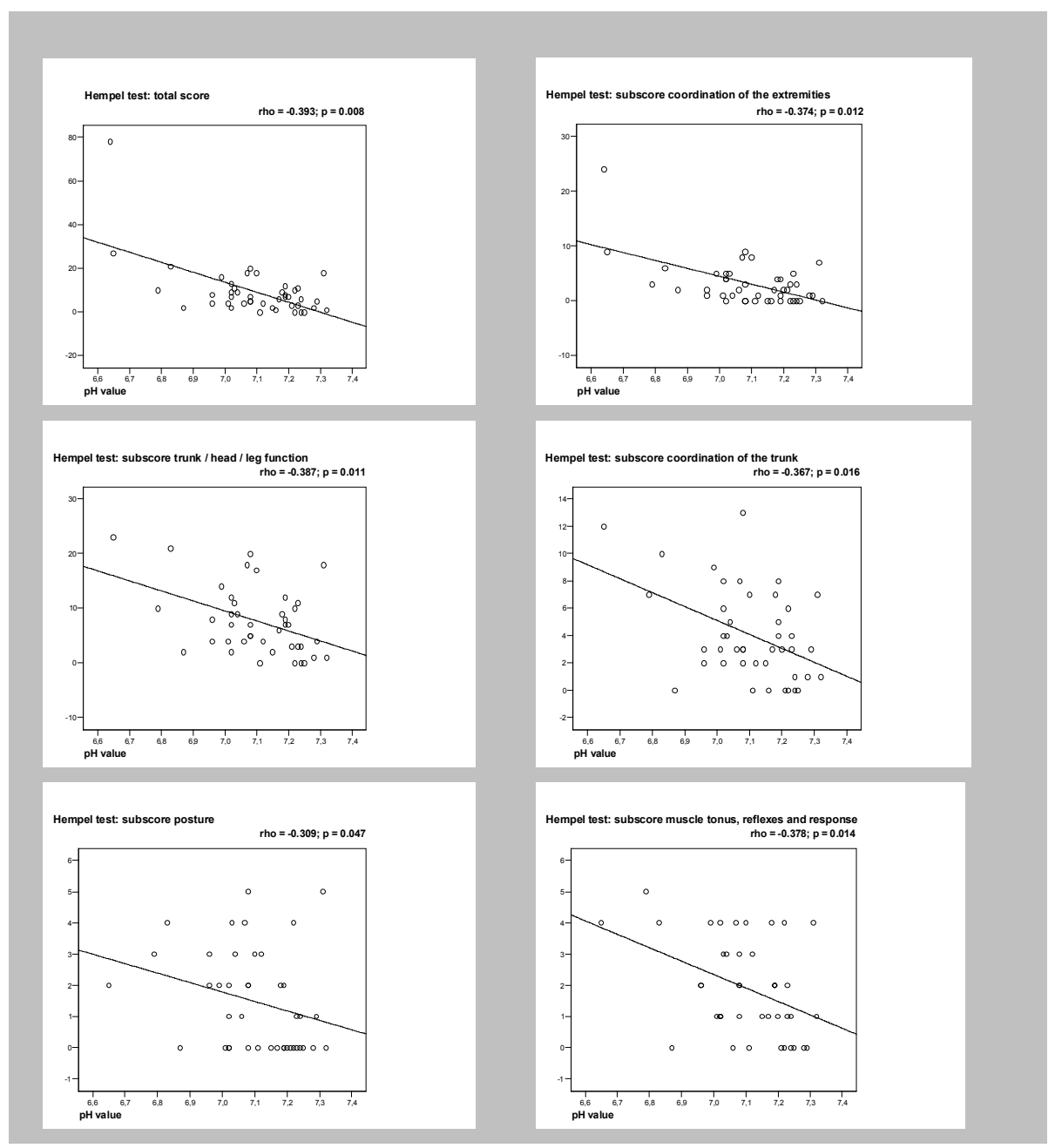

Figure 2.1: Relationships between umbilical artery $\mathrm{pH}$ and six subscores [items] of the Hempel examination. Only relationships with a statistically significantly correlation (Spearman's rho) are shown. Note that relationships remained statistically significant when outlying values were removed, with rho values between -0.31 and -0.39 


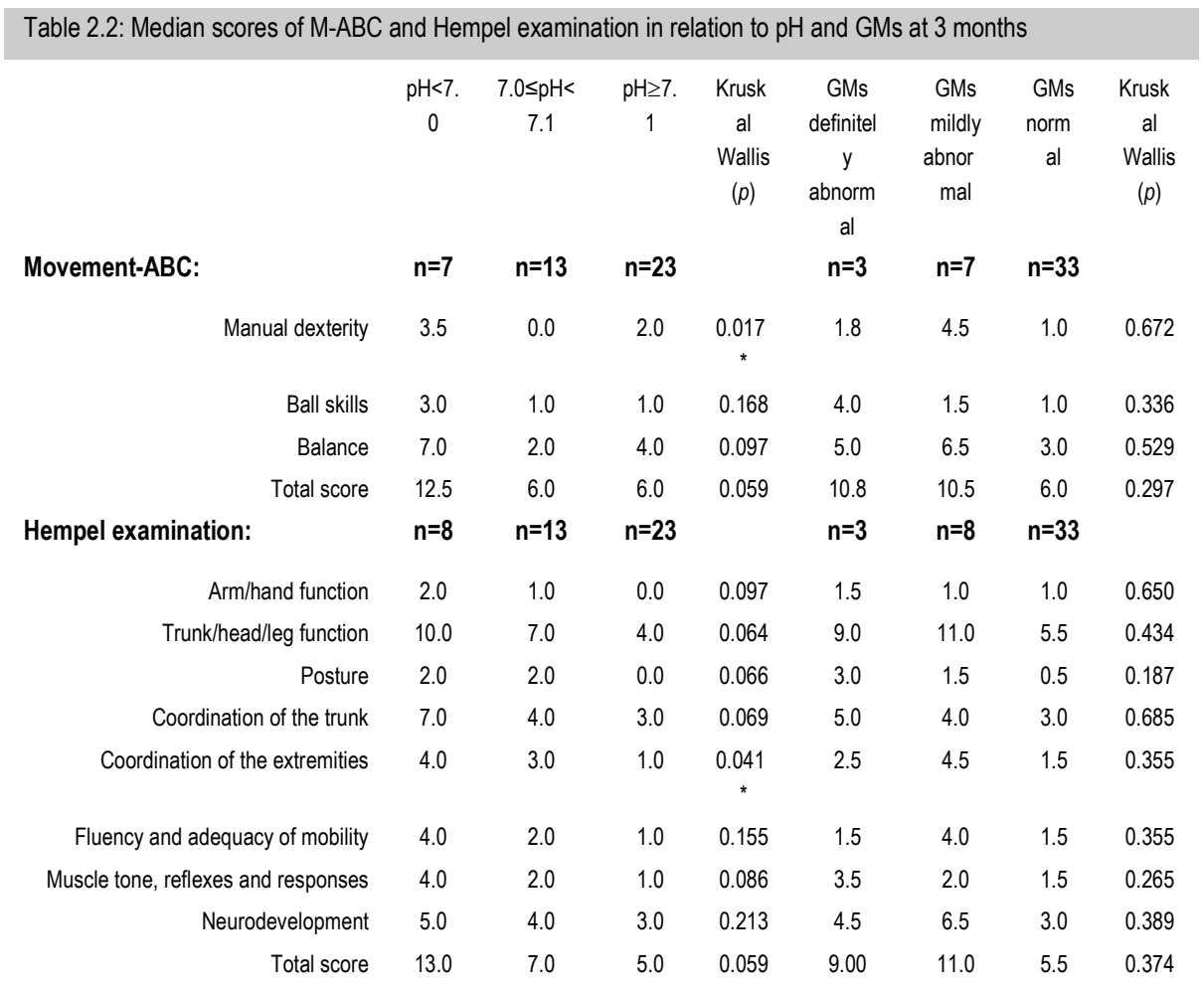

${ }^{*} p<0.05$

Table 2.3: Median scores of M-ABC and Hempel examination in relation to $\mathrm{pH}$ and $\mathrm{GMs} 3$ months

$\mathrm{pH}<7 . \quad \mathrm{pH} \geq 7.1 \quad$ Mann $\quad$ GMs abnormal / GMs Mann

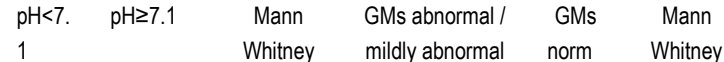

Movement-ABC:

$n=20 \quad n=23$

(p)

Manual dexterity $\quad 1.0 \quad 2.0$

Ball skills $\quad 1.0 \quad 1.0$

Balance $\quad 3.25 \quad 4.0$

Total score $\quad 7.75 \quad 6.0$

Hempel examination:

Total score

$\mathrm{n}=21 \quad \mathrm{n}=23$

Arm/hand function $\quad 1.0 \quad 0.0$

Trunk/head/leg function $\quad 8.5 \quad 4.0$

Posture $2.0 \quad 0.0$

Coordination of the trunk $\quad 4.0 \quad 3.0$

Coordination of the extremities $\quad 3.0 \quad 1.0$

Fluency and adequacy of mobility $\quad 2.0 \quad 1.0$

Muscle tone, reflexes and responses

2.0

1.0

0.224

0.224

0.364

0.971

0.798

0.063

$0.024^{*}$

$0.028^{*}$

$0.022^{*}$

$0.024^{*}$

0.117

0.065 al $\quad(p)$

$n=22 \quad n=21$

$\begin{array}{lll}1.5 & 1.0 & 0.677\end{array}$

$\begin{array}{lll}1.0 & 1.0 & 0.263\end{array}$

$\begin{array}{lll}5.5 & 3.0 & 0.039\end{array}$

$\begin{array}{lll}8.5 & 6.0 & 0.101\end{array}$

$n=23 \quad n=21$

$\begin{array}{lll}1.0 & 1.0 & 0.237 \\ 9.5 & 4.5 & 0.027^{\star} \\ 2.0 & 0.0 & 0.061 \\ 5.5 & 3.0 & 0.020^{\star} \\ 4.0 & 1.0 & 0.003^{\star *} \\ 3.0 & 0.0 & 0.006^{\star *} \\ 2.0 & 1.0 & 0.138\end{array}$


Neurodevelopment $\quad 4.0$

3.0

0.109

4.5

2.0

$0.006^{* *}$

${ }^{*} p<0.05 ;{ }^{* *} p<0.01$

Total score $\quad 9.0$

$5.0 \quad 0.016^{*}$

10.0

4.0

$0.006^{* *}$ 
Table 2.4: Score of the cognitive and behavioral tests in relation to $\mathrm{pH}$ and quality of GMs at 3 months

$\mathrm{pH}<7.0 \quad 7.0 \leq \mathrm{pH}<\quad \mathrm{pH} \geq 7.1 \quad$ Krusk $\quad$ GMs $\quad$ GMs $\quad$ GMs Krusk

7.1 al definitely mildly norm al

Wallis abnormal abnormal al Wallis

(p)

$n=7 \quad n=13 \quad n=18 \quad n=2 \quad n=7 \quad n=29$

Mental processing score

$101.0 \quad 104.0 \quad 111.0$

$\begin{array}{llll}0.341 & 125.5 & 110.0 & 110.0\end{array}$

Simultaneous processing

$103.0 \quad 106.0$

110.0

0.578

120.0

Sequential processing

106.0

102.0

108.5

0.176

120.5

$\begin{array}{lll}110.0 & 110.0 \quad 0.710\end{array}$

Visuo Motor Integration

106.5

104.

102.0

0.862

109.50

$106.0 \quad 106.0 \quad 0.856$

$\mathrm{CBCL}$ internalizing behavior

$49.0 \quad 59.0$

50.0

0.293

55.0

$\begin{array}{lll}104.0 & 104.0 \quad 0.942\end{array}$

$\mathrm{CBCL}$ externalizing behavior

46.0

60.0

52.0

0.048
$*$

46.0

49.0

$52.0 \quad 0.919$

CBCL

$\begin{array}{lll}48.0 & 65.0 & 50.0\end{array}$

0.275

56.0

46.0

$51.0 \quad 0.796$

total score

ADHD precursors

$5.5 \quad 9.0$

8.0

0.251

10.5

$\begin{array}{lll}47.0 & 51.0 \quad 0.868\end{array}$

${ }^{*} p<0.05$

Table 2.5: Median scores of the cognitive and behavioral tests in relation to $\mathrm{pH}$ and quality of GMs at 3 months

\begin{tabular}{|c|c|c|c|c|c|c|}
\hline & $\begin{array}{c}\mathrm{pH}<7 . \\
1\end{array}$ & $\begin{array}{c}\mathrm{pH} \geq 7 . \\
1\end{array}$ & $\begin{array}{c}\text { Mann } \\
\text { Whitney } \\
\text { (p) }\end{array}$ & $\begin{array}{c}\text { Abnormal /mildly abnormal } \\
\text { GMs }\end{array}$ & $\begin{array}{l}\text { Normal } \\
\text { GMs }\end{array}$ & $\begin{array}{c}\text { Mann } \\
\text { Whitney (p) }\end{array}$ \\
\hline Mental processing score & 103.0 & 111.0 & 0.213 & 109.0 & 105.5 & 0.907 \\
\hline Simultaneous processing & 104.5 & 110.0 & 0.334 & 108.0 & 107.0 & 0.736 \\
\hline Sequential processing & 102.5 & 108.5 & 0.155 & 106.0 & 105.0 & 0.736 \\
\hline Visuo Motor Integration & 104.5 & 102.0 & 0.605 & 104.0 & 102.0 & 0.939 \\
\hline $\mathrm{CBCL}$ internalizing behavior & 54.5 & 50.0 & 0.681 & 54.5 & 50.0 & 0.541 \\
\hline CBCL externalizing behavior & 47.5 & 52.0 & 0.659 & 49.0 & 51.0 & 0.807 \\
\hline $\mathrm{CBCL}$ total score & 52.5 & 50.0 & 0.345 & 52.5 & 50.0 & 0.344 \\
\hline ADHD precursors & 7.0 & 8.0 & 0.405 & 8.0 & 7.0 & 0.919 \\
\hline
\end{tabular}




\subsubsection{GMs and outcome at 4 years}

The quality of GMs at term was not correlated to scores of the M-ABC and the Hempel test. Whether using the trichotomy (normal, mildly abnormal, definitely abnormal) or the dichotomy (normal versus mildly abnormal and definitely abnormal) of GM-scores at term, no relation was found with any of the outcome parameters at 4 years of age. Furthermore, no correlation was observed with neurobehavioral outcome.

Using the rate of occurrence of GMs at term as a measure of quantitative motor behavior, no relation was found with $M-A B C$ and Hempel scores. For instance, children classified as abnormal, suspect or normal on the M-ABC had a median GMrate at term of $11.0,4.5$ and $7.7 \%$, respectively.

The quality of GMs at 3 months was not correlated to the scores of the M-ABC. However, quality of GMs was correlated significantly to the total score of the Hempel test (rho $=0.37 ; p=0.01$ ), and the subscores 'quality of the trunk' (rho $=0.31 ; p=$ 0.04 ), 'coordination of the trunk' (rho $=0.31 ; p=0.04$ ), 'coordination of the extremities' (rho $=0.37 ; p=0.01$ ), 'fluency of mobility' (rho $=0.32 ; p=0.03$ ) and 'level of neurodevelopment' (rho $=0.36 ; p=0.02$ ) of the Hempel test. A better quality of GMs was related to more optimal neuromotor behavior at 4 years.

Using the trichotomy of GM-quality resulted - by and large - in no relationships with neuromotor outcome (Table 2.2). Also using the dichotomy of normal GMs versus mildly abnormal and definitely abnormal GMs, there are no relationships with neuromotor outcome. There is only a tendency of a lower score in the groups with the normal quality of GMs than in the groups with mildly abnormal or definitely abnormal GMs (Table 2.3). Quality of GMs at 3 months was not related to cognitive and behavioral outcome at 4 years (Tables 2.4 and 2.5).

Analyzing retrospectively the children with a M-ABC score of more than 16 (=abnormal: $n=7$ ) there is a wide range in umbilical artery $\mathrm{pH}$, base excess, quality and quantity of GMs. However, a high M-ABC score in children was in most cases associated with a high Hempel total score (Table 2.6).

\begin{tabular}{|c|c|c|c|c|c|c|}
\hline Patient: & $\mathrm{pH}$ & Base Excess & Percentage of GMs & Quality of GMs at term & Quality of GMs 3 months & $\begin{array}{l}\text { Total score } \\
\text { Hempel test }\end{array}$ \\
\hline 1 & 6.65 & & 4.60 & abnormal & mildly abnormal & 27.00 \\
\hline 2 & 6.83 & -18.10 & 3.80 & mildly abnormal & normal & 21.00 \\
\hline 3 & 6.99 & -13.6 & 21.10 & abnormal & normal & 16.00 \\
\hline 4 & 7.10 & -9.00 & 2.30 & normal & normal & 18.00 \\
\hline 5 & 7.17 & & 11.00 & normal & normal & 6.00 \\
\hline 6 & 7.23 & -5.70 & 11.00 & normal & mildly abnormal & 11.00 \\
\hline 7 & 7.31 & -3.10 & 12.50 & normal & mildly abnormal & 18.00 \\
\hline
\end{tabular}




\subsection{DISCUSSION}

The present study showed that in a relatively small sample of infants with an umbilical artery $\mathrm{pH}$ value at birth within a range of 6.64-7.32, without conditions such as meconium aspiration, respiratory distress, infection, serious congenital disorders or severe neonatal neurological abnormalities, umbilical artery $\mathrm{pH}$ and the quality of GMs at 3 months were only to some extend related to qualitative neuromotor behavior at 4 years of age. No relation was found between umbilical artery $\mathrm{pH}$ and cognitive and behavioral development at 4 years. Previous reports indicated that fetal $\mathrm{pH}$ of children with few neonatal complications is not related to long-term neurological and behavioral outcome $[31,32,33,34]$. Only very low $\mathrm{pH}$ values might point to an increased risk for neurodevelopmental disorder [35]. The present data fit to the previous findings: neonatal acidemia was not related to motor milestone achievement at 4 years as measured by the Movement $A B C$, nor to cognitive and behavioral outcome. But our study also indicated that neonatal acidemia was related to subtle and qualitative signs of neuromotor dysfunction (as measured by the Hempel-test). In other words, the present findings underline the notion that perinatal stress may induce a less optimal function of the central nervous system [so-called simple form of minor neurological dysfunction (MND)] [36]. It is however important to realize that the clinical significance of simple MND is negligible.

Prechtl and co-workers found that the quality of GMs in infants with severe forms of asphyxia predicted neuromotor outcome [2]. The present study evaluated the value of the quality of GMs in term children in relation to acidemia. Quality and quantity of GMs at term age were not related to any of the neurobehavioral outcome measures. But the quality of GMs at the age of 3 months was related to neuromotor outcome at 4 years as measured with the Hempel test. The relationship could be established only by means of Spearman correlations, not when the children were trichotomized and dichotomized in various GM-groups. The absence of a relation with later outcome in the latter conditions can be attributed to the moderate strength of the relation between GM-quality and neuromotor outcome and to the limited sizes of the groups. Nevertheless, the finding that GM-quality at 3 months in a relatively healthy population is related to neuromotor status at 4 years fits to recent reports that GMquality at 3 months in children without cerebral palsy is related to neuromotor condition at school age $[37,38,39]$.

From a clinical point of view, our results are of great importance. First, we may conclude, that in a child with a history of perinatal acidemia of different degree without neurological signs at term, in general the prognosis for development is good. As a consequence, no regular check-up on developmental outcome of these children 
is needed. It is beyond discussion, that infants with perinatal acidemia in combination with signs of a hypoxic-ischemic encephalopathy should be carefully followed at regular intervals including judgment of GMs at the age of three months. Of the three infants with definitely abnormal GMs at term, two had mildly abnormal GMs at the age of three months and developed a severe motor disability one with mental retardation. The third infant was completely normal at follow up. Based on this observation, we could discuss which of the tools used (neurological examination or evaluation of GMs) is the most sensitive one to predict outcome. This discussion, is, however, with concern to optimal management, neither relevant nor in favor of good clinical practice. Irrespective of the results of these 'which better' studies [3, 4], it is good clinical practice to examine an (at risk) term born baby, and it is beyond discussion that the assessment of GMs at three months of age is a sensitive tool to predict outcome. However, it is of great value to select patients at risk, in order to guard against overconsumption of medical care and to load caregivers with some kind of uncertainty.

Secondly, if a child of 4 years of age is presented because of a developmental delay or a behavior disturbance, it is not justified to describe this developmental disorder to some degree of acidemia at term age, if this was the only abnormal parameter at that age.

From our data, we may conclude that good information to the caregivers for the group of children who have sustained some degree of acidosis, depicted by blood $\mathrm{pH}$ level, arterial base excess and $\mathrm{pCO}_{2}$ and without functional neurological indexes of post hypoxic-ischemic neonatal encephalopathy is a challenge. Our data indicate that perinatal acidemia may induce a somewhat less optimal condition of the brain; a less optimal brain rarely is the sole cause of behavior or learning problems. Thus, in children presenting with a developmental problem we should look for other causes in addition to perinatal acidemia, which might explain neurobehavioral outcome.

Acknowledgements: This study was supported by a grant from the University Hospital Maastricht fund for outstanding and competitive clinical research, 'Het Profileringsfonds'. 


\section{REFERENCES}

[1] Hadders-Algra M. The assessment of general movements is a valuable technique for the detection of brain dysfunction in young infants. A review. Acta Paediatr Suppl 1996; 416: 39-43.

[2] Prechtl HF, Ferrari F, Cioni G. Predictive value of general movements in asphyxiated full-term infants. Early Hum Dev 1993; 35(2): 91-120.

[3] Prechtl H, Einspieler C, Cioni G, Bos A, Ferrari F, Sontheimer D. An early marker for neurological deficits after perinatal brain lesions. Lancet 1997; 349(9062): 1361-1363.

[4] Cioni G, Prechtl HFR, Ferrari F, Paolicelli B, Einspieler C, Roversi MF. Which better predicts later outcome in fullterm infants: quality of general movements or neurological examination? Early Hum Dev 1997; 50: 71-85.

[5] Cioni G, Ferrari F, Einspieler C, Paolicelli PB, Barbani MT, Prechtl HF. Comparison between observation of spontaneous movements and neurologic examination in preterm infants [see comments]. J Pediatr 1997; 130(5): 704-711.

[6] Ferrari F, Cioni G, Prechtl HFR. Qualitative changes of general movements in preterm infants with brain lesions. Early Hum Dev 1990; 23: 193-233.

[7] Sival DA, Visser GH, Prechtl HF. The relationship between the quantity and quality of prenatal movements in pregnancies complicated by intra-uterine growth retardation and premature rupture of the membranes. Early Hum Dev 1992; 30(3): 193-209.

[8] Ferrari F, Prechtl HF, Cioni G, Roversi MF, Einspieler C, Gallo C, et al. Posture, spontaneous movements, and behavioural state organisation in infants affected by brain malformations. Early Hum Dev 1997; 50(1): 87-113.

[9] van der Heide J, Paolicelli PB, Boldrini A, Cioni G. Kinematic and qualitative analysis of lower-extremity movements in preterm infants with brain lesions. Phys Ther 1999; 79(6): 546-557.

[10] Kuenzle C, Baenziger O, Martin E, Thun-Hohenstein L. Prognostic value of early MR Imaging in term infants with severe perinatal asphyxia. Neuropediatrics (25): 191-200.

[11] Rutherford MA, Pennock JM, Dubowitz MS. Cranial ultrasound and magnetic resonance imaging in hypoxic-ischaemic encephalopathy: a comparison with outcome. Dev Med Child Neurol (36): 813-825.

[12] Low JA, Panagiotopoulos C, Derrick EJ. Newborn complications after intrapartum asphyxia with metabolic acidosis in the term fetus. Am J Obstet Gynecol 1994; 170(4): 1081-1087.

[13] van den Berg PP, Nelen WLDM, Jongsma HW, Nijland R, Kollée LAA, Nijhuis JG, Eskes TKAB. Neonatal complications in newborns with an umbilical artery $\mathrm{pH}<7.00$. Am J Obstet Gynecol 1996; 175(5): 1152-1157.

[14] Volpe JJ. Neurology of the brain. 3rd edition. Philadelphia: W.B. Sanders; 1995.

[15] Winkler CL, Hauth JC, Tucker JM, Owen J, Brumfield CG. Neonatal complications at term as related to the degree of umbilical artery acidemia. Am J Obstet Gynecol 1991; 164(2): 637-641.

[16] Low JA, Lindsay BG, Derrick EJ. Threshold of metabolic acidosis associated with newborn complications. Am J Obstet Gynecol 1997; 177(6): 1391-1394.

[17] Goldaber KG, Gilstrap LC 3rd, Leveno KJ, Dax JS, McIntire DD. Pathologic fetal acidemia. Obstet Gynecol 1991; 78(6): 1103-1107.

[18] Belai Y, Goodwin TM, Durand M, Greenspoon JS, Paul RH, Walther FJ. Umbilical arteriovenous PO2 and $\mathrm{PCO} 2$ differences and neonatal morbidity in term infants with severe acidosis. Am J Obstet Gynecol 1998; 178(1Pt1): 13-19.

[19] Hall van MHJA, Assessment of spontaneous motor behaviour in relation to umbilical artery $\mathrm{pH}$ in fullterm infants. Thesis. Maastricht University, the Netherlands, 1999.

[20] Brande van den JL, Monnens, LAH. Kindergeneeskunde. ( $2^{\text {nd }}$ edition) Utrecht: Wetenschappelijke Uitgeverij Bunge, 1993.

[21] Kranen van-Mastenbroek V, van Oostenbrugge R, Palmans L, Stevens A, Kingma H, Caberg H, et al. Inter- and intraobserver agreement in the assessment of the quality of spontaneous movements in the newborn. Brain Dev 1992; 14: 289-293. 
[22] Kranen van-Mastenbroek V.H.J.M. Spontaneous motor behaviour in full-term small for gestational age and appropriate for gestational age newborn infants. Thesis. Maastricht University, the Netherlands, 1993.

[23] Henderson SE, Sugden DA. Movement assessment battery for children; manual. London: The Psychological; 1992.

[24] Smits-Engelsman BCM. Handleiding movement assessment battery for children, Nederlandse bewerking. Lisse: Swets en Zeitlinger; 1998.

[25] Hempel MS. Neurological development during toddling age in normal children and children at risk of developmental disorders. Early Hum Dev 1993; 34: 47-57.

[26] Hempel MS. The neurological examination for toddler-age. Groningen: Rijksuniversiteit Groningen; 1993 [232 p].

[27] Kaufman AS, Kaufman NL. Kaufman assessment battery for children. Interpretive manual. Circle Pines, Minnesota: American Guide Service; 1983.

[28] Beery KE. The Beery-Buktenica Developmental Test of Visual-motor integration (VMI). Pasipanny, New Jersey: Modern Curriculum Press; 1997.

[29] Verhulst FC, Koot JM, Van der Ende J. Handleiding voor de CBCL (Child Behavior Checklist) [Manual for the CBCL]. Afd. Kinder- en Jeugdpsychiatrie, Sophia Kinderziekenhuis / Academisch Ziekenhuis Rotterdam / Erasmus Universiteit Rotterdam, the Netherlands, 1996.

[30] Hendriksen JGM, Steyaert J, Kroes M, Vles JSH. VVA: Vragenlijst Voorlopers ADHD [PAQ: Precursors of ADHD Questionnaire]. Dutch questionnaire; Manual. Leiden: PITS 2002

[31] Dennis J, Johnson A, Mutch L, Yudkin P, Johnson P. Acid-base status at birth and neurodevelopmental outcome at four and one-half years. Am J Obstet Gynecol 1989; 161(1): 213-220.

[32] Herbst A, Thorngren Jerneck K, Wu L, Ingemarsson I. Different types of acid-base changes at birth, fetal heart rate patterns, and infant outcome at 4 years of age. Acta Obstet Gynecol Scand 1997; 76(10): 953-958

[33] Handley-Derry M, Low JA, Burke SO, Waurick M, Killen H, Derrick EJ. Intrapartum fetal asfyxia and the occurence of minor deficits in 4- to 8-year-old children. Dev Med Child Neurol 1997; 39: 508-514.

[34] Yudkin PL, Jonhson A, Clover LM, Murphy KW. Clustering of perinatal markers of birth asphyxia and outcome at age five years. Br J Obstet Gynaecol 1994; 101(9): 774-781.

[35] Ingemarsson I, Herbst A, Thorngren Jerneck K. Long term outcome after umbilical artery acidaemia at term birth: influence of gender and duration of fetal heart rate abnormalities. $\mathrm{Br} \mathrm{J}$ Obstet Gynaecol 1997; 104(10): 1123-1127.

[36] Hadders-Algra M, Groothuis A. Quality of general movements in infancy is related to neurological dysfunction, ADHD, and aggressive behaviour. Dev Med Child Neurol 1999; 41: 381-391.

[37] Hadders-Algra M. Two distinct forms of minor neurological dysfunction: perspectives emerging from a review of data of the Groningen Perinatal Project. Dev Med Child Neurol 2002; 44: 561-571.

[38] Hadders-Algra M, Groen SE, De Blécourt ACE, Postema K. Abnormal general movements are related to co-ordination problems and fine manipulative disability at 10-12 years. Dev Med Child Neurol 2003; 45(suppl. 97): 44-45

[39] Hadders-Algra M, Mavinkurve-Groothuis AMC, Groen SE, Stremmelaar EF, Martijn A, Butcher PR. Quality of general movements and the development of minor neurological dysfunction at toddler and school age. Clin Rehabil 2004; 18(3): 287-299. 
CHAPTER 3

\section{Acid-base status at birth and neurocognitive outcome at preschool age}




\section{ABSTRACT}

Background: In literature umbilical cord blood acid-base analysis immediately after delivery is considered to be an objective way of assessing the newborn's condition.

Aim: The purpose of this prospective cohort study was to investigate the relationship between acid-base status at birth and long-term neurocognitive and behavioral outcome in children at four years of age.

Methods: The sample included a cohort of 66 newborns without neonatal complications. Stratification was applied based on umbilical artery blood $\mathrm{pH}$ values. Cognitive functioning and motor development of all infants was measured at age of 9 respectively 18 months using the Bayley's Development Scales. At the age of 4 years neurocognitive outcome was assessed with the Kaufman Assessment Battery for Children and the Beery Developmental Test of Visual Motor Integration. In addition behavioral functioning was measured with the Child Behavior Checklist and the Precursors of ADHD Questionnaire.

Results: This study revealed only significant positive correlations between initial umbilical artery $\mathrm{pH}$ and mental and motor development at the age of 18 months. At the age of four years no significant correlations could be found between initial umbilical artery $\mathrm{pH}$ values and mental processing, language reasoning and visual motor integration on the age of four years. Finally no relation was found between $\mathrm{pH}$ values at birth and behavioral outcome at four years.

Conclusions: Acid-base status at birth in full-term infants, without clinical evidence of perinatal hypoxic-ischemic encephalopathy, is a poor predictor of neurocognitive and behavioral outcome in preschool and early school-aged children. 


\section{INTRODUCTION}

Perinatal hypoxic-ischemic encephalopathy is an important perinatal complication thought to contribute not only to mortality and morbidity in the neonate, but also to poor neurocognitive outcome in surviving infants at later age. Several biochemical and physiological markers have been used to index the extent of perinatal hypoxicischemic risk: the biochemical hallmark of acute perinatal asphyxia is a profound acidemia, which is metabolic or mixed. Consequently, umbilical arterial $\mathrm{pH}$ is a shortterm indicator of the acid-base status of the fetus. It is considered to be an objective measurement, reflecting the baby's condition at the time of birth [1].

To determine the normal values of umbilical arterial $\mathrm{pH}$, Helwig et al. [2] studied acidbase data from 15073 vigorous neonates with an Apgar score $\geq 7$ at 5-minutes post partum. In this study a mean umbilical artery $\mathrm{pH}$ of 7.26 was reported. The range of normality expressed as either -2 SD or the 2.5 th percentile was 7.10 , expressing the outer limit of acidemia. They conclude "from a consideration of the published literature regarding fetal asphyxia, it seems clear that setting the outer limits of normal $\mathrm{pH}$ at the 2.5th percentile is extremely conservative in defining the likelihood of neurological sequelae" [2, page 1811]. In a study based on a population of 154 full-term newborns with an umbilical cord $\mathrm{pH}<7.05$, Ingemarsson et al. [3] reported that boys had more often pronounced acidemia and a complicated course. They suggested gender as a possible factor of importance for long-term outcome.

However, in literature the relationship between the degree of acidemia and neonatal neurological outcome is rather controversial. Some authors found a correlation between the degree of acidemia at birth and neonatal neurological outcome [4-6]. Other studies have demonstrated a poor correlation between profound acidemia and neurological outcome during neonatal period, suggesting that most neonatal neurological complications are due to other causes $[7,8]$. Historically a pH cut-off of less than 7.20 has been used for defining pathologic fetal acidemia as the threshold associated with major neonatal morbidity or mortality. Goldaber et al. [9] suggested a more realistic $\mathrm{pH}$ cut-off for defining pathologic fetal acidemia would appear to be less than 7.00. Carter et al. [10] revealed that $\mathrm{pH}$ values between 7.00 and 7.20 have no correlation with any immediate or long-term morbidity. Moreover, according to these authors, "most fetuses with an arterial $\mathrm{pH}<7.00$ will not suffer evidence of perinatal asphyxia, and such acidemia in itself is not evidence to establish that hypoxic injury has occurred" [10, page 293]. MacLennan [11], representing the International Cerebral Palsy Task Force, stated that a realistic cut-off point for defining pathological fetal acidemia that correlates with an increasing risk of neurological deficit has been found to be a $\mathrm{pH}$ of less than 7.00 and a base deficit of more than $12 \mathrm{mmol} / \mathrm{L}$. 
The consequences of birth acidosis on cognitive and behavioral functioning are not yet fully understood. Only a few prospective studies have been done. Methodological shortcomings are that different studies use (a) different cut-off points for defining acidosis, (b) different timing of outcome measurements, and (c) different instruments to evaluate outcome. Low et al. [12] report the incidence of both major and minor deficits at 1 year of age in 37 mature children (umbilical arterial pH below 7.00 ) to be significantly greater when compared with children in a control group. Dennis et al. [13] using a cut-off point of 7.10 , found no significant associations between acidosis and developmental outcome using the Griffiths Developmental Scales at $4 \frac{1}{2}$ years. Furthermore, the highest proportion of unimpaired children was found among those who were the most acidotic at birth ( $\mathrm{pH} \leq 7.04 ; 2$ SD below mean). This might imply that the fetus producing acidosis in response to stress of labor might be beneficial to long-term outcome. Hermansen [14] further discusses this phenomenon of beneficial acidemia. In the studies of Ruth \& Raivio [15], Dijxhoorn et al [16], and Nagel et al. [1] no major cognitive deficits were found in the follow-up of children with umbilical artery $\mathrm{pH}<7.0$. However, Raz and her co-workers [17] did extensive psychological followup in early school-age children born premature (gestational age $\leq 36$ weeks) with slight to moderate risk for perinatal hypoxia (initial arterial $\mathrm{pH}$ below 7.3 and above 7.1). They found that increasing acidosis was linearly related to decreases in cognitive skills as measured with the Wechsler intelligence scales and decreased language skills. They argue that the current study "suggests that a relatively small risk for birth related hypoxia defined as a $\mathrm{pH}$ value falling above the established critical level, is by no means too negligible to exert an appreciable influence on intellectual outcome". These results were in accordance with their earlier findings [18], where a linear relationship was found between perinatal arterial $\mathrm{pH}$ and cognitive outcome in a heterogeneous group of term and pre-term children at mild to moderate hypoxic risk.

In a recent study we concluded that umbilical artery $\mathrm{pH}$ at birth and quality of movements at the age of three months is not predictive for motor milestone achievement (Wildschut, Feron, Hendriksen, et al, 2004) [19]. Based on a sample of 44 children we found in addition no relationship between acid-base status at birth in full-term infants and spontaneous motor behavior at term and at 3 months and neurodevelopmental outcome at the age of four years.

The aim of the present study was to further investigate the relationship between acidbase status at birth and long-term neurocognitive and behavioral outcome using an extended sample size based on analysis of data collected at the age of 9 months, 18 months and four years. In particular this study was focused on the values of initial umbilical artery $\mathrm{pH}$ and base excess as predictors of neurocognitive and behavioral outcome at early school age as well as possible gender differences. 


\subsection{METHODS}

\subsubsection{Subjects}

The Medical Ethical Committee of the University Hospital in Maastricht, the Netherlands, approved the present study. The infants were selected from a birth cohort of about 1000 newborns, all born in the period between February 1994 and November 1996, from whom 84 infants fulfilled the below mentioned clinical selection criteria. Parental informed consent was obtained from 68 children.

Two children were severely acidotic at birth $(\mathrm{pH} \leq 6.65$; base excess $<-30.0)$ and developed cerebral palsy in the first year. Due to severe impairment these two children were not testable and were excluded from the study as yet. At the age of 9 months and 18 months the study included a sample of 66 children, 33 boys and 33 girls. At the age of four years 58 children participated in the study and 8 participants were lost to follow up, as parents of 6 children refused further participation and 2 children had moved to an unknown address. The children lost to follow-up did not differ from those continuing in the study in respect to pre- and perinatal condition.

Children were included in the study when they fulfilled the following criteria:

1. born at term (gestational age between 37 and 42 weeks, based on maternal dates);

2. birth weight between the 2.3 and 97.7 percentile of Kloosterman intrauterine growth curves [20];

3. with a known umbilical artery $\mathrm{pH}$;

4. born in vertex position;

5. obtained parental informed consent.

Children were excluded from the study when they met one ore more of the following criteria:

1. born before gestational age of 37 weeks;

2. birth weight $<2.3$ or $>97.7$ percentile of Kloosterman intra-uterine growth curves [20];

3. born after complicated pregnancy;

4. maternal use of medication, alcohol or drugs during pregnancy;

5. hypoxic-ischemia other than caused by perinatal adverse conditions as measured from umbilical artery $\mathrm{pH}$ (respiratory distress; children with meconium aspiration; neonatal infections or sepsis; hypovolaemia, low cardiac output and poor tissue perfusion; hypothermia; anemia; renal bicarbonate losses; cardiac failure / congenital cardiac anomalies; inborn error of metabolism)

6. severe head injury before the age of four years;

7. seizure disorders. 
These strict criteria for inclusion and exclusion were chosen tot get a sample where initial umbilical arterial $\mathrm{pH}$ would be a major factor determining outcome, without the confounding effect of birth complications or associated structural brain abnormalities. Apgar scores were left out of consideration in this study because the Apgar score usually does not reliably reflect the degree of acidosis at delivery as measured from umbilical artery $\mathrm{pH}[15,21]$. Immediately after delivery umbilical artery blood $(2 \mathrm{ml})$ was drawn from a double clamped segment of the umbilical cord into a heparinized syringe. An AVL 995 analyzer or a Ciba Corning 278 blood gas system was used to perform blood gas analysis within 15 minutes after blood collection and corrected for $37^{\circ}$ Celsius. Because abnormal glucose and calcium levels may influence outcome measures, serum glucose was determined on the first day and serum calcium on the second day. All glucose and calcium values were within normal limits.

\subsubsection{Procedure}

At the age of nine months and eighteen months the Bayley Scales of Infant Development were used to measure cognitive functioning and motor development. The Bayley Scales of Infant Development - First Edition (BSID-I) [22] were used for assessment of the current level of cognitive, language, personal-social, fine and gross motor development. Norms are provided for infants and toddlers in the age range from 2 months through 30 months of age (mean = 100; S.D. = 15; Dutch version [23]).

At the age of four years (mean age 51.3 months, S.D. = 3.6) the Kaufman Assessment Battery for Children [24] was used to assess information-processing capacities. This test, with an age range from $2 \frac{1}{2}$ years to $12 \frac{1}{2}$ years, includes eight subtests (mean score $=10 ; S D=3$ ). Based on these eight subscales, the K-ABC-test yields standard scores for sequential, simultaneous and total information processing ( mean score $=100$; S.D. $=15)$. Sequential processing refers to temporal or serial ordering the stimuli. Simultaneous processing requires a gestalt integration of stimuli. The subtest Riddles of the $K-A B C$ [24] is an achievement subtest that was used to measure language reasoning: a child is asked to discover a concept when only some characteristics are mentioned in the form of a riddle (mean score =10; S.D. $=3$ ).

The Beery Developmental Test of Visual Motor Integration (VMI) [25] was used to assess the integration of visual perceptual and fine motor abilities of children. The child has to copy as accurate as possible 24 geometric forms which difficulty increases (mean score = 100; S.D. $=15$ ).

Behavioral functioning of the children was measured by means of the Dutch version of the Child Behavior Checklist (CBCL) [26,27]. The CBCL is a parent-reported measure of child behavior problems. This questionnaire yields T-scores for a total problem scale, two broadband scales (i.e., externalizing and internalizing behavior problems) and nine narrowband scales (i.e., withdrawal, physical complaints, anxiety/depression, social problems, thought problems, attention problems, 
delinquent behavior, aggressive behavior, and sexual problems) (mean score $=50$; S.D. = 10).

Finally a parent-reported Dutch questionnaire for parents of pre-school children to detect precursors of ADHD was used. This questionnaire, the Precursors of $A D H D$ Questionnaire (PAQ), has been proven to be valid and reliable [28]. The PAQ consists of 23 items that yield scores on four subscales: Socially inadequate behavior, Impulsivity, Hyperactivity and Attention deficit problems [28].

\subsubsection{Analysis}

In the total sample of 66 children initial umbilical artery $\mathrm{pH}$ values were measured in the range between 6.74 and 7.46 (mean 7.11; S.D. = 0.15). Base Excess values varied in the range from -25.3 to $-1.0 \mathrm{mmol} / \mathrm{L}$ (mean $-10.8 \mathrm{mmol} / \mathrm{L}$; S.D. $=5.8$ ). Spearman's nonparametric test of correlation was used to analyze the effect of $\mathrm{pH}$ values and base excess on outcome measures. As there is not one clear cut-off point described in literature to be used in analyzing data on umbilical arterial $\mathrm{pH}$, stratification was used by separation of the 66 children into 4 groups on the basis of their umbilical arterial $\mathrm{pH}$ value. To compare the distributions of these groups the Kruskal-Wallis test was used. In this way several cut-off values could be analyzed. Table 3.1 reports on the baseline characteristics of the four groups stratified in accordance with different cut-off points of the initial umbilical artery $\mathrm{pH}$ values.

\begin{tabular}{|c|c|c|c|c|c|c|c|}
\hline \multirow[t]{2}{*}{ Subgroups $\mathrm{pH}$ values } & \multirow[t]{2}{*}{ Boys } & \multirow[t]{2}{*}{ Girls } & \multirow[t]{2}{*}{$n$} & \multicolumn{2}{|l|}{$\mathrm{pH}$} & \multicolumn{2}{|c|}{$\begin{array}{l}\text { Base Excess } \\
(\mathrm{mmol} / \mathrm{L})\end{array}$} \\
\hline & & & & Mean & S.D. & Mean & S.D. \\
\hline $\mathrm{pH}<7.00$ & 10 & 5 & 15 & 6.91 & 0.08 & -18.5 & 3.4 \\
\hline $7.00 \leq \mathrm{pH}<7.10$ & 7 & 7 & 14 & 7.05 & 0.03 & -13.5 & 2.2 \\
\hline $7.10 \leq \mathrm{pH}<7.20$ & 8 & 7 & 15 & 7.15 & 0.03 & -9.6 & 1.7 \\
\hline $\mathrm{pH} \geq 7.20$ & 8 & 14 & 22 & 7.27 & 0.06 & -4.6 & 1.7 \\
\hline Total & 33 & 33 & 66 & 7.11 & 0.15 & -10.8 & 5.8 \\
\hline
\end{tabular}

Because base excess determination quantifies the magnitude of metabolic acidosis, the association between outcome measures and base excess was investigated after dichotomization base excess values at the level of $-12.00 \mathrm{mmol} / \mathrm{L}$. This cut-off point was chosen in accordance with the international consensus statement in regard to arterial base deficit [11]. A base excess $\leq-12.00 \mathrm{mmol} / \mathrm{L}$ was found in 26 infants $(39.4 \%)$ whereas 40 infants $(60.6 \%)$ had a base excess above $-12.00 \mathrm{mmol} / \mathrm{L}$.

To determine whether there is a significant difference between boys and girls in umbilical arterial $\mathrm{pH}$ values the Mann-Whitney test was used. Data were analyzed with SPSS for windows version 12.0.1 (SPSS Inc., Chicago, IL). 


\subsection{RESULTS}

In the total sample of 66 infants (33 boys; 33 girls), male newborns $(n=10)$ more often had a pronounced acidemia $(\mathrm{pH}<7.00)$ than females $(\mathrm{n}=5)$, whereas there were more girls $(n=14)$ in the subgroup with a normal umbilical artery $\mathrm{pH} \geq 7.20)$ than boys $(n=8)$. These findings suggest a gender difference in the umbilical arterial $\mathrm{pH}$ values, but this difference was not statistical significant (Mann-Whitney $U=412.000, p=$ 0.089 , two-tailed).

To assess the correlation between umbilical arterial $\mathrm{pH}$ values and outcome measures, Spearman's rho nonparametric test of correlation was used. At the age of 9 months no significant correlations could be found between umbilical arterial $\mathrm{pH}$ values and outcome on Bayley Mental Scale respectively Bayley Motor Scale. However, there was a significant positive correlation between $\mathrm{pH}$ and the scores on Bayley Mental Scale at 18 months (rho $=0.445, p<0.0005$, two-tailed). There was also a positive significant correlation between $\mathrm{pH}$ and the scores on Bayley Motor Scale at 18 months (rho $=0.377, p=0.002$, two-tailed). Figure 3.1 shows the relationship between umbilical artery $\mathrm{pH}$ and the scores on the Bayley Mental and Motor Scales at the age of 18 months.
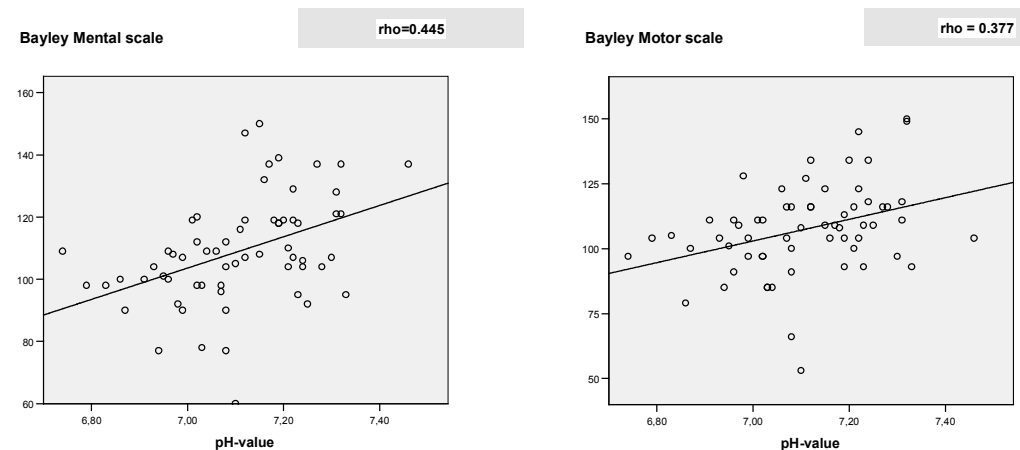

Figure 3.1: Relationship between initial arterial pH and Bailey Mental Scale respectively Bayley Motor Scale at 18 months.

After dichotomization for arterial base excess using a cut-off point of $-12 \mathrm{mmol} / \mathrm{L}$, no significant correlations were found at the age of 9 months. Significant correlations could be found between base deficit values and the scores at age 18 months on Bayley Mental Scales (Mann-Whitney $U=271.000, p=0.005$, two-tailed) and Bayley Motor Scales (Mann-Whitney $U=328.000, p=0.045$, two-tailed). 
As shown in table 3.2, no significant correlations could be found between umbilical arterial $\mathrm{pH}$ and the Bayley Scales of Infant Development at the age of 9 months.

Analysis of variance of all the outcome measures performing the Kruskal-Wallis test revealed only significant differences between the $\mathrm{pH}$ subgroups on outcome of the Bayley Mental Scale at 18 months $\left(\mathrm{Chi}^{2}=17.535, p=0.001\right)$ and the Bayley Motor Scale at 18 months $\left(\mathrm{Chi}^{2}=11.035, p=0.012\right)$.

Table 3.2: Median assessment scores in relation to stratified $\mathrm{pH}$ values

\begin{tabular}{|c|c|c|c|c|c|c|c|}
\hline $\begin{array}{l}\text { Outcome } \\
\text { measures }\end{array}$ & & $\begin{array}{c}\text { Spearman's } \\
\text { rho }\end{array}$ & $\mathrm{pH}<7.0$ & $\begin{array}{l}7.00 \leq \mathrm{pH}<7.1 \\
0\end{array}$ & $\begin{array}{l}7.10 \leq \mathrm{pH}<7.2 \\
0\end{array}$ & $\mathrm{pH} \geq 7.20$ & $\begin{array}{l}\text { Kruskal- } \\
\text { Wallis } \\
\text { Chi }^{2}\end{array}$ \\
\hline & Age & & $n=13$ & $n=14$ & $n=14$ & $n=17$ & \\
\hline $\begin{array}{l}\text { Bayley Mental } \\
\text { Scale }\end{array}$ & $\begin{array}{c}9 \\
\text { months }\end{array}$ & 0.050 & $\begin{array}{c}102.1 \pm 13.3 \\
a\end{array}$ & $102.4 \pm 13.7$ & $105.5 \pm 17.1$ & $104.0 \pm 9.8$ & 0.934 \\
\hline $\begin{array}{l}\text { Bayley Motor } \\
\text { Scale }\end{array}$ & $\begin{array}{c}9 \\
\text { months }\end{array}$ & 0.100 & $99.7 \pm 8.8$ & $97.2 \pm 10.6$ & $99.2 \pm 15.4$ & $102.8 \pm 11.2$ & 2.139 \\
\hline $\begin{array}{l}\text { Bayley Mental } \\
\text { Scale }\end{array}$ & $\begin{array}{c}18 \\
\text { months }\end{array}$ & $0.445^{\star * * b}$ & $98.9 \pm 8.8$ & $101.4 \pm 13.4$ & $122.6 \pm 28.6$ & $114.5 \pm 14.2$ & $17.535^{\star \star \star}$ \\
\hline $\begin{array}{l}\text { Bayley Motor } \\
\text { Scale }\end{array}$ & $\begin{array}{c}18 \\
\text { months }\end{array}$ & $0.377^{\star *}$ & $101.7 \pm 11.7$ & $99.0 \pm 15.7$ & $108.4 \pm 19.0$ & $117.0 \pm 17.6$ & $11.035^{*}$ \\
\hline $\begin{array}{l}\text { K-ABC } \\
\text { Sequential }\end{array}$ & 4 years & 0.114 & $109.3 \pm 15.8$ & $98.9 \pm 11.0$ & $107.9 \pm 8.4$ & $105.5 \pm 13.8$ & 4.556 \\
\hline $\begin{array}{l}\text { K-ABC } \\
\text { Simultaneous }\end{array}$ & 4 years & 0.165 & $106.3 \pm 17.9$ & $107.1 \pm 10.8$ & $109.3 \pm 11.2$ & $110.5 \pm 10.1$ & 1.557 \\
\hline $\begin{array}{l}\text { K-ABC } \\
\text { Riddels }\end{array}$ & 4 years & 0.113 & $100.4 \pm 11.3$ & $104.6 \pm 9.8$ & $106.1 \pm 6.5$ & $105.2 \pm 10.5$ & 1.458 \\
\hline VMI-Beery & 4 years & 0.071 & $101.9 \pm 15.3$ & $104.8 \pm 12.7$ & $103.3 \pm 11.1$ & $106.5 \pm 12.0$ & 0.947 \\
\hline $\begin{array}{l}\text { CBCL Total } \\
\text { score }\end{array}$ & 4 years & -0.104 & $51.9 \pm 9.3$ & $55.3 \pm 13.4$ & $50.7 \pm 13.8$ & $49.9 \pm 10.2$ & 1.327 \\
\hline $\begin{array}{l}\mathrm{CBCL} \\
\text { Internalizing }\end{array}$ & 4 years & -0.224 & $50.3 \pm 7.2$ & $52.3 \pm 9.6$ & $51.8 \pm 9.8$ & $45.9 \pm 7.0$ & 5.022 \\
\hline $\begin{array}{l}\mathrm{CBCL} \\
\text { Externalizing }\end{array}$ & 4 years & 0.046 & $50.8 \pm 10.5$ & $57.2 \pm 13.3$ & $50.7 \pm 12.5$ & $52.6 \pm 11.0$ & 1.207 \\
\hline $\begin{array}{l}\text { PAQ Socially } \\
\text { Inadeq. Beh. }\end{array}$ & 4 years & -0.148 & $1.1 \pm 1.3$ & $2.4 \pm 2.1$ & $1.1 \pm 1.6$ & $0.9 \pm 1.1$ & 5.269 \\
\hline PAQ Impulsivity & 4 years & -0.132 & $2.8 \pm 1.7$ & $2.4 \pm 1.5$ & $1.7 \pm 1.7$ & $2.2 \pm 1.5$ & 3.355 \\
\hline $\begin{array}{l}\text { PAQ } \\
\text { Hyperactivity }\end{array}$ & 4 years & -0.054 & $1.7 \pm 1.8$ & $2.6 \pm 2.1$ & $1.5 \pm 1.6$ & $1.8 \pm 1.7$ & 2.904 \\
\hline PAQ Inattention & 4 years & -0.181 & $2.5 \pm 1.4$ & $2.9 \pm 2.0$ & $1.3 \pm 1.3$ & $2.2 \pm 1.5$ & 7.265 \\
\hline
\end{tabular}


At the age of four years no significant correlations could be found between umbilical artery $\mathrm{pH}$ values and the information processing scores assessed by the Kaufman Assessment Battery for Children (K-ABC), neither for simultaneous nor for sequential processing scores. The subscale for language reasoning (subtest Riddles of the K$\mathrm{ABC}$ ) or any of the other subscales also showed to be not significant correlated with umbilical artery $\mathrm{pH}$ values. Four-year-old children with low scores on the dependent variables appeared not to have low umbilical artery $\mathrm{pH}$ values at birth. In illustration of this, at the age of four years only one child was found with a total mental processing score below 85 (K-ABC), whilst this child had an initial umbilical cord $\mathrm{pH}$ value above $7.20(\mathrm{pH}=7.25 ; \mathrm{BE}=-3.80)$. Contrarily, three four year aged children with an initial umbilical artery $\mathrm{pH}$ below 7.00 appeared to have a mental processing score above 115 . Furthermore $\mathrm{pH}$ values and bases excess were not significantly related to the integration of visual perception and fine motor abilities of the children at the age of four years as measured by the Beery Developmental Test of Visual Motor Integration (VMI). Finally, no relation was found between acid-base values at birth and the outcome on externalizing and internalizing behavior problems as rated by the parents on the Child Behavior Check List (CBCL) respectively the outcomes on the Precursors of ADHD Questionnaire (PAQ).

No significant gender differences could be found in performing on Bayley's Development Scales at the age of 9 months and 18 months, as well as on information processing (K-ABC) and integration of visual perception and fine motor abilities (Beery-VMI). So gender can be ruled out as an explanation for the differences between the $\mathrm{pH}$ subgroups on outcome of the Bayley Mental Scale at 18 months.

According to the results for the subscale "Socially inadequate behavior" of the Precursors of ADHD Questionnaire (PAQ) at the age of four years, boys tend to have more problems related to socially inadequate behavior than girls (Mann-Whitney $\mathrm{U}=$ 282.000, $p=0.014$, two-tailed). However, the outcome of Child Behavior Checklist $(\mathrm{CBCL})$ showed no statistically significant gender differences.

\subsection{DISCUSSION}

In this prospective follow-up study neurocognitive and behavioral outcome was studied in a sample of 66 infants, all born at term, without neonatal complications and with an umbilical artery $\mathrm{pH}$ in the range 6.74 to 7.46 . Strict criteria of inclusion and exclusion were chosen to get a sample where initial umbilical artery $\mathrm{pH}$ would be the major factor determining outcome, ruling out the confounding effect of other birth complications or structural brain abnormalities. The present study is a sequel to an earlier study (Wildschut, Feron, Hendriksen, et al, 2004) [19], which was focused on the relationship between umbilical artery $\mathrm{pH}$ at birth and quality of movements at the 
age of three months, based on a sample of 44 children. This previous study indicated no relationship between acid-base status at birth in full-term infants and cognitive and behavioral development at four years. Therefore, the current study was based on a higher number of infants $(n=66)$ in order to describe the neurocognitive profile of the children in study, subsequently using three points of measurement: 9 months, 18 months and four years of age. It was shown that only a statistically significant relation could be found between initial umbilical artery $\mathrm{pH}$ and mental and motor functioning at the age of 18 months. Despite the use of an extended sample of infants, no other relations between umbilical cord $\mathrm{pH}$ and neurocognitive and behavioral outcome could be found, neither at the age of 9 months nor at the age of 4 years.

Where umbilical arterial $\mathrm{pH}$ values provide information regarding the acid-base status of the neonate after delivery, base excess values are assumed to reflect the quantitative range of metabolic acidosis [11,35]. Because threshold levels of base excess below $-12 \mathrm{mmol} / \mathrm{L}$ have been associated with an increased risk of neonatal neurological injury [11,29], in this study a base deficit $\geq 12 \mathrm{mmol} / \mathrm{L}$ was chosen as cut-off point for dichotomization. As the results have shown, base excess was correlated only with Bayley Mental Scales and Bayley Motor Scales at 18 months. For the other entire cognitive and behavioral outcome measures no correlation with base excess values could be found.

In literature there is no consensus on the clinical relevant cut-off point for $\mathrm{pH}$ values. For this reason the total group of 66 children was split up in 4 subgroups on the basis of their $\mathrm{pH}$ value, so several cut-off values could be analyzed. The results of the study indicate that acid-base status at birth in full-term born infants without clinical evidence of perinatal hypoxic-ischemic encephalopathy is a poor predictor of neurocognitive and behavioral outcome in preschool and early school-aged children. A "dose-response" relationship between umbilical arterial $\mathrm{pH}$ respectively base excess and cognitive outcome at early school age could not be found and increasing acidosis was not linearly related to decreases in long-term cognitive outcome. Consequently, our current findings are not in accordance with the recent findings of Hopkins-Golightly, Raz \& Sander [17], who stated that increasing acidosis in newborn infants is linearly related to decreases in cognitive skills at early school-age, based on a sample of preterm-birth infants. This indicates that gestational age, and not acidbase status at birth, is the major factor in explaining individual long-term cognitive outcome scores. However, in an earlier study of Stevens, Raz \& Sander [18] a significant effect of gestational age on intellectual abilities was not observed [18]. On this point further research is needed.

Goodwin et al [7] found no gender differences among 129 infants with an initial umbilical artery pH below 7.00. However, Ingemarsson et al [3] and Van den Berg et al [5] reported a significant male dominance among newborns with severe acidemia $(\mathrm{pH}<7.00)$. In the present study also a tendency to male dominance in newborns 
with severe acidemia was found, but this finding was not statistically significant. This might be attributed to the use of a relatively small sample, which is a consequence of the strict selection criteria used in this study.

Not only in literature but also in clinical practice it is often incorrectly assumed that hypoxia, ischemia, acidosis, acidemia, asphyxia and birth depression all are synonymous. Birth asphyxia can be defined as a perinatal occurring interference with respiration resulting in hypoxia (a fall in oxygen supply) and tissue acidosis (accumulation of acid in the tissues), whereas acidemia is synonymous with accumulation of acid in the blood with a resultant fall in the blood $\mathrm{pH}$. Low fetal oxygen saturation measured at birth seems to be associated with low fetal $\mathrm{pH}$ and base excess values according to Arikan et al [30], but its predictive value for acidosis appeared limited. Hermansen [14] stated that acidosis is not synonymous with acidemia, so an infant may produce acid in the tissues without developing circulating acidemia. Because tissue acidosis is usually associated with circulating acidemia, it is generally assumed that infants born with acute birth asphyxia invariably demonstrate acidemia in umbilical artery blood at birth. Moreover it is unknown whether and to what extend the degree of acidemia, as measured by umbilical cord $\mathrm{pH}$, is related to the degree of fetal brain lesion because acidemia is modulated by the individual variable vulnerability of the child. In literature several authors indicated already the compensatory mechanisms associated with "beneficial acidemia", providing protection to ischemic encephalopathy $[13,14]$. The specific influence of the so called "beneficial acidemia" on postnatal neurogenesis and synaptogenesis in newborn with severe postpartum acidemia is not yet understood and might be of influence on the results of this study.

Furthermore, numerous studies have demonstrated that the developing brain of the newborn has the fascinating ability to recover from brain injury in terms of neural and functional plasticity [31]. It is beyond doubt that multifactorial neurobiological repair mechanisms play a considerable role in recovering from neurocognitive disabilities, a phenomenon known as "growing out of deficit". The results of the present study, in particular the improvement in some measures of cognitive outcome measures at the age of 18 months across time, suggest a specific role of this phenomenon. Further research is needed to elucidate the multifactorial mechanisms that trigger neuroprotective effects in perinatal hypoxic-ischemic injury.

As stated before, the Apgar scores were left out of consideration in this study considering that the relation between the Apgar score and the acid-base status is not close [15,21]. Low Apgar scores assigned at 1 and 5 minutes after birth certainly can indicate birth depression. In general with an increased duration of low Apgar scores there is a higher risk of neonatal mortality or increased probability of long-term neurological sequelae. Nevertheless Apgar scores have a poor sensitivity and according to a review of Carter et al [10, page 295] "the diagnostic value of low Apgar 
scores in identifying truly asphyxiated patients, when compared with biochemical indices such as umbilical cord arterial $\mathrm{pH}$ or base deficit, is nil". Furthermore in the same review [10] was stated that Apgar scores have fair specificity in predicting acidosis but not in an absolute sense, so yet it is possible that infants with significant acidosis at birth assign normal Apgar scores. From an epidemiological point of view, Damman \& Leviton [32] argued that the concept of equating perinatal damage by any symptom or status of the child has severe limitations. Decreased Apgar scores have to be interpreted rather as an effect, than as the cause, of perinatal brain injury. In recent literature several authors $[33,34]$ argue a refining of the Apgar score within the context of contemporary perinatal and neonatal care.

It is known that an initial hypoglycemia is an important risk factor for perinatal brain injury in term infants with severe fetal acidemia $(\mathrm{pH}<7.00)$ [35]. For that reason serum glucose was determined on the first day after birth. All glucose values of the newborns enclosed in this study were within normal limits. In clinical practice, presence of acidosis and negative base excess is commonly assumed to reflect impaired tissue perfusion. Lactate is invariably produced when critical tissue hypoxia is reached and tissues switch to anaerobic metabolism. In the present study, measurements of initial blood lactate concentrations of the neonates were not available. In literature, a strong association between the initial lactate levels and neonatal neurological evolution is reported [36,37]. The sensitivity and negative predictive value of lactate even appear to be greater than either $\mathrm{pH}$ or base excess in predicting moderate to severe hypoxic-ischemic encephalopathy [36]. In contrast to general opinion, initial acid-base status or base excess does not correlate well with blood lactate concentrations [37]. According to literature, blood lactate measurements may provide important prognostic information in asphyxiated neonates. However, further prospective research is needed to determine the value of blood lactate concentrations in neonates in predicting long-term developmental outcome.

Finally, it is obvious that the acid-base status at birth in full-term born infants is a poor predictor of neurocognitive and behavioral outcome at preschool age. The later outcome of children in terms of school career and academic performance is probably more determined by a broad variety of biological, psychosocial and sociodemographic factors [38]. Not only pediatricians and child neurologists, but also psychologists and youth health care practitioners should be extremely careful in predicting the future of a particular child, especially in cases where newborns fulfill criteria of a severe acidemia without other clinical evidence of perinatal hypoxicischemic encephalopathy. More antenatal and perinatal parameters than only acidbase status just after delivery are requested in predicting long-term outcome in children. 
The present study is relevant in the sense that outcome measures for cognitive and behavioral functioning were performed in an unique sample of children with a known umbilical artery $\mathrm{pH}$, who were born at term after a normal pregnancy without any neonatal complications. Strict selection criteria were used to minimize several confounding factors. However, this study has a few limitations. As mentioned before, the used sample was relatively small. Consequently, the possibility of lack of sufficient power in the results of this study is not precluded. Besides chosen ways to control confounding, differences in study population and outcome assessments might be restrictions in comparing the current study with other studies of initial fetal acidemia and developmental perspectives. Furthermore, only umbilical cord blood was used to measure acid-base status at birth, so a possible confounding of maternal acid-base status remains unknown in this study. Finally, environmental influences, such as socio-demographic factors and socio-economic circumstances, were not investigated in this study.

\subsection{CONCLUSIONS}

Acid-base status at birth in full-term born infants, without clinical evidence of perinatal hypoxic-ischemic encephalopathy, is a poor predictor of neurocognitive and behavioral outcome in preschool and early school-aged children. Increasing acidosis is not linearly related to decreases in neurocognitive outcome. Supposing a "doseresponse" relationship between umbilical arterial $\mathrm{pH}$ and cognitive outcome at early school age is not warranted. Consequently, low values of initial umbilical artery $\mathrm{pH}$ cannot be taken alone as a predictive factor for long-term outcome at early school age. The results of this study imply that the greatest caution is needed in attributing perinatal acidemia in children as the sole explanation of learning disabilities at school age. Long-term follow-up studies in children older than four years are necessary to completely elucidate all the factors of birth events in causal relationship with the genesis of infant brain disorders. 


\section{REFERENCES}

[1] Nagel HTC, Vandenbussche FPHA, Oepkes D, Jennekens-Schinkel A, Laan LAEM, Bennebroek Gravenhorst J. Follow-up of children born with an umbilical arterial blood $\mathrm{pH}<7$. Am J Obstet Gynecol 1995; 173: 1758-1764

[2] Helwig JT, Parer JT, Kilpatrick SJ, Laros RK. Umbilical cord blood acid-base state: What is normal? Am J Obstet Gynecol 1996; 174: 1807-1814.

[3] Ingemarsson I, Herbst A, Thorngren-Jerneck K. Long term outcome after umbilical artery acidaemia at term birth: influence of gender and duration of fetal heart rate abnormalities. $\mathrm{Br} \mathrm{J}$ Obstet Gynaecol 1997; 104: 1123-1127.

[4] Low JA, Panagiotopoulos C, Derrick EJ. Newborn complications after intrapartum asphyxia with metabolic acidosis in the term fetus. Am J Obstet Gynecol 1994; 170: 1081-1087.

[5] van den Berg PP, Nelen WLDM, Jongsma HW, Nijland R, Kollée LAA, Nijhuis JG, Eskes TKAB. Neonatal complications in newborns with an umbilical artery $\mathrm{pH}<7.00$. Am J Obst Gynecol 1996; 175 : 1152-1157.

[6] Williams KP, Singh A. The correlation of seizures in newborn infants with significant acidosis at birth with umbilical artery cord gas values. Obstet Gynecol 2002; 100: 557-560.

[7] Goodwin TM, Belai IM, Hernandez P, Durand M, Paul RH. Asphyxial complications in the term newborn with severe umbilical acidemia. Am J Obstet Gynecol 1992; 167: 1506-1512.

[8] King TA, Jackson GL, Josey AS, Vedro DA, Hawkins H, Burton KM, Burks MN, Yellin WM, Laptook AR. The effect of profound umbilical artery acidemia in term neonates admitted to a newborn nursery. $J$ Pediatr 1998; 132: 624-629.

[9] Goldaber KG, Gilstrap LC 3rd, Leveno KJ, Dax JS, McIntire DD. Pathologic fetal acidemia. Obstet Gynecol 1991; 78: 1103-1107.

[10] Carter BS, Haverkamp AD, Merenstein GB. The definition of acute perinatal asphyxia. Clin Perinatol 1993; 20: 287-304

[11] MacLennan A. A template for defining a causal relation between acute intrapartum events and cerebral palsy: international consensus statement (International Cerebral Palsy Task Force). BMJ 1999; 319: 1054-1059.

[12] Low JA, Galbraith RS, Muir DW, Killen HL, Pater EA, Karchmar EJ. Motor and cognitive deficits after intrapartum asphyxia in the mature fetus. Am J Obstet Gynecol 1988;158:356-61.

[13] Dennis J, Johnson A, Mutch L, Yudkin P, Johnson P. Acid-base status at birth and neurodevelopmental outcome at four and one-half years. Am J Obstet Gynecol 1989; 161: 213-220.

[14] Hermansen MC. The acidosis paradox: asphyxial brain injury without coincident acidemia. Dev Med Child Neurol 2003; 45: 353-356.

[15] Ruth VJ, Raivio KO. Perinatal brain damage: predictive value of metabolic acidosis and the Apgar score. BMJ 1988; 297: 24-27.

[16] Dijxhoorn MJ, Visser GHA, Huisjes HJ, Fidler VJ, Touwen BCL. The relation between umbilical pH values and neonatal neurological morbidity in full term appropriate-for-date infants. Early Hum Dev 1985; $11: 33-42$

[17] Hopkins-Golightly T, Raz S, Sander CJ. Influence of slight to moderate risk for birth hypoxia on acquisition of cognitive and language function in the preterm infant: a cross-sectional comparison with preterm-birth controls. Neuropsychology 2003; 17: 3-13.

[18] Stevens CP, Raz S, Sander CJ. Peripartum hypoxic risk and cognitive outcome: a study of term and preterm birth children at early school age. Neuropsychology 1999; 13: 598-608

[19] Wildschut J, Feron FJM, Hendriksen JGM, van Hall M, Gavilanes-Jiminez DWD, Hadders-Algra M,Vles $\mathrm{JSH}$. Acid-base status at birth, spontaneous motor behaviour at term and 3 months and neurodevelopmental outcome at age 4 years in full-term infants. Early Hum Dev 2005; 81: 535-544.

[20] Kollée LAA, Sauer PJJ. De pasgeborene. In: van den Brande JL, Heymans HAS, Monnens LAH. Kindergeneeskunde. (3th edition) Maarssen: Elsevier gezondheidszorg, 2002: 145-190.

[21] Sykes GS, Molloy PM, Johnson P, Gu W, Ashworth F, Stirrat GM, Turnbull AC. Do Apgar scores indicate asphyxia? The Lancet 1982; 1: 494-496. 
[22] Bayley N. Manual for the Bayley Scales of Infant Development. San Antonio, TX: The Psychological Corporation; 1969

[23] van der Meulen BF, Smrkovsky M. Handleiding bij de Bayley Ontwikkelingsschalen BOS 2-30. [Manual]. Lisse: Swets \& Zeitlinger; 1983.

[24] Kaufman AS, Kaufman NL. Kaufman Assessment Battery for Children. Interpretive manual. Circle Pines, Minnesota, USA: American Guide Service; 1983.

[25] Beery KE. The Beery-Buktenica Developmental Test of Visual-motor integration (VMI). Manual. Parsippany, New Jersey: Modern Curriculum Press; 1997.

[26] Achenbach TM. Manual for Child Behavior Checklist / 4-18 and 1991 profile. Burlington VT: University of Vermont Department of Psychiatry; 1991.

[27] Verhulst FC, Koot JM, van der Ende J. Handleiding voor de CBCL 4-18 (Child Behavior Checklist) [Manual for the $\mathrm{CBCL}$. Rotterdam, The Netherlands: Afdeling Kinder- en Jeugdpsychiatrie, Sophia Kinderziekenhuis/Academisch Ziekenhuis Rotterdam/Erasmus Universiteit Rotterdam; 1996.

[28] Hendriksen JGM, Steyaert J, Kroes M, Vles JSH. VVA: Vragenlijst Voorlopers ADHD (PAQ: Precursors of Attention deficit Questionnaire). Dutch questionnaire; manual. Leiden: PITS 2002.

[29] Ross MG, Gala R. Use of umbilical artery base excess: algorithm for the timing of hypoxic injury. Am $J$ Obstet Gynecol 2002; 187: 1-9.

[30] Arikan GM, Scholtz HS, Haeusler MCH, Giuliani A, Haas J, Weiss PA. Low fetal oxygen saturation at birth and acidosis. Obstet Gynecol 2000; 95: 565-571.

[31] Vaccarino FM, Ment LR. Injury and repair in developing brain. Arch Dis Child-Fetal Neonatal Ed. 2004; 89: 190-192

[32] Dammann O, Leviton A. The role of perinatal brain damage in developmental disabilities: an epidemiologic perspective. MRDD Research Reviews 1997; 3: 13-21.

[33] Chong DS, Karlberg J. Refining the Apgar score cut-off point for newborns at risk. Acta Paediatr 2004;9 3: $53-59$

[34] Bharti B, Bharti S. A review of the Apgar score indicated that contextualization was required within the contemporary perinatal and neonatal care framework in different settings. J Clin Epidemiol 2005; 58: 121-129.

[35] Salhab WA, Wyckoff MH, Laptook AR, Perlman JM. Initial hypoglycemia and neonatal brain injury in term infants with severe fetal acidemia. Pediatrics 2004; 114: 361-366.

[36] Shah S, Tracy M, Smyth J. Postnatal lactate as an early predictor of short-term outcome after intrapartum asphyxia. J Perinatol 2004; 24: 16-20.

[37] Deshpande SA, Platt MP. Association between blood lactate and acid-base status and mortality in ventilated babies. Arch Dis Child Fetal Neonatal Ed 1997; 76: F15-20.

[38] Resnick MB, Gueorguieva RV, Carter RL, Ariet M, Sun Y, Roth J, Bucciarelli RL, Curran JS, Mahan CS. The impact of low birth weight, perinatal conditions and sociodemographic factors on educational outcome in kindergarten. Pediatrics 1999; 104: 74-84. 
CHAPTER 4

The effect of Clonidine and Methylphenidate in children with Attention Deficit Hyperactivity Disorder: a comparison of neuropsychological and behavioral effects in 37 children 


\section{ABSTRACT}

The core symptom of Attention Deficit Hyperactivity Disorder (ADHD) is a lack in inhibition control manifested in learning, information processing and behavioral dysfunction at school and at home. We systematically investigated the effects of methylphenidate $(n=20)$ and clonidine $(n=17)$ in a group of 37 children with ADHD who showed no evidence of neurological dysfunction at medical evaluation. Medication monitoring was conducted by means of neuropsychological assessment and the Child Behavior Checklist (CBCL), which assesses behavioral functioning in the home situation, before and eight weeks after medication was started.

Methylphenidate and clonidine both showed significant positive effects on sustained attention, information processing, and hyperactive behavior. It was found that methylphenidate had significant positive effects on spatial reasoning and aggressive behavior. The difference in effect on aggressive behavior between methylphenidate and clonidine was statistically significant.

It was concluded that both types of medication in children with ADHD without neurological dysfunction can effectively improve information processing and inhibition control in behavior. The use of methylphenidate and clonidine had different as well as similar effects.

Neuropsychological assessment is not only an important tool to establish the treatment diagnosis of ADHD, but it is also a useful instrument to objectively evaluate the effect of medication. The latter should also be considered in cases of relative contraindications to methylphenidate, such as in children with neurological dysfunctions, in whom clonidine can be prescribed. 


\section{$4.1 \quad$ INTRODUCTION}

The neuropsychological profile of children with attention deficit hyperactivity disorder (ADHD) is characterized by disturbed behavioral inhibition and self-control. The probable origin of this functional disorder is anatomically localized in the prefrontal cortex and the basal ganglia. Hereditary factors seem to play an important role in the development of the disorder [1]. ADHD is a developmental disorder in children, which makes them unable to inhibit motor or emotional responses to an event. This results in the two core symptoms of ADHD according to the DSM-IV classification, i.e. attention deficit and hyperactivity/impulsiveness [2]. ADHD rarely occurs in isolation. In an estimated $65 \%$ of ADHD children, comorbidity includes learning problems, motor coordination problems and social-emotional problems including aggressive behavior [3]. In practice, ADHD also often occurs in combination with pervasive developmental problems, which are characterized by problems with social behavior and stereotype behavior [4]. Literature comprehensively describes the effect of medication on ADHD, although data about the effect of clonidine are still limited [3]. Recent research has suggested that, on the one hand, ADHD results from a lack of dopamine activity (DA) and 5-hydroxytryptamine (5HT) in the frontal striatal system and frontal mesolimbic areas. On the other hand, increased activity of norepinephrine $(\mathrm{NE})$ in the locus coeruleus has been assumed [1].

Several types of medication, such as DA- and 5HT- agonists, have been used in children with ADHD to stimulate DA and 5HT activity (methylphenidate) or to suppress NE activity (clonidine). Because of the different metabolic action, it seemed important to compare the effects of methylphenidate (MPH) and clonidine on neuropsychological and behavioral functioning. Usually, the effect of medication in children with $A D H D$ is measured by means of scoring questionnaires on which problem behaviors of ADHD are scored [5]. Neuropsychological assessment is generally not applied, although dysfunction in this area is presumed [1]. The aim of the present study was to determine the effects of MPH and clonidine on several aspects of neuropsychological and behavioral functioning of children with ADHD and to investigate which aspects of neuropsychological assessment are useful to evaluate prescribed medication.

\subsection{PATIENTS AND METHODS}

Thirty-seven children (35 boys and 2 girls with an average age of 8.4 years; S.D.=1.9) in whom the diagnosis of ADHD had been established participated in the study. The diagnosis of ADHD was made on the basis of a recently described protocol [3]. This protocol included extensive history taking, cognitive testing, general 
physical and neurological examination of the child as well as behavioral assessment of ADHD characteristics by means of structured questions based on the DSM-IV criteria and on the scores on the Child Behavior Checklist (CBCL) filled out by the parents and the scores on the Teacher's Report Form (TRF) filled out by the teachers $[6,7,8,9]$. Subsequently, the compiled data were discussed in a multidisciplinary meeting with a pediatric neurologist, pediatric neuropsychologist and youth health care physician, which eventually resulted in the diagnosis of ADHD. This diagnostic protocol was applied in all children. To our knowledge, this procedure has not been described before in the Netherlands. None of the children had any neurological dysfunctions, such as epilepsy and tic disorders or other pathologies including congenital and non-congenital brain injuries. Most children (71\%) attended a normal primary school.

This was a prospective, non-randomized study in which 20 children were given MPH and 17 were given clonidine. Medication was assigned at random. Prescription of medication was based on a well-tolerated dosage: clonidine b.i.d. with a maximum of $100 \mathrm{mcg} /$ day and MPH $2 \mathrm{mg}$ per kilogram of body weight with a maximum daily dose of $60 \mathrm{mg}$. Titration took place after 2 or 3 weeks, depending on the intended positive effects as well as the reported side effects. The prescribed dose was continued for 8 weeks after which the children were reexamined.

Prior to starting the medication, all children were tested by means of the Kaufman Assessment Battery for Children [10] in order to determine the general level of information processing. At the same time, the CBCL for parents was administered. The Kaufman test measures simultaneous and sequential information processing (mean=100; S.D.=15). The test has been normed and validated for American children aged 2.5 to 12.5 . The combination of the two processing systems provides a rough indication of intellectual functioning. The $\mathrm{CBCL}$ results in T-scores (mean=50; S.D.=10) for total behavioral problems, internalized behavioral problems, such as depression and anxiety, and externalized behavioral problems, such as aggressive behavior. Besides total scores, T-scores can be determined for subscales. A $t$-test comparing both medication groups showed that there was no significant difference with respect to the level of information processing and reported behavioral problems. Table 4.1 provides an overview of the main characteristics of the two groups.

\begin{tabular}{l|c|c|}
\hline \multicolumn{2}{|l|}{ Table 4.1: The main characteristics of the children in the clonidine group and MPH group (mean \pm SD) } \\
\hline Sex & Clonidine group & MPH group \\
\hline Age & 16 boys 1 girl & 19 boys, 1 girl \\
\hline School & 8.1 years $(S D=1.8)$ & 8.7 years $(S D=1.9)$ \\
Mean IQ & 10 primary school; & 15 primary school; \\
CBCL total & 7 special school & 5 special school \\
CBCL internalization & $95.2 \pm 10.5$ & $94.7 \pm 13.1$ \\
CBCL externalization & $66.6 \pm 10.7$ & $68.2 \pm 6.3$ \\
& $61.5 \pm 11.0$ & $63.2 \pm 8.1$ \\
\hline
\end{tabular}


Three tests were used to evaluate the effect of medication and were administered according to a pretest-posttest design. The researcher was not blinded for the type of medication. The first test was a test for sustained visual attention: the Bourdon-Vos test [11]. Speed and accuracy of processing were reflected in standard scores: mean=0; S.D. $=1$. Second, four subtests of the Kaufman scale were administered twice, mean score=10; S.D.=3. These included two subtests for simultaneous processing and two subtests for sequential processing. The subtests were selected on the basis of the specific aspects they assessed and on previous research, which showed that these tests were good predictors of the total of simultaneous and sequential information processing [12]. Simultaneous information processing was investigated by means of the subtest 'gestalt closure', a visual perception task in which the child has to name objects depicted in incomplete drawings, and the subtest 'matrix analogies', which is a spatial task measuring the insight into conceptual relationships between figures. Sequential information processing was assessed by means of the subtest 'number recall', measuring auditory working memory, and the subtest 'word order', a test in which the child has to indicate on an answer sheet the correct order in which a series of objects are read to him. Third, the test for visualmotor integration (VMI) was also administered [13], in which the child has to copy a number of geometrical figures of increasing complexity (mean score $=100$; S.D.=15).In addition to these tests, the parents had to do the CBCL again after the 8 medication weeks. For the effect study, the scores on the behavioral scales for hyperactive, compulsive and aggressive behavior were determined (mean=50; S.D. $=10)$.

The results were analyzed by means of SPSS-PC, which included the Student's ttest. Since the samples were relatively small, a nonparametric test procedure was applied as well (Wilcoxon signed-ranks test) to evaluate the differences per medication group. The Mann-Whitney $U$ test was used to investigate the difference in effect between the MPH group and the clonidine group.

\subsection{RESULTS}

The Wilcoxon signed-ranks test and the Student's t-test showed similar results. Table 4.2 is limited to an overview of the mean scores before and after medication including the corresponding t-values and significance. The scores for sustained attention, and for speed and accuracy of processing as well as the scores for naming incomplete drawings and hyperactive behavior on the $\mathrm{CBCL}$ showed statistically significant positive effects for both MPH and clonidine. A positive effect for the spatial task about conceptual relationships between figures and aggressive behavior on the CBCL was only found in the MPH group, whereas a significant positive effect for indicating word order was only found in the clonidine group. 
The difference in scores between the MPH group and the clonidine group were calculated for each variable. Subsequently, the Mann-Whitney $U$ test was conducted. The only significant difference in effect between MPH and clonidine was for the CBCL-score of aggressive behavior $(U=68 ; p=0.02)$ : MPH leads to a significantly greater reduction of aggressive behavior than clonidine. Accuracy of processing did not show a significant difference between the two medication groups, although it did show a tendency $(p=0.09)$ of a more prominent effect in the MPH group.

\begin{tabular}{|c|c|c|c|c|c|c|}
\hline & \multicolumn{3}{|c|}{ Clonidine group ( $\mathrm{N}=17$ ) } & \multicolumn{3}{|c|}{ MPH group $(\mathrm{N}=20)$} \\
\hline & Pre & Post & t-value & Pre & Post & $\mathrm{t}$-value \\
\hline \multicolumn{7}{|l|}{ Attention: } \\
\hline - Speed of Processing & -0.73 & -0.36 & $-2.48 *$ & -1.06 & -0.61 & $-3.06^{* *}$ \\
\hline - Accuracy of Processing & -0.73 & 0.21 & -3.48 ** & -1.11 & -0.61 & $-5.73^{* \star *}$ \\
\hline \multicolumn{7}{|l|}{ Sequential processing: } \\
\hline - Auditory Working Memory & 8.41 & 9.06 & -0.99 & 8.50 & 9.00 & -0.94 \\
\hline - Indicating Word Order & 7.59 & 8.73 & $-2.40 *$ & 6.77 & 7.77 & -1.98 \\
\hline \multicolumn{7}{|l|}{ Simultaneous processing: } \\
\hline - Incomplete Drawings & 9.12 & 10.71 & $-2.86^{*}$ & 9.17 & 11.89 & -3.68 ** \\
\hline - Conceptual Relationships Figures & 10.25 & 11.07 & -1.44 & 8.86 & 10.86 & -2.23 * \\
\hline Visual Motor Integration & 90.76 & 92.53 & -0.48 & 89.44 & 90.33 & -0.21 \\
\hline \multicolumn{7}{|l|}{ CBCL: Behavioral Functioning } \\
\hline - Hyperactive Behavior & 72.36 & 66.00 & $3.57^{* *}$ & 74.32 & 65.37 & 3.56 ** \\
\hline - Compulsive Behavior & 65.43 & 65.71 & -0.19 & 65.65 & 60.71 & 1.96 \\
\hline - Aggressive Behavior & 69.08 & 68.15 & 0.42 & 69.53 & 62.42 & 4.21 ** \\
\hline
\end{tabular}

\subsection{DISCUSSION}

According to a 341-study meta-analysis published by Swanson et al., MPH in ADHD has a mean effect of 0.83 (no effect is 0.00 ; maximum effect is 1.00 ) on behavioral functioning and attention, and an effect of 0.35 on learning achievement [14]. Other researchers have also found specific effects of MPH on cognitive functioning [15]. Hunt et al. were the first to report a positive effect of clonidine in ADHD children [16]. Later, when scoring questionnaires were used, a similar effect was found for both clonidine and $\mathrm{MPH}$. This positive effect occurred in $50 \%$ of the children [17].

In addition, our study has shown that clonidine also has some effects - similar to those of MPH - on information processing. The positive effect of clonidine was found especially on speed and accuracy of processing and the visual observation task in which incomplete drawing had to be named. Neither medication was found to have an effect on auditory working memory and copying geometrical figures. However, 
three medication-specific effects were found: clonidine lead to improvement on the task in which word order had to be indicated, MPH lead to improved performance on the spatial task about conceptual relationships between figures, and MPH also had a markedly positive effect on aggressive behavior. The latter effect was not found for clonidine, although both clonidine and MPH appeared to have a comparable effect on hyperactive behavior. It can therefore be concluded that, despite their different metabolic actions, MPH and clonidine have a number of similar effects on information processing. Further research into the specific relationship between brain and behavior, particularly information processing, is indicated.

Although only MPH is registered for the treatment of ADHD in the Netherlands [18], clonidine appears to have a similar effect on information processing and hyperactive behavior. Clonidine therefore seems to be a good second-choice drug for the group of ADHD children in whom aggressive behavior is not a comorbidity. In addition, it has already been described that MPH may be contraindicated in children with tic disorders or neurological comorbidity. Also in the 17 children without neurological problems in our study, we have found a significant effect of clonidine.

Side effects in the group of children who were treated with MPH included deterioration of mostly preexisting difficulties falling asleep and decreased appetite. In case of the first side effect, it was usually enough to change the administration time of the last daily dose to an early time during the day. If this measure did not solve the problem sufficiently, melatonin was prescribed with good results. In cases of decreased appetite, parents spontaneously reported that the children ate extra in the evening. Weight measurement did not show clinically relevant weight loss. The side effects of clonidine, decreased blood pressure and pulse rate, did not lead to complaints of postural hypotension or stress-related complaints.

What do these results mean for clinical practice? The treatment of children with ADHD should be multidimensional, i.e. include the child, the parents and possibly the teacher. Medication is used to support treatments with a more long-term effect, such as behavioral therapy, cognitive training and parental guidance [5]. Neuropsychological diagnostics is not essential to diagnose ADHD, although the exact criteria for ADHD are still subject of discussion [3]. The diagnostic protocol by Goldman et al. [3], which was used in this study, is considered useful for clinical practice. The value of neuropsychological diagnostics lies, in our opinion, in its use as a tool to establish the correct treatment diagnosis. For this diagnosis it is important to determine the differential diagnosis and comorbidity for other behavioral neurological disorders and learning disorders, such as motor coordination disorders known as Developmental Coordination Disorder (DCD) in the DSM-IV - dyslexia, and pervasive developmental disorders. In addition, neuropsychological assessment helps to establish the indication for medication, especially when development stagnates in the case of sufficient mental capacities and when other types of 
treatment are not effective. Finally, neuropsychological assessment can represent the effect of medication in degree and number. Gunning only mentioned assessment of problem behavior as a means to establish the effect of medication [5]. As shown in the present study, however, neuropsychological assessment can also make a useful contribution in clinical practice. In view of the increasing knowledge about the organic cerebral substrate of ADHD [1], neuropsychological assessment is an important area for future research. The present study provides the first step towards a research protocol for neuropsychological medication monitoring, in which at least speed and accuracy of information processing and visual perception of incomplete figures are important. Further research is indicated to complete this protocol, also with respect to the differences in effect between MPH and clonidine. 


\section{REFERENCES}

[1] Barkley RB. Attention deficit hyperactivity disorder. Scientific American 1998; 279: 44-49.

[2] American Psychiatric Association. Diagnostic and statistical manual of mental disorders (DSM-IV). Lisse: Swets \& Zeitlinger, 1994.

[3] Goldman LS, Genel M, Bezman RJ, Slanetz PJ. Diagnosis and treatment of attention deficit/hyperactivity disorder in children and adolescents. JAMA 1998; 279: 1100-1107.

[4] Minderaa RB. Overlap en relatie met andere stoornissen [Overlap and relationships with other disorders]. In: Gunning WB (red). Behandelingsstrategieën bij kinderen en jeugdigen met ADHD [Treatment strategies in children and adolescents with $A D H D$ ]. Houten: Bohn Stafleu Van Loghum, 1998.

[5] Gunning WB. Farmacotherapie bij ADHD. In: Gunning WB (red). Behandelingsstrategieën bij kinderen en jeugdigen met ADHD [Treatment strategies in children and adolescents with ADHD]. Houten: Bohn Stafleu Van Loghum, 1998.

[6] Achenbach TM. Manual for the Child Behavior Checklist / 4-18 and 1991 profile. Burlington University of Vermont Department of Psychiatry, 1991.

[7] Verhulst FC, Koot JM, Van der Ende J. Handleiding voor de CBCL (Child Behavior Checklist) [Manual for the $\mathrm{CBCL}$. Afd. Kinder- en Jeugdpsychiatrie, Sophia Kinderziekenhuis / Academisch Ziekenhuis Rotterdam / Erasmus Universiteit Rotterdam, the Netherlands, 1996.

[8] Achenbach, TM (1991). Manual of the Teacher's Report Form and 1991 profile. Burlington, VT: University of Vermont, Department of Psychiatry.

[9] Verhulst FC, Van der Ende J, Koot HM. Handleiding voor de Teacher's Report Form (TRF) [Manual for the TRF]. Afd. Kinder- en Jeugdpsychiatrie, Sophia Kinderziekenhuis / Academisch Ziekenhuis Rotterdam / Erasmus Universiteit Rotterdam, the Netherlands, 1997.

[10] Kaufman AS, Kaufman NL. K-ABC: Kaufman assessment battery for children. Interpretive manual Circle Pines, Minnesota: American Guidance Service Inc.; 1983.

[11] Vos PG. Bourdon-Vos test: handleiding (3de herziene uitgave)—Manual for the Bourdon-Vos test. Lisse, the Netherlands: Swets en Zeitlinger; 1998.

[12] Jurjens HB, Hendriksen JGM. De Kaufman Assessment Battery for Children: psychometrische kenmerken en toepasbaarheid. Proceedings van de Najaarsconferentie sectie revalidatiepsychologen [The Kaufman Assessment Battery for Children: Psychometric properties and applications. Proceedings of the Fall Conference, Section of Rehabilitation Psychologists]. Amsterdam: Nederlands Instituut voor Psychologen, 1991.

[13] Beery KE. The Beery-Buktenica Developmental Test of Visual-motor integration (VMI). Pasipanny, New Jersey: Modern Curriculum Press; 1997.

[14] Swanson JM, McBurnet K, Wigal T, et al. Effects of stimulant medication in children with Attention Deficit Disorder. A 'review of the reviews'. Exceptional Children 1993; 60: 154-162.

[15] Rapport MD, Kelly KL. Psychostimulant effects on learning and cognitive functions: findings and implications for children with attention deficit hyperactivity disorder. Clin Psych Rev 1991; 11: 61-92.

[16] Hunt RD, Minderaa R, Cohen DJ. Clonidine benefits in children with attention deficit disorder and hyperactivity: a report of a double blind crossover therapeutic trial. J Am Acad Child Adolesc Psychiat 1985; 24: 617-629

[17] Gunning WB. A controlled trial of clonidine in hyperkinetic children. Erasmus Universiteitsbibliotheek, Thesis, 1992.

[18] Farmacotherapie bij aandachtstekortstoornis met hyperactiviteit bij kinderen [Farmacotherapy in children with attention deficit disorder with hyperactivity]. Geneesmiddelenbulletin 1996; 30: 16-20. 
CHAPTER 5

Methylphenidate down-regulates the dopamine receptor and transporter system in children with Attention Deficit Hyperactivity Disorder (ADHD) 


\section{ABSTRACT}

Adults suffering from Attention Deficit Hyperactivity Disorder (ADHD) are known to have disturbed central dopaminergic transmission. With Single-Photon Emission Computed Tomography (SPECT) we studied brain dopamine transporter and receptor activity in six boys with ADHD.

Three months after initiation of treatment with methylphenidate we found a downregulation of the post-synaptic dopamine receptor with a maximum of $20 \%$ and a down-regulation of the dopamine transporter with a maximum of $74.7 \%$ in the striatal system. This corresponded with a positive clinical response evaluated by neuropsychological questionnaires and tests.

We suggest that dopamine transporter imaging by SPECT might be used to monitor psychostimulant treatment in children suffering from ADHD. 


\section{$5.1 \quad$ INTRODUCTION}

Attention Deficit Hyperactivity Disorder (ADHD) is a childhood disorder characterized by impaired attention, excessive motor activity, and impulsivity. Although its exact cause is unknown, dopamine pathways in the brain are hypothesized to play an important role [1]. The dopamine system is the main target of the commonly used stimulant medications, e.g. methylphenidate [2]. The increasing frequency with which $A D H D$ is diagnosed has led to a considerable rise in the prescription of these drugs. Long-term use of stimulant medication may adversely affect the maturing brain. Therefore, additional instruments are needed to monitor medical treatments in ADHD more precisely.

Dougherty et al. recently showed that Single-Photon Emission Computed Tomography (SPECT) may be used to visualize an increased dopamine transporter (DAT) activity in adult ADHD patients [3,4]. Krause et al. [5] demonstrated using SPECT with [Tc-99m]TRODAT, a ligand specifically binding to the dopamine transporter, that after 4 weeks of methylphenidate treatment, the increased striatal DAT availability lowers in adults suffering from ADHD.

Following this line of thought we studied dopamine pathways in six boys with ADHD, before and after methylphenidate treatment.

\subsection{PATIENTS AND METHODS}

Children (six boys: aged 6-10 yrs) included fulfilled the criteria for diagnosis of ADHD, made through a clinical interview, according to DSM-IV criteria (Diagnostic and Statistical Manual of Mental Disorders). Apart from the ADHD diagnosis additional inclusion criteria were: no additional psychiatric disorders, no seizures disorders, normal EEG examination results, and no current or previous psychopharmacological treatment. On neurological examination all children were normal.

All boys showed inappropriate behavior within the classroom with severe consequences for their academic and social functioning. The Child Behavior Check List, an instrument to detect the presence of problem behavior in children aged 4-18 years commonly encountered in ADHD children, was used [6]. Furthermore, an extensive neuropsychological examination (Continuous Performance Task, Kaufman Assessment battery for children, developmental test of Visual Motor Integration task, a Digit Repetition task and Gestalt Closure task) was performed [7,8,9]. After informed consent we measured baseline dopamine transporter and post-synaptic dopamine $D_{2}$ receptor integrity in the brain with ${ }^{123}$ I-loflupane (FP-CIT, Nycomed, Amersham, UK) SPECT, and ${ }^{123}$ I-benzamide (IBZM, Amersham, Cygne, Netherlands) respectively. SPECT was performed with a triple head camera 
(MultiSPECT3, Siemens) equipped with fan-beam collimators. A semi-automatic template model program was used to calculate the ratios between left striatal and right striatal and occipital regions respectively. Total time of acquisition was 30 minutes (45 seconds per frame for 40 views per detector). Zoom factor used was 1.23 and the matrix size was $128 \times 128$. Filtered back-projection acquisition was performed. Images were filtered using Butterworth clinical filter with a cut-off value of: 0.500.6 and an order of 0.4-0.5.

A division between the caudate nucleus and putamen was made. The ratios were corrected using Alderson's brain phantom (striatum/occipital cortex for the ${ }^{123}$ I-IBZM and putamen/occipital cortex and the caudate nucleus/occipital cortex in case of ${ }^{123}$ IFP-CIT, respectively). After baseline SPECT studies, the boys received methylphenidate at $0.25-0.6 \mathrm{mg} / \mathrm{kg} / \mathrm{day}$. After 3-4 months we repeated SPECT studies and a child-neurologist and a neuropsychologist saw all children. The neuropsychologist re-evaluated the boys with the instruments mentioned above.

\subsection{RESULTS}

The baseline and follow-up for IBZM SPECT and FP-CIT SPECT ratio's (mean values + S.D.) are shown in table $5.1 \mathrm{a}$ and table $5.1 \mathrm{~b}$, respectively. Base line IBZM SPECT values in the six boys varied from 3.47 to 4.84 in the left striatum and 3.49 to 5.05 in the right striatum respectively. In the six patients $D_{2}$-receptor availability in basal ganglia changed in a range of +4 to $-44 \%$ (table $5.1 \mathrm{a}$ ) after three months of methylphenidate treatment. We observed no consistent left-right asymmetry of receptor integrity before and after treatment with methylphenidate.

\begin{tabular}{|c|c|c|c|c|c|}
\hline & & \multicolumn{2}{|c|}{ Baseline striatum } & \multicolumn{2}{|c|}{ Follow-up striatum } \\
\hline Patient & Age (yrs) & Left & Right & Left & Right \\
\hline 1 & 7 & 3.83 & 3.96 & 4.02 & 4.60 \\
\hline 2 & 9 & 4.84 & 5.05 & 3.82 & 3.27 \\
\hline 3 & 9 & 4.52 & 4.12 & 3.77 & 4.17 \\
\hline 4 & 9 & 4.57 & 3.81 & 2.60 & 3.30 \\
\hline 5 & 8 & 4.57 & 4.63 & 3.84 & 3.22 \\
\hline 6 & 10 & 3.47 & 3.49 & 3.29 & 3.71 \\
\hline \multicolumn{2}{|c|}{ Mean (sd) } & $4.3(0.52)$ & $4.17(0.56)$ & $3.55(0.52)$ & $3.71(0.56)$ \\
\hline
\end{tabular}




\begin{tabular}{|c|c|c|c|c|c|c|c|c|c|}
\hline \multicolumn{10}{|c|}{$\begin{array}{l}\text { Table } 5.1 \mathrm{~b} \text { : Bas } \\
\text { methylphenidate }\end{array}$} \\
\hline \multirow[b]{3}{*}{ Pat } & \multirow[b]{3}{*}{ Age } & \multicolumn{4}{|c|}{ Baseline } & \multicolumn{4}{|c|}{ Follow-up } \\
\hline & & \multicolumn{2}{|c|}{ Left } & \multicolumn{2}{|c|}{ Right } & \multicolumn{2}{|c|}{ Left } & \multicolumn{2}{|c|}{ Right } \\
\hline & & Caudatus & Putamen & Caudatus & Putamen & Caudatus & Putamen & Caudatus & Putamen \\
\hline 1 & 7 & 9.28 & 11.57 & 10.98 & 10.52 & 3.56 & 4.49 & 4.30 & 4.62 \\
\hline 2 & 9 & 11.50 & 14.10 & 17.00 & 15.80 & 4.14 & 4.02 & 4.34 & 3.84 \\
\hline 3 & 9 & 13.06 & 14.25 & 13.50 & 15.09 & 4.72 & 4.44 & 5.18 & 5.23 \\
\hline 4 & 9 & 12.36 & 12.06 & 14.25 & 11.85 & 7.19 & 7.34 & 5.53 & 5.89 \\
\hline 5 & 8 & 10.47 & 11.22 & 11.96 & 11.07 & 7.55 & 8.67 & 6.95 & 7.47 \\
\hline 6 & 10 & 12.63 & 11.13 & 14.05 & 14.16 & 5.67 & 4.33 & 5.10 & 5.08 \\
\hline \multicolumn{2}{|c|}{ Mean (sd) } & $11.6(1.4)$ & $12.4(1.4)$ & $13.6(2.1)$ & $13.1(2.2)$ & $5.5(1.6)$ & $5.5(2.0)$ & $5.2(1.0)$ & $5.4(1.2)$ \\
\hline
\end{tabular}

Base line FP-CIT SPECT values in the six boys varied from 9.28 to 17.0 in the nucleus caudatus (normal range: $8.23 \pm 2.36$ ) and were $10.52-15.09$ in the putamen (normal range: $9.18 \pm 3.71$ ). In all six boys a left-right asymmetry $(\mathrm{Le}<\mathrm{Ri})$ in DAT activity in the caudate nucleus in the drug naive boys was observed. No left-right consistent asymmetry in DAT activity before treatment was observed in the putamen. Follow-up FP-CIT SPECT in the six boys showed reduction of dopamine transporter (DAT) activity in the left and right caudate nucleus within a range of $27.8-64 \%$ and $41.9-74.5 \%$, respectively. It is of interest that the left-right asymmetry disappeared. DAT activity in the left and right putamen decreased in a range of $22.7-71.5 \%$ and $32.5-74.7 \%$, respectively (table 5.1b). Behavior problems, accuracy of working, continuous performance and visuo-motor integration improved according to the used tests (table 5.2).

Table 5.2: Baseline and follow-up neuropsychological findings in 6 boys with ADHD, treated with methylphenidate

\begin{tabular}{lc|c|c|c}
\hline & Mean before & Mean after & $Z$ & $P$ \\
\hline Neuropsychological testing & & & & \\
\hline CPT: speed of working & -0.80 & -0.25 & -1.633 & 0.102 \\
CPT: accuracy of working & -1.00 & 0.75 & -1.841 & 0.066 \\
Auditory working memory & -0.78 & -0.34 & -1.490 & 0.136 \\
Gestalt closure & -0.12 & 0.56 & -1.841 & 0.066 \\
Visual-Motor Integration & -0.64 & -0.15 & -1.826 & 0.068 \\
\hline Behavior report (CBCL) & & & & \\
Externalizing behavior problems & 2.28 & 1.20 & -1.826 & 0.68 \\
Internalizing behavior problems & 1.72 & 0.92 & -1.826 & 0.68 \\
Attention problems & 2.73 & 1.35 & -1.826 & 0.68 \\
Aggressive behavior & 2.68 & 1.43 & -1.826 & 0.68
\end{tabular}

Transformed z-scores (mean $=0$; standard-deviation $=1$ ); differences between mean-scores before and after medication started were analyzed using Wilcoxon signed ranks test. 
In one child (no. 3), methylphenidate treatment was withdrawn after one year, to initiate a drug holiday. One month afterwards IBZM- SPECT and FP-CIT-SPECT were performed. Post-synaptic striatal dopamine receptor density returned to pretreatment values. On FP-CIT SPECT the right nucleus caudatus and right putamen ratio's returned to pre-treatment values. However, in the left nucleus caudatus and putamen the obtained ratios after withdrawal methylphenidate were increased by 30 $\%$ (left nucleus caudatus: pre-treatment 11.50, after withdrawal 14.65; left putamen: pre-treatment ratio 14.10, after withdrawal 21.37) and $50 \%$ compared to pretreatment values respectively. There were no complications during SPECT investigations. The well-known complaints/side effects of methylphenidate were mostly dose-dependent and disappeared in time or with lowering of the daily dose.

\subsection{DISCUSSION}

The signs of underarousal and underfocused attention in ADHD might be due to a decreased Dopamine (DA) and Serotonin (5HT) activity in the fronto-striatal and fronto-mesolimbic areas and / or an increased norepinephrine (NE) activity in the locus coeruleus. The dopamine system consists of two primary ascending systems: a) the nigrostriatal system originating in the substantia nigra and terminating in the striatum, which consists of the caudate nucleus and putamen; and b) the mesocorticolimbic pathway in which several limbic structures receive their dopaminergic input from the midbrain. Both systems are thought to play an important role in the two main characteristics of ADHD, namely, attention and motor behavior. The association of the dopamine transporter gene (DAT1) with ADHD is of particular importance. Over-expression of DAT results in lower concentrations of dopamine in the synaptic cleft. This relative dopamine deficiency is postulated to be one of the causes of $A D H D$ and is the main target for medication. Different specialized medications have been used in infants with ADHD in order to stimulate DA and HT activity (methylphenidate) or to antagonize NE-activity (clonidine). Because of the different neurometabolic action of these abovementioned drugs, it is of interest to study these drug-induced metabolic changes related to neuropsychological functioning in infants with ADHD.

Our results extend those of Dougherty [3] and Krause et al. [5], showing an increase of dopamine transporter density in basal ganglia of untreated adult ADHD patients, to the child ADHD population. As a result, a selective deficiency in the availability of dopamine at the synaptic cleft may be the cause of this disorder characterized by impaired attention, excessive motor activity and impulsivity. It is assumed that methylphenidate increases the synaptic concentration of dopamine by blocking the dopamine transporter (DAT). SPECT ratios of DAT during treatment in the six boys under study are in accordance with this hypothesis. Our results in six boys indicate that dopamine transporter metabolism is an important primary target of 
methylphenidate treatment. Dopamine transporter imaging by FP-CIT SPECT may be useful to monitor psychostimulant treatment in ADHD in children.

Recently Ilgin and co-workers [10] were able to show a decrease of midbrain dopamine receptors in ADHD patients as a result of methylphenidate treatment. We found a dopamine receptor down-regulation of the same magnitude, but this was much smaller than the one we observed for the dopamine transporter. The smaller decrease in $D_{2}$ dopamine receptor studied by IBZM-SPECT is probably secondary to the down-regulation of the dopamine transporter system. An alternative explanation for the dopamine 2 receptor density decrease is an increase in dopamine concentration in the synaptic cleft competing with a tracer for binding sites.

The left-right asymmetry (Ri>Le) in DAT activity in the caudate nucleus, not found in the putamen in the drug naive boys, is consistent with the findings of Castellanos et al. [11] and accords with the hypothesis of ADHD as a right hemispheral disorder. Whether asymmetry is physiological in this age group, or is a sign of abnormal function, is still a matter of debate. The studies related to this topic of asymmetry are very inconsistent (Spalletta et al. 12]). Moreover, to decide which side is the pathological one is difficult to answer without studying a control sample of normal children. The observation in one boy that after stopping medication, the obtained ratios returned to pre-treatment values on the right side, and above pre-treatment values on the left side, is suggestive of a functional, and not a structural disorder in the dopamine metabolism. This is in accordance with the observation that in all neuroimaging studies performed in ADHD no evidence of brain damage was found. Whether long-term methylphenidate prevents the natural down-regulation in DAT activity with aging and even gives rise to an up-regulation of DAT activity in the left hemisphere is of clinical importance and needs further study.

\subsection{CONCLUSION}

Dopamine transporter imaging by FP-CIT SPECT may be useful in the pathophysiological clinical research of $A D H D$ as well as in evaluating different treatment approaches. 


\section{REFERENCES}

[1] Swanson JM, Flodman P, Kennedy J, Spence MA, Moyzis R, Schue S, et al. Dopamine genes and ADHD. Neuroscience and Biobehavioral Reviews 2000; 24: 21-25.

[2] Swanson JM. Dopamine-transporter density in patients with ADHD. The Lancet 2000; 355: 1461.

[3] Dougherty DD, Bonab AA, Spencer TJ, Rauch L, Madras BK, Fischmann AJ. Dopamine transporter density in patients with attention deficit hyperactivity disorder. The Lancet 1999; 354: 2132-2133.

[4] Dougherty DD, Bonab AA, Spencer TJ, Rauch SL, Madras BK, Fischman AJ. Dopamine transporter density in patients with ADHD. The Lancet 2000; 355: 1461-1462.

[5] Krause KH, Dresel SH, Krause J, Kung HF, Tatsch K. Increased striatal dopamine transporter in adult patients with attention deficit hyperactivity disorder: effects of methylphenidate as measured by single photon emission computed tomography. Neuroscience Letters 2000; 285; 107-110.

[6] Verhulst FC, Koot JM, Van der Ende J. Handleiding voor de CBCL (Child Behavior Checklist) [Manual for the $\mathrm{CBCL}$. Afd. Kinder- en Jeugdpsychiatrie, Sophia Kinderziekenhuis / Academisch Ziekenhuis Rotterdam / Erasmus Universiteit Rotterdam, the Netherlands, 1996.

[7] Vos PG. Bourdon-Vos test: handleiding (3de herziene uitgave)—Manual for the Bourdon-Vos test. Lisse, Netherlands: Swets en Zeitlinger; 1998.

[8] Kaufman AS, Kaufman NL. Kaufman assessment battery for children. Interpretive manual. Circle Pines, Minnesota: American Guide Service; 1983.

[9] Beery KE. The Beery-Buktenica Developmental Test of Visual-motor integration (VMI). Pasipanny, New Jersey: Modern Curriculum Press; 1997.

[10] Ilgin N, Senol S, Gucuyener K, Gokcora N, Atavci S, Sener S. Is increased D2 receptor availability associated with response to stimulant medication in ADHD. Developmental Medicine \& Child Neurology 2001; 43: 755-760.

[11] Castellanos FX, Giedd JN, Marsh WL, Hamburger SD, Vaituzis AC, Dickstein DP et al. Quantitative brain magnetic resonance imaging in attention-deficit hyperactivity disorder. Arch Gen Psychiatry 1996; 53: 607-616.

[12] Spalletta G, Pasini A, Pau F, Guido G, Menghini L, Caltagirone C. Prefrontal blood flow dysregulation in drug naive ADHD children without structural abnormalities. J Neural Transm 2001; 108: 1203-1216. 
CHAPTER 6

Dopamine transporter in AttentionDeficit Hyperactivity Disorder normalizes after cessation of Methylphenidate 


\section{ABSTRACT}

Attention Deficit Hyperactivity Disorder (ADHD) is a common neurodevelopmental disorder of childhood, which is increasingly treated with methylphenidate. The shortterm response on treatment with methylphenidate is a substantial decrease in dopamine transporter density, with improvement in neuropsychological tests. In this study, single-photon emission computed tomography was used to investigate possible long-term alterations in the cerebral dopamine system after cessation of treatment with methylphenidate in five children with ADHD. Three months after initiation of treatment with methylphenidate, a reduction of the dopamine transporter in the striatal system was observed. Methylphenidate was administered for a period of 9 to 20 months. Follow-up with single-photon emission computed tomography after withdrawal of methylphenidate medication showed an increase of dopamine transporter activity comparable with pretreatment values. The observed up-regulation of dopamine transporter activity might support the assumption that methylphenidate does not lead to permanent damage of the nigrostriatal dopaminergic pathways. 


\subsection{INTRODUCTION}

Attention Deficit Hyperactivity Disorder (ADHD), a common neurodevelopmental disorder of childhood, is a clinically heterogeneous syndrome, with core symptoms of inattention, excessive motor activity and impulsivity. The therapeutic use of methylphenidate for the management of children with ADHD is increasing on a large scale, as its short-term efficacy in modifying motor, cognitive and affective responses is well documented $[1,2,3,4]$. Trials with 14 to 24 months follow-up suggested that consistent use of stimulant medication was associated with maintenance of effectiveness [5,6].

However, as ADHD can persist into adulthood, concern has been raised about the possible negative effects of long-term exposure of developing brains to methylphenidate $[3,4,7]$. Data on chronic methylphenidate use and abuse are scarce. In addition, the possibility that methylphenidate, like other psychostimulant amphetamine derivates, might produce toxic effects on central monoaminecontaining neurons has received relatively little attention [8]. Extrapolating experimental animal data, methylphenidate is probably safer than amphetamine, as it lacks the dopamine neurotoxic potential that has been well documented for amphetamine [8]. However, data in children related to this topic are unavailable.

Recent research suggests that the cerebral dopamine transporter is the primary target for methylphenidate in ADHD patients [4]. Both adults and children with ADHD appear to have increased dopamine transporter binding ratios in the basal ganglia compared with normal subjects $[9,10]$. We recently found that imaging of the cerebral dopamine system using single-photon emission computed tomography is a useful instrument to monitor psychostimulant treatment in children with ADHD: a reduction of dopamine transporter activity during methylphenidate treatment was observed [11]. In order to be informed about the potential long-term effects of chronic methylphenidate treatment, in the present study, single-photon emission computed tomography was used to monitor the dopamine system in five males with ADHD after cessation of methylphenidate treatment.

\subsection{METHODS}

\subsubsection{Subjects and Procedure}

In the present study, single-photon emission computed tomography was used to monitor the dopamine system in five children with ADHD before $(=T 0)$, during methylphenidate treatment $(=\mathrm{T} 1)$, and after withdrawal methylphenidate $(=\mathrm{T} 2)$ after a duration of 9-20 months treatment. The study included five children, all right-handed 
males, mean age 8.54; S.D. $=0.88$ years, range $7.3-9.6$ years. Mean intelligence level as measured with the Kaufman Assessment Battery for Children (K-ABC) [12] was in the average to low-average range: mean score 88.8; S.D.=8.3. Written informed consent was obtained from the parents of all children after the procedures had been explained to the parents and children in detail. The study protocol was approved by an institutional clinical audit. On ethical considerations it was not possible to involve in our study the effects of methylphenidate in a matched control sample.

The diagnosis of ADHD included medical, developmental, school, psychosocial data, and family histories obtained by the youth health care practitioner as well as input from parents and teachers, using the Child Behavior Check List (CBCL) and Teacher's Report Form (TRF), examination by a child-neurologist, and neuropsychological assessment to cover the presenting symptoms, differential diagnosis and possible comorbid conditions [13]. Children included fulfilled the criteria for diagnosis of ADHD, made through a clinical interview, according to criteria set forth in the Diagnostic and Statistical Manual of Mental Disorders, Fourth Edition $[14,15,16]$.

Apart from the ADHD diagnosis, additional inclusion criteria were: no additional psychiatric disorders, no seizures disorders, no history of tics, normal electrocardiographic and electroencephalographic examination results, and no current or previous psychopharmacological treatment. The males included showed inappropriate behavior within the classroom with severe consequences for their academic and social functioning. On neurological examination, all children were normal. The child neurologist who examined the boys also prescribed the methylphenidate medication. The subjects had not received any psychotropic medication whatsoever and were not using any other medication after methylphenidate cessation.

\subsubsection{Neuropsychological instruments}

In addition to single-photon emission computed tomography, medication monitoring was done by means of neuropsychological testing and assessment of behavioral functioning in the home situation, by using the Child Behavior Checklist $[17,18]$ and Teacher's Report Form $[19,20]$ before methylphenidate medication $(=T 0)$, after 3 months of medication (=T1), and after withdrawal of medication (=T2). Furthermore, a comprehensive neuropsychological examination was performed at T0, T1 and T2. To test information processing in the children, the Kaufman Assessment Battery for Children $(\mathrm{K}-\mathrm{ABC})$ [12] was used. This battery is designed for testing children aged 2.5 to 12.5 years, and includes eight subtests (mean score=10; S.D.=3). Based on these eight subscales, two total scales for information processing can be derived: the Sequential information processing scale and the Simultaneous information processing scale (mean score=100; S.D.=15) [12,21]. Sequential processing refers to solving problems in which the emphasis is on the serial or temporal order of the 
stimuli [12] and to measure the child's ability to tackle and solve problems in turn and with logical consistency. Simultaneous processing is defined as 'using a gestalt-like or holistic approach to integrate many stimuli to solve problems' [12,21]. A Continuous Performance Task (CPT) was used to measure sustained visual attention (Bourdon-Vos test for children [22]). Standard scores can be calculated measuring speed of working and accuracy of working (mean score=0; S.D.=1). The Developmental Test of Visual-Motor Integration (VMI Beery) [23] was used to measure the visuomotor integration abilities. The child must copy geometric forms that become progressively more difficult and which are presented simultaneously with three forms on one page (mean score=100; S.D. $=15$ ).

\subsubsection{Procedure}

Neuropsychological medication monitoring was performed by using a Continuous Performance Task (speed and accuracy of working), the Developmental Test of Visual-Motor Integration (VMI Beery), and two subtests of the Kaufman Assessment Battery for Children (auditory working memory and Gestalt closure) [12]. To assess short-term auditory working memory, the Number Recall subtest of the Kaufman Assessment Battery for Children was used. During methylphenidate treatment ( $\mathrm{T} 1=$ after 3 months of methylphenidate medication), and following withdrawal methylphenidate $(=\mathrm{T} 2)$ after a duration of 9-20 months treatment neuropsychological testing was repeated.

With ${ }^{123}$ I-ioflupane (FP-CIT; Nycomed, Amersham, U.K.) single-photon emission computed tomography, baseline dopamine transporter integrity in the brain was measured. Single-photon emission computed tomography was performed with a triple head camera (MultiSPECT3, Siemens) equipped with fan-beam collimators. A semi-automatic template model program was used to calculate the ratios between left striatal and right striatal and occipital regions respectively. Total time of acquisition was 30 minutes ( 45 seconds per frame for 40 views per detector). Zoom factor used was 1.23 and the matrix size was $128 \times 128$. Filtered back-projection acquisition was performed. Images were filtered using a Butterworth filter with a cut-off value of 0.40.5 and an order of 5. A division between the caudate nucleus and putamen was made. The ratios were corrected using Alderson's brain phantom, with known activities in the caudate nucleus and putamen. Scans were not reviewed in a blinded fashion, because we believed that the use of regions of interest led to an acceptable interrater reliability [24].

After baseline single-photon emission computed tomography studies $(=\mathrm{T0})$, the males received methylphenidate at $0.25-0.6 \mathrm{mg} / \mathrm{kg} /$ day. After $3-4$ months $(=\mathrm{T} 1)$, single-photon emission computed tomography studies were repeated, and a child neurologist and a neuropsychologist saw all children again. The neuropsychologist reevaluated the subjects with the instruments mentioned above. It is our policy to withdraw medication during summer holidays. After a drug-free period of at least 4 weeks (mean=5.6; S.D.=0.54), a third FP-CIT single-photon emission computed 
tomography (=T2) was performed. Scans at T0, T1, and T2 were done under the same conditions. Furthermore, the neuropsychologist again reevaluated the subjects. Data were analyzed with SPSS version 12.0 (SPSS Inc., Chicago, IL). A General Linear Model [25] repeated measures design was used to perform analysis of variance of the FP-CIT SPECT uptake values before (=T0), during methylphenidate treatment $(=\mathrm{T} 1)$, and after withdrawal methylphenidate $(=\mathrm{T} 2)$. To compare the results of two subsequent moments, a paired $t$-test was employed.

\subsection{RESULTS}

Baseline FP-CIT single-photon emission computed tomography uptake values in the five subjects varied from 11.78 to 17.00 in the right caudate nucleus and from 10.47 to12.63 in the left caudate nucleus (normal range: $8.23 \pm 2.36$ ) and were $11.07-15.80$ in the right and 11.13-14.10 in left putamen (normal range: $9.18 \pm 3.71$ ) (Table 6.1). Follow-up FP-CIT SPECT in the five boys after using methylphenidate for three months showed a reduction of dopamine transporter activity in the right and left caudate nucleus within a range of $42-74 \%$ and $28-64 \%$ respectively. Dopamine transporter activity in the right and left putamen decreased in a range of $28-76 \%$ and $23-71 \%$ respectively. The five males manifested a positive clinical response evaluated by neuropsychological questionnaires and tests during methylphenidate treatment. The period, medication was used before the third drug-naïve FP-CIT single-photon emission computed tomography was carried out, varied from 9 to 20 months.

Table 6.1: FP-CIT SPECT: Baseline (=T0), after 3 months methylphenidate (=T1), and after withdrawal methylphenidate (=T2) in 5 males with $A D H D$

\begin{tabular}{|c|c|c|c|c|c|c|c|c|c|c|c|c|c|}
\hline \multirow[b]{3}{*}{ Pat } & \multirow[b]{3}{*}{$\begin{array}{c}\text { Age } \\
\text { (yrs } \\
\text { ) }\end{array}$} & \multicolumn{4}{|c|}{ Baseline $^{\top 0}$} & \multicolumn{4}{|c|}{3 months methylphenidate ${ }^{\top 1}$} & \multicolumn{4}{|c|}{ follow-up ${ }^{\top 2}$} \\
\hline & & \multicolumn{2}{|c|}{ left } & \multicolumn{2}{|c|}{ right } & \multicolumn{2}{|c|}{ left } & \multicolumn{2}{|c|}{ right } & \multicolumn{2}{|c|}{ left } & \multicolumn{2}{|c|}{ right } \\
\hline & & $\begin{array}{c}\text { caudatu } \\
\mathrm{s}\end{array}$ & $\begin{array}{c}\text { putame } \\
n\end{array}$ & $\begin{array}{c}\text { caudatu } \\
\mathrm{s}\end{array}$ & $\begin{array}{c}\text { putame } \\
n\end{array}$ & $\begin{array}{c}\text { caudatu } \\
\mathrm{s}\end{array}$ & $\begin{array}{c}\text { putame } \\
n\end{array}$ & $\begin{array}{c}\text { caudatu } \\
\mathrm{s}\end{array}$ & $\begin{array}{c}\text { putame } \\
n\end{array}$ & $\begin{array}{c}\text { caudatu } \\
\mathrm{s}\end{array}$ & $\begin{array}{c}\text { putame } \\
n\end{array}$ & $\begin{array}{c}\text { caudatu } \\
\mathrm{s}\end{array}$ & $\begin{array}{c}\text { putame } \\
n\end{array}$ \\
\hline 1 & 8 & 10.47 & 11.22 & 11.96 & 11.07 & 7.55 & 8.67 & 6.95 & 7.97 & 17.12 & 15.51 & 16.72 & 16.31 \\
\hline 2 & 9 & 11.70 & 14.10 & 12.66 & 11.68 & 4.80 & 4.02 & 6.09 & 4.16 & 15.87 & 13.94 & 14.99 & 13.74 \\
\hline 3 & 8 & 11.78 & 11.91 & 11.78 & 12.50 & 5.70 & 7.25 & 5.18 & 6.96 & 12.13 & 13.16 & 11.46 & 14.66 \\
\hline 4 & 9 & 11.50 & 14.10 & 17.00 & 15.80 & 4.14 & 4.02 & 4.34 & 3.84 & 14.65 & 21.37 & 16.22 & 15.94 \\
\hline 5 & 10 & 12.63 & 11.13 & 14.05 & 14.16 & 5.67 & 4.33 & 5.10 & 5.08 & 13.14 & 12.32 & 14.69 & 16.40 \\
\hline
\end{tabular}

Longitudinal FP-CIT SPECT data: T0 = baseline (drug naive); T1 = after 3 months treatment methylphenidate; $\mathrm{T} 2$ = 4-6 weeks after withdrawal methylphenidate treatment. Duration of treatment: 9-12 months in five males with ADHD Abbreviations: FP-CIT = 123I-ioflupane; SPECT = Single-photon emission computed tomography

Dopamine transporter activity in the right and left caudate nucleus varied within a range of $11.46-16.72$ and $12.13-17.12$ respectively. Dopamine transporter activity in the right and left putamen varied within a range of 13.74-16.40 and 12.32-21.37 
respectively. Seventeen of these 20 calculated ratios for dopamine transporter activity were above pretreatment values. The increase of dopamine transporter activity above pretreatment values varied within a range of $3-64 \%$ (mean: $17 \%$ ) (Table 6.2).

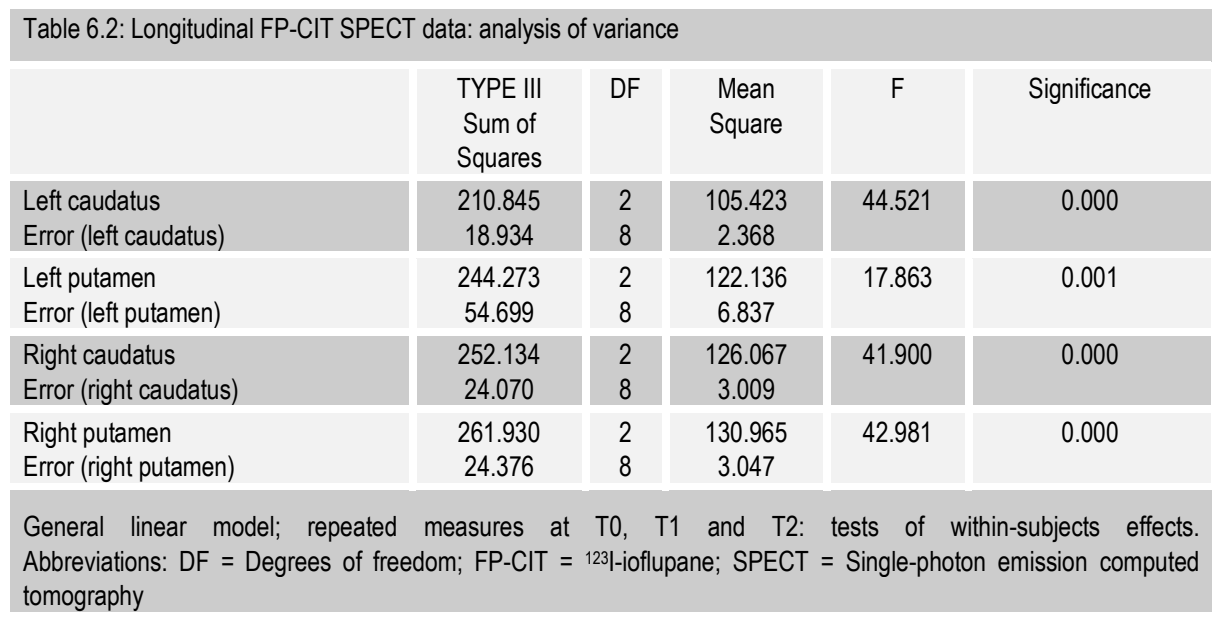

Analysis of variance, using General Linear Model - repeated measures, documented significant effects:

Left caudate nucleus

$\left(\mathrm{F}_{(2,8)}=44.521, p<0.0005\right)$;

Right caudate nucleus

$\left(\mathrm{F}_{(2,8)}=41.900, p<0.0005\right)$;

Left putamen

$\left(F_{(2,8)}=17.863, p=0.001\right)$;

Right putamen

$\left(F_{(2,8)}=42.981, p<0.0005\right)$.

Paired samples $t$-test yielded significant differences of the FP-CIT single-photon emission computed tomography uptake values in left and right caudate nucleus, respectively left and right putamen before $(=T 0)$, during methylphenidate treatment $(=$ T1), and after withdrawal methylphenidate (=T2) (Table 6.3). Neuropsychological questionnaires and test results were comparable with pretreatment data (Table 6.4).

Wilcoxon signed rank test was used to test the significance of the effect between T0 and T1 on the one hand and the difference between T1 and T2 on the other. As the group of children was small $(n=5)$ differences were not significant. We saw a clear tendency of better scores in T1 compared to T0 especially for speed of working and Gestalt Closure, which could be expected as medication was started. When comparing T2 with T1 we saw a tendency to diminished scores especially in Gestalt Closure and Visuomotor Integration, which is again in accordance with our expectations. 


\begin{tabular}{|c|c|c|c|c|}
\hline & Pair & $\mathrm{T}$ & DF & $P$ Value \\
\hline Left Caudatus & $\begin{array}{l}\mathrm{T} 0-\mathrm{T} 1 \\
\mathrm{~T} 1-\mathrm{T} 2 \\
\mathrm{~T} 0-\mathrm{T} 2\end{array}$ & $\begin{array}{c}7.478 \\
-10.126 \\
-2.510\end{array}$ & $\begin{array}{l}4 \\
4 \\
4\end{array}$ & $\begin{array}{l}0.002 \\
0.001 \\
0.066\end{array}$ \\
\hline Left Putamen & $\begin{array}{l}\mathrm{T} 0-\mathrm{T} 1 \\
\mathrm{~T} 1-\mathrm{T} 2 \\
\mathrm{~T} 0-\mathrm{T} 2\end{array}$ & $\begin{array}{c}4.599 \\
-4.686 \\
-2.065\end{array}$ & $\begin{array}{l}4 \\
4 \\
4\end{array}$ & $\begin{array}{l}0.010 \\
0.009 \\
0.108\end{array}$ \\
\hline Right Caudatus & $\begin{array}{l}\text { T0-T1 } \\
\text { T1-T2 } \\
\text { T0-T2 }\end{array}$ & $\begin{array}{c}5.969 \\
-10.303 \\
-1.312\end{array}$ & $\begin{array}{l}4 \\
4 \\
4\end{array}$ & $\begin{array}{l}0.004 \\
0.001 \\
0.260\end{array}$ \\
\hline Right Putamen & $\begin{array}{l}\mathrm{T} 0-\mathrm{T} 1 \\
\mathrm{~T} 1-\mathrm{T} 2 \\
\mathrm{~T} 0-\mathrm{T} 2\end{array}$ & $\begin{array}{c}4.929 \\
-11.644 \\
-2.897\end{array}$ & $\begin{array}{l}4 \\
4 \\
4\end{array}$ & $\begin{array}{c}0.008 \\
<0.0005 \\
0.044\end{array}$ \\
\hline
\end{tabular}

Table 6.4: Transformed z-scores (mean=0; S.D.=1).

\begin{tabular}{|l|c|c|c|c|c|}
\hline & T0 & T1 & T2 & Chi-Square & Significance \\
\hline CPT speed of working & $-1.00(0.71)$ & $0.75(1.25)$ & $0.60(1.14)$ & 6.50 & 0.039 \\
\hline CPT accuracy of working & $-0.20(1.10)$ & $0.25(0.96)$ & $0.00(0.71)$ & 0.13 & 0.936 \\
\hline Auditory working memory & $-0.86(0.38)$ & $-0.18(0.81)$ & $-0.66(0.46)$ & 1.50 & 0.472 \\
\hline Gestalt closure & $0.06(0.51)$ & $1.10(0.62)$ & $0.86(1.12)$ & 6.16 & 0.037 \\
\hline Visuomotor integration & $-0.60(0.87)$ & $-0.53(0.78)$ & $-1.22(0.44)$ & 1.50 & 0.472 \\
\hline
\end{tabular}

Differences between mean-scores before medication (T0), after 3 months of medication (T1) and after withdrawal of medication (T2) were analyzed by using Friedman nonparametric test $(n=5)$. Abbreviation: $\mathrm{CPT}=$ Continuous Performance Task 


\subsection{DISCUSSION}

To study possible long-term alterations in the cerebral dopamine system by methylphenidate, single-photon emission computed tomography imaging was used in five males with ADHD after cessation of treatment with methylphenidate. Methylphenidate reduced dopamine transporter activity in the caudate nucleus and putamen in males with ADHD, and that after withdrawal methylphenidate medication an increase of dopamine transporter activity was observed in 17 of the 20 calculated ratios compared with baseline values. Although these data seem to point in one direction, one should be cautious to draw firm conclusions from this, as the numbers are small. We would nevertheless like to make a few points.

Whether this is a simple rebound phenomenon or an active up-regulation after treatment with methylphenidate is unclear. To study this phenomenon precisely, more sequential single-photon emission computed tomography scans during treatment would have to be performed. In our small pilot study, we chose a drug-free period of at least 4 weeks, because animal studies demonstrate that, despite the relatively short half-life of methylphenidate, pharmacological effects on dopamine systems can persist for several days [8].

Little is known of possible consequences of long-term exposure to methylphenidate $[26,27,28,29,30]$. One study in rats concluded that there is no abuse liability associated with therapeutic methylphenidate treatment [31]. These authors found no increase in dopamine levels in the nucleus accumbens and no sensitized locomotor responses in adolescent rats treated with methylphenidate. Our data after withdrawal methylphenidate might accord with their observation that methylphenidate does not lead to definite damage of the nigrostriatal dopaminergic pathways [31,32]. However, our data, albeit from a small group of patients, do indicate an increased dopamine transporter activity after cessation of methylphenidate. If one assumes that increased dopamine transporter activity is associated with clinical severity of ADHD, then our observation should be followed up on, to assess whether this rebound phenomenon is temporary or more permanent. It is generally assumed that outgrowth of the disorder ADHD is associated with a decrease per decade of life in striatal dopamine transporters [33].

Taken together our data seem to support the hypothesis that the dopamine transporter is a primary target for methylphenidate in $\operatorname{ADHD}[10,33,34,35]$; this seems in contrast with the observation that dopamine transporter gene knockout mice do respond clinically to methylphenidate [36], but others have pointed out that this model does not necessarily represent human ADHD [37]. And although labeled dihydrotetrabenazine appears to be a superior marker for dopaminergic 
hyperinnervation [38], we believe that the ease of use of single-photon emission computed tomography to assess dopamine transporter activity makes it a superior tool in the clinical setting $[34,35,39,40]$. 


\section{REFERENCES}

[1] National Institute of Mental Health Multimodal Treatment Study of ADHD follow-up: Changes in effectiveness and growth after the end of treatment. Pediatrics 2004; 113: 762-769.

[2] Conners CK. Forty years of methylphenidate treatment in Attention-Deficit/ Hyperactivity Disorder. J Atten Disord 2002; 6 (Suppl 1): S17-30.

[3] Jensen P. Longer term effects of stimulant treatments for Attention-Deficit/Hyperactivity Disorder. J Atten Disord 2002; 6 (Suppl 1): S45-56.

[4] Volkow ND, Fowler JS, Wang G, Ding Y, Gatley SJ. Mechanism of action of methylphenidate: insights from PET imaging studies. J Atten Disord 2002; 6 (Suppl 1): S31-43.

[5] Moderators and mediators of treatment response for children with attention-deficit/hyperactivity disorder: the Multimodal Treatment Study of children with Attention-deficit/hyperactivity disorder. Arch Gen Psychiatry 1999; 56:1088-1096.

[6] Seeman P, Madras BK. Anti-hyperactivity medication: methylphenidate and amphetamine. Mol Psychiatry 1998; 3: 386-396.

[7] Biederman J, Spencer T. Methylphenidate in treatment of adults with Attention-Deficit/Hyperactivity Disorder. J Atten Disord 2002; 6 (Suppl 1): S101-107.

[8] Yuan J, McCann U, Ricaurte G. Methylphenidate and brain dopamine neurotoxicity. Brain Res 1997; 767: $172-175$

[9] Dresel S, Krause J, Krause KH, LaFougere C, Brinkbaumer K, Kung HF, et al. Attention deficit hyperactivity disorder: binding of [99mTc]TRODAT-1 to the dopamine transporter before and after methylphenidate treatment. Eur J Nucl Med 2000; 27: 1518-1524.

[10] Cheon KA, Ryu YH, Kim YK, Namkoong K, Kim CH, Lee JD. Dopamine transporter density in the basal ganglia assessed with [123I]IPT SPET in children with attention deficit hyperactivity disorder. Eur J Nucl Med Mol Imaging 2003; 30: 306-311.

[11] Vles JS, Feron FJ, Hendriksen JG, Jolles J, van Kroonenburgh MJ, Weber WE. Methylphenidate downregulates the dopamine receptor and transporter system in children with attention deficit hyperkinetic disorder (ADHD). Neuropediatrics 2003; 34: 77-80.

[12] Kaufman AS, Kaufman NL. Kaufman Assessment Battery for children. Interpretive manual. Circle Pines, Minnesota: American Guide Service; 1983.

[13] Hendriksen JGM, Feron FJM, Njiokiktjien C, Vles JSH. The effect of clonidine and methylphenidate in children with Attention Deficit Disorder with Hyperactivity: a comparison of neuropsychological and behavioral effects in 37 Children. [Article in Dutch]. Tijdschr v Kindergeneeskunde 2000; 68: 94-99

[14] Clinical practice guideline: diagnosis and evaluation of the child with attention-deficit/hyperactivity disorder. American Academy of Pediatrics. Pediatrics 2000; 105: 1158-1170.

[15] Diagnostic and statistical manual of mental disorders, 4th edition (DSM-IV). Washington DC: American Psychiatric Association; 1994.

[16] Goldman LS, Genel M, Bezman RJ, Slanetz PJ. Diagnosis and treatment of attentiondeficit/hyperactivity disorder in children and adolescents. Council on Scientific Affairs, American Medical Association. Jama 1998; 279: 1100-1107.

[17] Achenbach TM. Manual for the Child Behavior Checklist / 4-18 and 1991 profile. Burlington, University of Vermont Department of Psychiatry, 1991.

[18] Verhulst FC, Koot JM, Van der Ende J. Handleiding voor de CBCL (Child Behavior Checklist) [Manual for the CBCL]. Afd. Kinder- en Jeugdpsychiatrie, Sophia Kinderziekenhuis / Academisch Ziekenhuis Rotterdam / Erasmus Universiteit Rotterdam, the Netherlands, 1996.

[19] Achenbach, T. M. (1991). Manual of the Teacher's Report Form and 1991 profile. Burlington, VT: University of Vermont, Department of Psychiatry.

[20] Verhulst FC, Van der Ende J, Koot HM. Handleiding voor de Teacher's Report Form (TRF) [Manual for the TRF]. Afd. Kinder- en Jeugdpsychiatrie, Sophia Kinderziekenhuis / Academisch Ziekenhuis Rotterdam / Erasmus Universiteit Rotterdam, the Netherlands, 1997. 
[21] Hurks PPM, Hendriksen JGM, Feron FJM, Jolles J, Vles JSH. Information processing in ADHD children with or without Learning Disabilities. In: The influence of environment, behaviour, and attention deficits on cognitive development in school-aged children. Thesis. Maastricht: Maastricht University; 2003 : 143-162.

[22] Vos PG. Bourdon-Vos test: handleiding (3de herziene uitgave)-Manual for the Bourdon-Vos test. Lisse, Netherlands: Swets en Zeitlinger; 1998

[23] Beery KE. The Beery-Buktenica Developmental Test of Visual-motor integration (VMI). Pasipanny, New Jersey: Modern Curriculum Press; 1997.

[24] Lobaugh NJ, Caldwell CB, Black SE, Leibovitch FS, Swartz RH. Three brain SPECT region-of-interest templates in elderly people: normative values, hemispheric asymmetries, and a comparison of singleand multihead cameras. J Nucl Med 2000; 41: 45-56

[25] Ferron J. Reconsidering the use of the general linear model with single-case data. Behav Res Methods Instrum Comput 2002; 34: 324-331.

[26] Gadow KD, Sverd J, Sprafkin J, Nolan EE, Grossman S. Long-term methylphenidate therapy in children with comorbid attention-deficit hyperactivity disorder and chronic multiple tic disorder. Arch Gen Psychiatry 1999; 56: 330-336.

[27] Stiebel V, Kemp K. Long-term methylphenidate use in the medically ill patient with organic mood syndrome. Psychosomatics 1990; 31: 454-456.

[28] Volkow ND, Insel TR. What are the long-term effects of methylphenidate treatment? Biol Psychiatry 2003; 54: 1307-1309.

[29] Weiss G, Kruger E, Danielson U, Elman M. Long-term methylphenidate treatment of hyperkinetic children. Psychopharmacol Bull 1974; 10: 34-35.

[30] Weiss G, Kruger E, Danielson U, Elman M. Effect of long-term treatment of hyperactive children with methylphenidate. Can Med Assoc J 1975; 112: 159-165.

[31] Kuczenski R, Segal DS. Exposure of adolescent rats to oral methylphenidate: preferential effects on extracellular norepinephrine and absence of sensitization and cross-sensitization to methamphetamine. J Neurosci 2002; 22: 7264-7271.

[32] Greenhill L, Beyer DH, Finkleson J, Shaffer D, Biederman J, Conners CK, et al. Guidelines and algorithms for the use of methylphenidate in children with Attention-Deficit/ Hyperactivity Disorder. $J$ Atten Disord 2002; 6 (Suppl 1): S89-100.

[33] Volkow ND, Ding YS, Fowler JS, Wang GJ, Logan J, Gatley SJ, et al. Dopamine transporters decrease with age. J Nucl Med 1996; 37: 554-559.

[34] Dougherty DD, Bonab AA, Spencer TJ, Rauch SL, Madras BK, Fischman AJ. Dopamine transporter density in patients with attention deficit hyperactivity disorder. Lancet 1999; 354(9196): 2132-2133.

[35] Krause KH, Dresel SH, Krause J, Kung HF, Tatsch K. Increased striatal dopamine transporter in adult patients with attention deficit hyperactivity disorder: effects of methylphenidate as measured by singlephoton emission computed tomography. Neurosci Lett 2000; 285: 107-110.

[36] Gainetdinov RR, Wetsel WC, Jones SR, Levin ED, Jaber M, Caron MG. Role of serotonin in the paradoxical calming effect of psychostimulants on hyperactivity. Science 1999; 283(5400): 397-401.

[37] Sarkis EH. "Model" behavior. Science 2000; 287(5461): 2160-2162.

[38] Meyer P, Bohnen NI, Minoshima S, Koeppe RA, Wernette K, Kilbourn MR, et al. Striatal presynaptic monoaminergic vesicles are not increased in Tourette's syndrome. Neurology 1999; 53: 371-374.

[39] Amen DG, Carmichael BD. High-resolution brain SPECT imaging in ADHD. Ann Clin Psychiatry 1997; 9: 81-86.

[40] O'Tuama LA, Treves ST. Brain single-photon emission computed tomography for behavior disorders in children. Semin Nucl Med 1993; 23: 255-264. 
CHAPTER 7

Status Epilepticus in a child with Cerebral Palsy and ADHD: a proconvulsant effect of Clonidine? 


\section{ABSTRACT}

Background: Clonidine is used as second line medication for the treatment of attention deficit hyperactivity disorder in children. Clonidine is an imidazoline derivate and acts as an agonist on alpha- 2 adrenergic receptors. Product information concerning clonidine reports seizures only after overdosage of clonidine and prescription of clonidine is up till now not contraindicated in patients with known epilepsy.

Objective: The aim of the present case report is to discuss the possible proconvulsant effect of clonidine as we witnessed status epilepticus in a 9-year-old girl.

Case description: Attention deficit hyperactivity disorder in 9-year-old girl with cerebral palsy was treated with clonidine. Two weeks after initializing treatment with clonidine, the girl was transferred to emergency room because of a secondarily generalized convulsive status epilepticus.

Conclusions: Within the spectrum of pharmacological interventions for the management of ADHD in school-aged children the role of clonidine is changing. The hypothesis that clonidine may play a proconvulsant in children with a prior history of seizures or with electroencephalographic abnormalities in absence of seizures, is theoretically elaborated and will be awaiting for confirmation from other clinicians. 


\subsection{INTRODUCTION}

Attention-deficit-hyperactivity disorder (ADHD) is the most common neurodevelopmental disorder of childhood. Methylphenidate is within stimulants the most frequently prescribed psychotropic drug in treatment of ADHD and its efficacy and safety is well established in literature [1]. In children with cerebral palsy (CP) and ADHD, the efficacy of methylphenidate was demonstrated by Gross-Tsur et al. (2002) in a double-blinded clinical trial of 29 patients [2]. Data about seizure risk of stimulants treatment in non-epileptic children with ADHD are rather scarce. Hemmer et al. (2001) studied seizure risk of stimulant therapy in an unselected population of 234 non-epileptic children with uncomplicated ADHD [3]. In the used sample there appeared to be a considerable high incidence of electroencephalographic epileptiform abnormalities (15.4\%) in neurologically normal children with ADHD in comparison with an unselected population of nonepileptic children (2\%). Furthermore it was concluded that an epileptiform EEG in neurological normal children with ADHD predicts considerable risk for the eventual occurrence of seizures when treated with stimulants (incidence 10\%). Holtmann et al (2003) prospectively evaluated the frequency of rolandic spikes in ADHD children without epilepsy and reported an incidence of $5.6 \%$ [4]. The safety of psychostimulants in treatment of children with ADHD combined with seizures or epilepsy is still a topic of discussion. According to product information, methylphenidate may lower the convulsive threshold in patients with prior history of seizures or with prior EEG abnormalities in absence of seizures. However, in several studies is argued that the risk of seizures is not necessarily attributable to the use of stimulant therapy $[1,5,6,7]$. It is generally assumed to be good clinical practice to perform an EEG as a regular part of the work-up before initiating a planned psychostimulant therapy in children with ADHD combined with neurological sequelae such as cerebral palsy, even if there is no history of seizures or epilepsy $[4,7,8]$. If epileptic discharges are present on the EEG, second line medications can be considered and in this respect clonidine may provide benefit as an alternative to psychostimulants [9,10]. Dall et al. (1996) suggested that clonidine might be useful in the management of spasticity in reducing extremity hypertonicity [11]. Clonidine has initially been used to reduce hypertension in adults and as an analgesic. Clonidine is being prescribed with increasing frequency to treat ADHD in children and its use became widespread [12]. The efficacy of clonidine is less than that of the established treatment stimulants like methylphenidate [10,12]. Furthermore, the use of clonidine is associated with side effects such as: sedation, irritability, drop in blood pressure, hypotension, sleep disturbance, dry mouth, dizziness, skin irritation and ECG changes [10]. However, an increased risk for developing seizures has not yet been reported as side effect $[9,10,12,13,14]$. In earlier experimental studies it was indicated that clonidine has neither anticonvulsant 
nor proconvulsant effects in rats (Yokoyama et al. 1993) [15]. Shouse et al. (1994) reported that clonidine significantly increases focal and general seizure thresholds in amygdala-kindled kittens [16].

We recently witnessed status epilepticus following clonidine for treatment of ADHD in a child with cerebral palsy, which we report here. Recent data related to the hypothesized proconvulsant role of clonidine will be discussed.

\section{Case report}

At the outpatient department of child neurology, a 9-year-old girl was seen because of ADHD. She was born at term after an uneventful pregnancy. At the age of 3 months the mother noticed asymmetry of spontaneous motility and after extensive work-up a diagnosis of stroke in utero was made. The girl developed a right-sided spastic hemiplegia. Except for gross motor performances, the milestones were reached at normal age. During early childhood hyperactivity was noticed and when she entered kindergarten, difficulties in sustaining attention were observed. At elementary school age, symptoms of attention deficit negatively influenced her school performance. Her intelligence was within normal range. The child's symptoms, i.e. inattention, hyperactivity and impulsivity, met DSM-IV criteria for ADHD. Because of the association of spastic hemiplegia and ADHD, she was referred to our department for medical advice. There was no history of seizures, but there was a family history of epilepsy (childhood onset epilepsy in the girl's mother). Physical and neurological examinations were normal, besides a right-sided spastic hemiplegia. Height and weight were consistent with age. Tension and pulse rate were normal. ECG was within normal limits. EEG showed frequent spike wave discharges in the left temporoparieto-occipital area. A fixation-off phenomenon (disappearance of epileptiform discharges with fixation, and appearance of discharges with eye closure) was noticed. Magnetic resonance imaging (MRI) of the head showed congenital infarction with complete disruption of the left lentiform nucleus and mild atrophy of the head of the left caudate nucleus. Because of estimated risk for seizures using methylphenidate in a child with electroencephalographic abnormalities associated with evident brain injury, clonidine was started in a dose of 2 times daily $0.025 \mathrm{mg}$ to treat ADHD.

Two weeks after initializing treatment with clonidine, the girl was transferred to emergency room in a secondary generalized convulsive status epilepticus, which occurred during the waking state without the existence of triggering factors of epilepsy like fever, stress or lack of sleep. Treatment was started with $10 \mathrm{mg}$ diazepam rectally, followed by administration of midazolam intravenously $(0.1 \mathrm{mg} / \mathrm{kg})$ and phenytoin intravenously $(18 \mathrm{mg} / \mathrm{kg}$ ). Clonidine medication was stopped. After two days carbamazepine was started in a dose of $100 \mathrm{mg}$ twice a day and after two weeks raised to $200 \mathrm{mg}$ twice a day. ADHD in this child is now treated with methylphenidate medication successfully. To date, after one year follow-up, no seizures were noticed. 


\section{DISCUSSION}

The prescription of clonidine is up till now not contraindicated in patients with known epilepsy and product information concerning clonidine reports seizures only after overdosage of clonidine. In current literature is reported that clonidine is associated with many adverse effects being mostly moderate and transient [1,10,12,14], whereas treatment-emergent side effects of clonidine are relative exceptional [17]. However, the safety of clonidine in regard to a possible proconvulsant risk never seemed to be a point of debate $[17,18]$.

In the case as reported, clonidine medication was introduced to treat ADHD because there were several major risk factors for epilepsy: (a) focal cortical prenatal lesion with spastic hemiplegia, (b) family history of epilepsy, and (c) active EEG epileptic focus at the time of drug introduction. Although we cannot define clear evidence of causality, it cannot be ruled out that clonidine has triggered the status epilepticus in the above reported case. Therefore, we believe it is important to make clonidine subject of a critical reconsideration concerning possible unexpected proconvulsant effects.

Clonidine is an imidazoline derivate and acts as an agonist on alpha-2 adrenergic receptors in the central nervous system as well as peripherally. Alpha-2adrenoreceptors are composed of three well-characterized subtypes, confirmed by gene sequencing: alpha-2A-, alpha-2B-, and alpha-2C-adrenoreceptors $[19,20,21,22]$. Alpha-2A- and alpha-2C-adrenoreceptors function as presynaptic autoreceptors as well as postsynaptic receptors on noradrenergic neurons. The presynaptic alpha-2A- and alpha-2C-adrenoreceptors function as autoreceptors and regulate, as important receptors in the noradrenergic negative feedback control, the release of norepinephrine. On the other hand the postsynaptic alpha-2A- and alpha$2 \mathrm{C}$-adrenoreceptors function as heteroreceptors regulating the release of other neurotransmitters such as dopamine and seretonine. Clonidine stimulates presynaptic alpha-2-adrenergic receptors in the brain stem, without discriminating between the subtypes of alpha-2-adrenoreceptors. One of the working mechanisms of clonidine is down-regulation of norepinephrine release from the locus coeruleus. It is known that the neurotransmitter norepinephrine plays a relevant role in modulating seizures. Giorgi et al. demonstrated a powerful effect of noradrenergic terminals in regulating the onset of limbic status epilepticus owing to damage to locus coeruleus in experimental model using rats [23]. Many effects of clonidine occur by stimulating the presynaptic alpha-2-receptors. However, there is evidence that clonidine also mediates effects through postsynaptic alpha-2-adrenoreceptors, by demonstrating that norepinephrine can enhance cognitive functioning of the prefrontal cortex through actions at alpha-2A adrenergic receptors postjunctional to noradrenergic terminals [24]. Furthermore, experimental research indicates a beneficial effect of 
clonidine on spatial working memory in normal young rhesus monkeys mediated through postsynaptic alpha-2-adrenoreceptors when clonidine was given in high doses [25].

Previous experimental animal studies indicated an anticonvulsant effect of clonidine in low doses $[26,27,28]$. On the contrary, Kirchberger et al. for the first time in 1998 established that clonidine increases epileptic activity in adult patients with focal epilepsies [29]. In accordance with these findings, Kettenmann et al. (2005) recently demonstrated that the spike or sharp-wave inducing effect of clonidine is superior to the potency of sleep deprivation in patients suffering from drug-resistant localization related epilepsy [30]. Other case reports also indicate a role of clonidine in facilitating specific discharges and seizure activities in adult patients [31,32]. In the pediatric age range, Scaramuzza et al. reported a noteworthy case of seizures following clonidine test for growth hormone reserve evaluation [33]. Recent experimental research in animals revealed that clonidine in low dose aggravates spike-wave seizures in a genetic model of absence epilepsy, the WAG/Rij rats [34].

From experimental studies it was already known that alpha-2-adrenoreceptors have an impact on modulating seizure activity, but the effects of alpha-2-adrenoreceptor agonists on seizure activity are rather inconsistent. The exact role of the alpha-2adrenoreceptors is not yet fully understood because of the complexity of the alpha-2adrenoreceptor subtypes and the distribution of these receptors. In this respect Szot et al. hypothesized that the alpha-2A-presynaptic autoreceptors are responsible for the proconvulsant effect of alpha-2-adrenergic agonists, while the alpha-2Apostsynaptic receptors are responsible for the anticonvulsant effect of alpha-2adrenergic agonists [35]. As said before, clonidine acts as a non-selective alpha-2adrenergic agonist, both presynaptic as postsynaptic. The side effect profile of clonidine is possibly dose related. This might be an explanation for the apparent inconsistency in literature concerning proconvulsant versus anticonvulsant effects of clonidine. According to the hypothesis of Szot and colleagues [35], the anticonvulsant effect of clonidine might be achieved through postsynaptic alpha-2A-adrenoreceptors on norepinephrine target neurons, possibly by inhibition of the release of excitatory neurotransmitters in regions implicated in regulating seizures such as the hippocampus, cortex or amygdala. Consequently, presynaptic alpha-2adrenoreceptors would be responsible for potentiating a proconvulsant effect of clonidine by inhibiting neurons of the locus coeruleus or by reducing the release of norepinephrine in regions that have an impact on modulating seizure activity [23]. Various experimental studies $[25,34,36]$ indicated a relationship between the dosage of clonidine and its selectivity for the presynaptic autoreceptors respectively postsynaptic heteroreceptors. Maura and co-workers revealed that the affinity of clonidine at the presynaptic alpha 2-autoreceptors was 10 times higher than at the postsynaptic alpha 2-heteroreceptors [37]. In this respect it could be hypothesized 
that clonidine in low doses mediates more selectively the presynaptic autoreceptors producing a proconvulsant response. Consequent to this reasoning, clonidine produces only an anticonvulsant effect if dosage level is high enough to stimulate postsynaptic heteroreceptors. But this would be contradictory to prior experimental animal studies indicating an anticonvulsant effect of clonidine in low doses $[26,27,28]$. However, experimental research is often based on model systems using rats or mice, whereas it is known that the pharmacological profile of the alpha-2Aadrenoreceptor subtype in man differs from the alpha-2A profile in rat and mouse [38]. Although the alpha-2-adrenoreceptors are responsible for the key mechanism in the various effects of clonidine, in addition there is presumably an impact of a complex pattern of reciprocal autoreceptor and heteroreceptor control of monoamine release [39]. Furthermore, there is some evidence that there is an age-related fall in the effectiveness of prejunctional alpha-2 adrenoreceptor activation $[40,41,42]$, giving rise to the speculation that the proconvulsant response of presynaptic alpha 2autoreceptors in children might be higher than in adults.

The use of clonidine in children is notable because clonidine treatment of ADHD in children is based on off-label prescribing, i.e. indication and age are not included in the product information. Besides known side effects, any indication of possible unknown adverse effects of clonidine should be a cause of concern, because children's responses to clonidine are not necessarily similar to those of adults. While it is reassuring that anecdotal case reports have rarely documented seizures or epilepsy as adverse effects of clonidine, the possibility of these effects in the developing brain cannot be ruled out. Therefore it is necessary in any case to report clinical impressions suspecting an unknown side effect of medication like in the present case as reported above. Because the possibility of epileptic discharges and seizures might be related to clonidine use, further studies are warranted to clarify the proconvulsant risk of clonidine regarding the specific key mechanism of the alpha-2adrenoreceptors.

\subsection{CONCLUSIONS}

Within the spectrum of pharmacological interventions for the management of ADHD in school-aged children, the role of clonidine is changing. The alpha-2-adrenergic agonist clonidine has been used for many years in the treatment of ADHD in children, alone or combined with stimulants, despite difference of opinion on the safety of clonidine in respect to adverse affects such as sedation and cardiovascular complications. A new issue to keep in mind regarding treatment with clonidine in children is any proconvulsant effect. While clonidine has been used without generating large numbers of adverse-event reports on the occurrence of seizures or epilepsy, both experimental research and clinical case reports indicate the possible 
proconvulsant effect of clonidine. This should be taken into consideration in providing parents and patients with appropriate information for making decisions for a treatment plan. Furthermore, product information about clonidine should include the risk of seizures, based on recent literature information. Special caution is warranted in administration of clonidine as treatment for ADHD in children with a prior history of seizures or with electroencephalographic abnormalities in absence of seizures. As with any medicine, the use of clonidine should be monitored closely, especially when used in children. 


\section{References}

[1] DuPaul GJ, Barkley RA, Connor DF. Stimulants. In: Barkley RA, ed. Attention-deficit hyperactivity disorder: A handbook for diagnosis and treatment. New York: Guilford Press, 1998, $2^{\text {nd }}$ ed: 511-551.

[2] Gross-Tsur V, Shalev RS, Badihi N, Manor O. Efficacy of methylphenidate in patients with cerebral palsy and attention-deficit hyperactivity disorder (ADHD). J Child Neurol 2002; 17: 863-866.

[3] Hemmer SA, Pasternak JF, Zecker SG, Trommer BL. Stimulant therapy and seizure risk in children with ADHD. Pediatr Neurol 2001; 24: 99-102.

[4] Holtmann M, Becker K, Kentner-Figura B, Schmidt MH. Increased frequency of rolandic spikes in ADHD children. Epilepsia 2003; 44: 1241-1244.

[5] Tan M, Appleton R. Attention deficit and hyperactivity disorder, methylphenidate, and epilepsy. Arch Dis Child 2005; 90: 57-59.

[6] Gucuyener K, Erdemoglu AK, Senol S, Serdaroglu A, Soysal S, Kockar AI. Use of methylphenidate for attention-deficit hyperactivity disorder in patients with epilepsy or electroencephalographic abnormalities. J Child Neurol 2003; 18: 109-112.

[7] Schmidt JK, Pluck J, von Gontard A. Waived EEG diagnosis before administration and during drug therapy with methylphenidate: dangerous of justifiable? [Article in German]. Z Kinder Jugendpsychiatr Psychother 2002; 30: 295-302.

[8] Millichap J. Temporal lobe arachnoid cyst-attention deficit disorder syndrome: role of the electroencephalogram in diagnosis. Neurology 1997; 48: 1435-1439.

[9] Hendriksen JGM, Feron FJM, Njiokiktjien C, Vles JSH. The Effect of Clonidine and Methylphenidate in Children with Attention Deficit Disorder and Hyperactivity: a Comparison of Neuropsychological and Behavioral Effects in 37 Children [Article in Dutch]. Tijdschr Kindergeneeskunde 2000; 98: 94-99.

[10] Connor DF, Fletcher KE, Swanson JM. A meta-analysis of clonidine for symptoms of attention-deficit hyperactivity disorder. J Am Acad Child Adolesc Psychiatry 1999; 38: 1551-1559.

[11] Dall JT, Harmon RL, Quinn CM. Use of clonidine for treatment of spasticity arising from various forms of brain injury: a case series. Brain Inj 1996; 10: 453-458.

[12] Gunning BW. A controlled trial of clonidine in hyperkinetic children. Thesis 1992. Department of Child and Adolescent Psychiatry, Academic Hospital, Erasmus University, Rotterdam, The Netherlands.

[13] Connor DF, Barkley RA, Davis HT. A pilot study of methylphenidate, clonidine, or the combination in ADHD comorbid with aggressive oppositional oppositional defiant or conduct disorder. Clin Pediatr 2000; 39: 15-25.

[14] Himpel S, Banaschewski T, Heise CA, Rothenberger A. The safety of non-stimulant agents for the treatment of attention-deficit hyperactivity disorder. Expert opinion on drug safety 2005; 4: 311-321.

[15] Yokoyama M, Hirakawa M, Goto H. Clonidine does not affect lidocaine seizure threshold in rats. Can J Anaesth 1993; 40: 1205-1209.

[16] Shouse MN, Langer J, Bier M, Farber PR, Alcalde O, Moghimi R, Richkind M, Szymusiak R. The alpha 2-adrenoreceptor agonist clonidine suppresses seizures, whereas the alpha 2-adrenoreceptor antagonist idazoxan promotes seizures in amygdala-kindled kittens: a comparison of amygdala and pontine microinfusions effects. Epilepsia 1996; 37: 709-717

[17] Cantwell DP, Swanson J, Connor DF. Case Study: Adverse response to clonidine. J Am Acad Child Adolesc Psychiatry 1997; 36: 539-544.

[18] Klein-Schwartz W. Trends and toxic effects from pediatric clonidine exposures. Arch Pediatr Adolesc Med 2002; 156: 392-396.

[19] Zeng DW, Lynch KR. Distribution of alpha 2-adrenergic receptor mRNAs in the rat CNS. Brain Res Mol Brain Res 1991; 10: 219-225.

[20] Nicholas AP, Pieribone V, Hökfelt T. Distributions of mRNA for alpha-2 adrenergic receptor subtypes in rat brain: an in situ hybridisation study. J Comparat Neurol 1993; 328: 575-594.

[21] Bucheler MM, Hadamek K, Hein L. Two alpha(2)-adrenergic receptor subtypes, alpha(2A) and alpha(2C), inhibit transmitter release in the brain of gene-targeted mice. Neuroscience 2002; 109: 819826.

[22] Sinclair MD. A review of the physiological effects of $\alpha_{2}$-agonists related to the clinical use of medetomidine in small animal practice. Can Vet J 2003; 44: 885-897. 
[23] Giorgi FS, Ferrucci M, Lazzeri C, pizzamelli C, Lenzi P, Allessandrl MG, Murri L, Fornai F. A damage to locus coeruleus neurons converts sporadic seizures into selfsustaining limbic status epilepticus. Eur J Neurosc 2003; 17: 2593-2601.

[24] Arnsten AF, Steere JC, Hunt RD. The contribution of alpha-2 noradrenergic mechanisms to prefrontal cortical cognitive function. Archives of General Psychiatry 1996; 53: 448-455.

[25] Franowicz JS, Arnsten AFT. Treatment with the noradrenergic alpha-2 agonist clonidine, but not diazepam, improves spatial working memory in normal young rhesus monkeys. Neuropsychopharmacology 1999; 21: 611-621.

[26] Papanicolaou J, Summers RJ, Vajda FJ, Louis WJ. Anticonvulsant effects of clonidine mediated through central alpha2-adrenoreceptors. Eur J Pharmacol 1982; 77: 163-166.

[27] Papanicolaou J, Summers RJ, Vajda FJ, Louis WJ. The relationship between alpha 2-adrenoreceptor selectivity and anticonvulsant effect in a series of clonidine-like drugs. Brain Res 1982; 241: 393-397.

[28] Jackson HC, Dickinson SL, Nutt DJ. Exploring the pharmacology of the pro-convulsant effects of alpha 2-adrenoreceptor antagonists in mice. Psychopharmacology 1991; 105: 558-562.

[29] Kirchberger K, Schmitt H, Hummel C, Peinemann A, Pauli E, Kettenmann B, Stefan H. Clonidine and methohexital-induced epileptic magnetoencephalographic discharges in patients with focal epilepsies. Epilepsia 1998; 39: 841-849.

[30] Kettenmann B, Feichtinger M, Tilz C, Kaltenhauser M, Hummel C, Stefan H. Comparison of clonidine to sleep deprivation in the potential to induce spike-wave activity. Clin Neurophysiol 2005; 116: 905-912.

[31] Schmitt H, Druschky K, Hummel C, Stefan H. Detection of an epileptic mirror focus after oral application of clonidine. Br J Anaesth 1999; 83: 349-351.

[32] Ahmed SU, Vallejo R, Hord ED. Seizures after a bier block with clonidine and lidocaine. Anesth Analg 2004; 99: 593-594.

[33] Scaramuzza a, Torresani P, Arisi D, Rossoni R. Seizures following clonidine test for growth hormone reserve: unusual presentation of benign partial epilepsy. J Pediatr Endocrinol Metab 2000; 13: 451 452.

[34] Sitnikova E, van Luijtelaar G. Reduction of adrenergic neurotransmission with clonidine aggravates spike-waves seizures and alters activity in the cortex and the thalamus in WAG/Rij rats. Brain Research Bulletin 2005; 64: 533-540.

[35] Szot P, Lester M, Laughlin ML, Palmiter RD, Liles LC, Weinshenker D. The anticonvulsant effects of alpha 2 adrenoreceptor agonists are mediated by distinct populations of alpha $2 \mathrm{~A}$-adrenoreceptors. Neuroscience 2004; 126: 795-803.

[36] Homayoun A, Khavandgar S, Dehpour AR. The role of $\alpha_{2}$-Adrenoceptors in the modulatory effects of morphine on seizure susceptibility in mice. Epilepsia 2002; 43 (8): 797-804.

[37] Maura G, Gemignani A, Raiteri M. Alpha 2-adrenoreceptors in rat hypothalamus and cerebral cortex: functional evidence for pharmacologically distinct subpopulations. Eur J Pharmacol 1985; 116: 335 339 .

[38] Bylund DB. Alpha-2 adrenoceptor subtypes: are more better? Br J Pharmacol 2005; 144: 159-160.

[39] Gobert A, Rivet JM, Audinot V, Newman-Tancredi A, Cistarelli L, Millan MJ. Simultaneous quantification of serotonin, dopamine and noradrenaline levels in single frontal cortex dialysates of freely moving rats reveals a complex pattern of reciprocal auto- and heteroreceptor-mediated control of release. Neuroscience 1998; 84: 413-429.

[40] Buchholtz J, Duckles SP. Effect of age on preconjunctional modulation of norepinephrine release. J Pharmacol Exp Ther 1990; 252: 159-164.

[41] Buchholz J, Tsai H, Friedman D, Duckles SP. Influence of age on control of norepinephrine releas from the rat tail artery. J Pharmacol Exp Ther 1992; 260 (2): 722-727.

[42] Docherty JR. Age-related changes in adrenergic neuroeffector transmission. Auton Neurosci 2002; 96 : 8-12. 
CHAPTER 8

\section{Transmural consultation hour for Attention Hyperactivity Disorder at the Youth Health Care Department}

A collaboration model in the south of the province of Limburg, the Netherlands. 


\section{ABSTRACT}

An easily accessible consultation hour for pediatric neurological and neuropsychological diagnostic assessment for ADHD has been realized at the Public Health Service (GGD) of southern Limburg, the Netherlands. The advantage for the clients (children, parents, schools, intermediaries) is the fast and smooth referral for both inpatient and outpatient treatment in secondary and tertiary health care. This procedure has created a vertical link between youth health care and the diagnostics and treatment in the various care levels. The added value is that Youth Health Care Departments can monitor follow-up care, e.g. make sure findings are acted upon in educational treatment plans and guidance to parents. This means that an effective health care chain has been created, providing 'trans-compartment' care, i.e. not limited by care levels and institutes. 


\section{$8.1 \quad$ INTRODUCTION}

Since 1994, the Youth Health Care Department of the Maastricht Public Health Service has participated in the Limburg regional multidisciplinary ADHD team. This initiative - taken by the Neurology Department of Maastricht University Hospital (AZM) and the Children's Rehabilitation Center (Franciscusoord) - aimed to improve the quality of care for children with Attention Deficit Hyperactivity Disorder (ADHD) [1]. In addition, a longitudinal study into the determinants and developmental profile of children with attention deficit disorder with hyperactivity was started in 1996 . The study - called the SAM study [2] - applied a multidisciplinary approach and followed children from the second year in primary school (approx. age 5) onwards to gain insight into the factors that contribute to the development of this complex of symptoms.

These two initiatives resulted in a new cooperative project in 1998. Within a multidisciplinary collaboration, a transmural consultation hour was started for children aged 4 to 12 with behavioral development disorders in general and ADHD in particular. As regards content, the project should be seen as an initiative of the various participating health care institutes. The project could be an example for broader transmural multidisciplinary collaboration for the benefit of children with learning and behavioral disorders, especially ADHD. First of all, the project aimed at the possibilities of early diagnostics in the Youth Health Care Department at the Public Health Service. All children from the age they start attending school are seen at the Youth Health Care Department as part of a preventive care program, including periodic medical examination.

The aims of this cooperative project are formulated as follows:

- early medical and neuropsychological diagnostics and treatment advice for children with behavioral-neurological developmental disorders, in particular ADHD;

- $\quad$ short, fast referral lines for additional diagnostics and treatment;

- integration of care and use of care protocols for behavioral-neurological developmental disorders, promoting effectiveness and quality;

- $\quad$ stimulation to fit in treatment in a continuous care chain.

- these aims correspond closely to the advice for the diagnosis and treatment of ADHD as formulated by the Dutch Health Council in November 2000 [1].

In practice, behavioral-neurological developmental disorders usually seem to involve a combination of learning and behavioral problems. Youth health care physicians are frequently confronted with learning and behavioral problems in children in their daily practice. It concerns a heterogeneous group of children with a diversity of 
developmental problems affecting their learning process. As a result, these children lack behind compared to what can be expected on the basis of their learning potentials. It is therefore important that youth health care physicians establish the correct indication for referral by means of history taking, examination, and their knowledge of a variety of disorders and corresponding developmental courses. The children may need to be referred for additional diagnostic examination to a neuropsychologist, pediatric neurology and, if necessary, to a pediatric psychiatrist.

The following categories of specific learning disorders are distinguished in practice [3]:

- Language-based learning disabilities, including dyslexia and children with a specific language impairment (SLI).

- Non-language-based learning disabilities, including Nonverbal Learning Disabilities (NLD) and a number of calculation disorders.

- Attention and motor disorders: such as ADHD, Developmental Coordination Disorder (DCD), and a combination of attention disorders and motor and perceptual disorders (known as DAMP, Deficits in Attention Motor control and Perception).

Behavioral-neurological developmental disorders are based on neurological, neurophysiological and biochemical processes, which implies that diagnostic examination and treatment should take place in collaboration with the relevant disciplines.

\subsection{PROCEDURES WITHIN THE COLLABORATION MODEL}

The youth health care physician, child neuropsychologist and child neurologist in succession see the children who are listed for the transmural consultation hour on the same afternoon.

\subsubsection{The role of the youth health care physician}

Registration for the joint consultation hour takes place on the advice of the youth health care physician, based on the symptoms of attention problems, possibly in combination with behavioral problems (hyperactivity, impulsiveness) as well as comorbidity of motor problems, learning disorders, pervasive developmental disorders and/or speech and language development disorders. It is the youth health care physician's responsibility to compile the relevant data of the child's medical history. Obstetric and developmental data can be found in the records of pre-school health for infants and children aged 0-4 years. In addition, the youth health care physician provides the data concerning family history and patient care history, including previous treatments and medication. Based on his own observations, the youth health care physician describes the present symptoms and complaints with 
reference to the observed learning and behavioral problems and adds the observations provided by the school. The school also supplies the available data about the child's performance. Parents and teachers always fill out a behavioral questionnaire: the CBCL (Child Behavior Checklist) and the TRF (Teacher's Report Form), respectively. Computer scoring is used to identify which type of problem behavior is significantly present at home and at school [4]. Also, the youth health care physician reports his own recent examination findings regarding hearing and vision, growth data, general physical examination, lateralization and motor function assessment. Finally, the youth health care physician formulates a clear question and, if possible, his own probability diagnosis.

\subsubsection{The role of the child neuropsychologist}

Prior to the actual joint consultation hour, the child is seen for neuropsychological tests, in which a number of cognitive functions are assessed. Important are: perception, memory, planning and adjusting behavior (the 'executive functions'), speech and language functions, spatial constructive skills, complex fine motor skills and finally attention / concentration. The assessment of the test scores is related to the child's history, observed behavior during examination, and school results. Subsequently, a profile of the weak and strong areas with respect to the child's functioning is constructed and a diagnosis is made as a starting point for treatment $[5,6,7]$. In addition, follow-up of treatment can be provided by means of neuropsychological assessment.

\subsubsection{The role of the child neurologist}

Pediatric neurological examination is important in order to distinguish between cryptogenic, idiopathic and symptomatic types of ADHD [6]. Neurological assessment begins with neurological history taking, in which specific attention is paid to the family history, tic disorders, paroxysmal disorders (epilepsy), thyroid disorders, and congenital disorders. If necessary, the child is referred for additional examination to the outpatient pediatric neurology department at AZM, following the ultra-fast referral principle ('Friday afternoon at the joint consultation hour, Monday morning at the outpatient department').

When medication is indicated in a child with ADHD, a standard additional pediatric neurological examination takes place, which includes EEG, ECG, thyroid function, kidney and liver function and blood tests. The medication is adjusted on the basis of two-weekly check-ups and neuropsychological reassessment takes place after 8 weeks. When neuropsychological evaluation confirms the observed positive changes, the prescribed medication is continued and adjusted regularly when changes are reported during check-ups. 


\subsubsection{The function of multidisciplinary team consultations}

The collaborating disciplines keep a joint file. When the child has been seen by the three disciplines mentioned above, the examination findings will be discussed during the joint consultation. Based on this team consultation, conclusions are drawn with respect to a preliminary diagnosis and indication for further intervention or referral. Subsequently, the conclusions and recommendations are discussed with the parents. When additional diagnostics are indicated, new appointments are made as soon as possible. Finally, the findings of the collaborating disciplines are described in one integral report.

\subsubsection{The role of the youth health care physician in follow-up care}

After the multidisciplinary team consultation, the conclusions and recommendations are discussed with the parents and, where necessary, explained or elaborated. This is done by the referring youth health care physician, who also monitors the agreed intervention/treatment and determines when repeat consultations should take place. Another important task of the youth health care physician is the contact with the child's school following a joint diagnosis. In consultation with the parents, the youth health care physician informs a teacher or the school's internal pupil care coordinator about the diagnostic findings and the consequences for educational support of the child at school. When indicated, the school is asked to provide extra care (remedial support) or arrange external care (preventive ambulatory care or referral to a special education school). When psychiatric treatment is indicated, the child is referred to a Regional Institute for Ambulatory Mental Health Care (Riagg) or the outpatient department of Pediatric Psychiatry.

\subsection{DESCRIPTION OF THE STUDY POPULATION 1998-2000}

At each joint consultation hour at the Youth Health Care Department, now held once a month, an average of four children were seen for examination. Pre-examination by the youth health care physician (duration: 40 minutes) and neuropsychological assessment (duration: 120 minutes) had already taken place.

Invested time per discipline per consultation per child amounted: neuropsychologist 60 minutes, neurologist 60 minutes and youth health care physician 20 minutes. During the start-up phase from September 1998 to July 2000, a total of 66 children were seen: 56 new cases and 10 children for evaluation and follow-up on the basis of previous contact.

The group of 66 children consisted of 55 boys $(83 \%)$ and 11 girls $(17 \%)$ aged between 4 and 16 years, mean age 8 years and 6 months. The reasons to register for the joint consultation hour are presented in Table 8.1. 
Table 8.1: Reasons for presentation by the youth health care physician at a joint consultation

\begin{tabular}{|l|c|c|}
\hline Reason for registration & number & $\%$ \\
\hline Suspected ADHD & 34 & 52 \\
\hline Suspected ADD & 3 & 4 \\
\hline ADHD/ADD + Comorbidity & 11 & 17 \\
\hline Evaluation & 10 & 15 \\
\hline Autism Spectrum Disorder & 3 & 4 \\
\hline Other Learning/ Behavioral Problems & 5 & 8 \\
\hline Total: & 66 & 100 \\
\hline
\end{tabular}

ADHD was diagnosed in 18 of the 34 children who were put forward at a joint consultation by the youth health care physician because of suspected ADHD [9]. One of these children also had DAMP (Deficits in Attention, Motor control and Perception). In 3 of the 34 children, the diagnosis of ADHD was postponed. Four children showed hyperactive behavior without attention problems and 3 children had attention problems without hyperactive / impulse behavior. Five children were diagnosed with oppositional defiant disorder (ODD). In one child no diagnosis was established.

The following secondary problems were diagnosed in the above-mentioned group of 34 children: dyslexia / reading problems (7x), oppositional defiant disorder (3x), social-emotional problems (3x), tic disorder (1x), dyspraxia (1x), NLD (1x), and other learning disorders $(6 \mathrm{x})$.

In the 3 children who were put forward at the joint consultation by the youth health care physician because of suspected ADD the diagnosis was confirmed. In addition, the following secondary problems were found: indication of dyslexia / reading problems (2x) and social emotional-problems (1x).

As shown in Table 8.1, 11 children were presented because of suspected ADHD or ADD with comorbidity. Of this group, 6 children were found to have attention disorders, 2 children were diagnosed with ADHD and 1 child showed hyperactive / impulsive behavior without attention problems. Furthermore, DAMP was suspected in one child (postponed diagnosis) and 1 child was found to be retarded.

The secondary diagnoses in this group of 11 children included anxiety disorder (2x), symptoms of autism spectrum disorder (4x), and indications of dyslexia or reading problems $(3 \mathrm{x})$. Furthermore, one child was found to have learning problems and one had social-emotional problems.

In 2 of the 3 children who were put forward by the youth health care physician because of suspected pervasive developmental disorder (PDD-NOS) the diagnosis was confirmed. The other child was diagnosed with oppositional defiant behavior. 
Table 8.2 presents the findings of the pediatric neurologist. In the total study population of 66 children, the neurologist found 3 children with an evident tic disorder. In addition, the neurologist noticed motor problems in 16 children: 6 children with quantitative retardation of gross motor skills (one of these children was diagnosed with ADHD), 6 children with quantitative problems of fine motor skills (3 of these children were diagnosed with ADHD), and finally 4 children with qualitative motor problems ( 3 of these children had ADHD).

\begin{tabular}{|l|c|c|}
\hline Table 8.2: Findings pediatric neurologist & & \\
\hline Findings Child neurologist & number & $\%$ \\
\hline Problems Gross Motor Skills / Quantitative & 6 & 9 \\
\hline Problems Fine Motor Skills / Quantitative & 6 & 9 \\
\hline Motor Problems / Qualitative & 4 & 6 \\
\hline Tic Disorder & 3 & 4 \\
\hline Evident Concentration Problems & 9 & 14 \\
\hline No Neurological Disorders & 38 & 58 \\
\hline Total: & 66 & 100 \\
\hline
\end{tabular}

Neuropsychological assessment in the total study population of 66 children demonstrated an average level of information processing (equivalent to IQ scores of 85 to 115 ) in 34 children (52\%), a disharmonious profile at the expense of sequential processing in 8 children (12\%), and a disharmonious profile at the expense of simultaneous processing in 2 children (3\%).

Above-average scores were obtained by 7 children $(11 \%)$, of whom one had a disharmonious profile at the expense of simultaneous processing.

Subnormal or weak scores were obtained by 25 children (38\%), of whom 9 children $(14 \%)$ had a disharmonious profile at the expense of sequential processing.

Assessment into sustained attention and concentration showed a weak score in 35 children (53\%). A subnormal score was obtained by 15 children (23\%). No abnormalities in concentration or attention were found in 16 children (24\%).

\subsection{TREATMENT ADVICE AFTER EXAMINATION}

Of the total group of 66 children, 56 children were seen at the joint consultation hour for the first time, 10 were seen for evaluation and follow-up.

Table 8.3 provides an overview of the interventions after examination and discussion during the joint consultation hour at the Public Health Service. 
Table 8.3: Interventions after examination

Interventions

Trial Medication after 1st Consultation

Trial Medication after Evaluation

Further Neuropsychological Diagnostics

Further Pediatric Neurological Diagnostics

Referral: Regional Institute for Ambulatory Mental Health Care (Riagg)

Referral: Neuropsychiatry at AZM

Referral: Children's Rehabilitation Center

Referral: Other (Special Education Schools)

None of the above-mentioned interventions

\begin{tabular}{|c|c|}
\hline number & $\%$ \\
\hline 16 & 24 \\
\hline 3 & 4 \\
\hline 4 & 6 \\
\hline 3 & 4 \\
\hline 13 & 20 \\
\hline 6 & 9 \\
\hline 4 & 6 \\
\hline 11 & 17 \\
\hline 6 & 9 \\
\hline
\end{tabular}

In all children who were recommended for trail medication (19x), standard additional pediatric neurological examination was performed (EEG, ECG, thyroid function, kidney and liver function and blood tests). In addition, 3 children were seen for more extensive pediatric neurological examination (including MRI and quantitative EEG). Standard, effect measurement was performed in all children who were eligible for trial medication.

With respect to the prescribed medication, methylphenidate (Ritalin ${ }^{\circledR}$ ) was prescribed to 18 children and clonidine (Dixarit ${ }^{\circledR}$ ) to one child. After a trial period of 2 months, the medication (methylphenidate) in one child was discontinued, because it had insufficient effect. Instead, non-medication intervention was provided.

With regard to further follow-up after the joint consultation, the youth health care physician made arrangements with the schools of all 66 children about educational support, remedial support, preventive ambulatory care or referral to special education schools. The follow-up of all children was monitored by the youth health care physician, 19 children (29\%) had regular check-ups with a pediatric neurologist, 3 children $(4 \%)$ were supervised by a pediatric psychiatrist and a neuropsychologist, 4 children $(6 \%)$ remained in follow-up at the children's rehabilitation center, and, finally, 13 children (20\%) were supervised by the Regional Institute for Ambulatory Mental Health Care (Riagg).

\subsection{DISCUSSION AND CONCLUSIONS}

The monthly transmural joint consultation hour at the Public Health Service clearly fills a need. The parents appreciate the accuracy of the diagnostic procedure (a diagnosis is made within one week after the child has been seen), the joint file (no history overlap but a clear, specified history clarifying the problem) and the fast referral if the child needs to be seen for outpatient follow-up (appointments within a week). 
The successfulness of the joint consultation hour has resulted in its main bottleneck: the waiting time has increased from a maximum of 1 month during the start-up phase of the project to 3 months two years later. This is not surprising, considering the prevalence of the disorders the project is focusing on.

It is not necessary to have a referral note from a family doctor for the joint consultation hour at the Public Health Service. If a family doctor suspects ADHD in a child, he can contact the youth health care physician and ask if the child can be invited for examination and assessment to see if the child has an indication to register for a joint consultation at the Public Health Service. The costs of this collaboration model have as yet been financed by a grant for specific goals, complemented by financial support of the participating institutes.

The added value of the project lies in a number of factors. First, the lines between the finding place (school or family) and secondary health care are very short for case finding by the youth health care physician. The youth health care physician's findings are provided to the consultants in secondary health care according to a standard procedure. An advantage to direct referral by the family doctor to an outpatient department is that the children have already been pre-examined according to a standard protocol before they are presented to secondary health care consultants at the joint consultation. In addition, the consultants can consult directly with the youth health care physician if necessary. The examination results are discussed not only directly with the parents, but the youth health care physician will always also pass on the information (with the parents' permission) to the school. This implies that the immediate consequences of the examination results for educational support at school are discussed and that tailored advice is provided. Once treatment has started, the same short lines of communication are used to include the school's experiences with the child in the evaluation.

This procedure appeared to be extremely pragmatic in practice, especially due to the 'bridging function' of the youth health care physician between secondary health care and schools, and the youth health care physician's intermediate position in the health care chain both at the start and the end of secondary health care. Finally, it turned out that the close collaboration greatly contributed to the youth health care physician's expertise.

After examination and the joint consultation meeting, a large part (19 children $=29 \%$ ) of the children who were diagnosed with ADHD were also given medication besides non-medication therapy. This relatively high percentage may be explained by the fact that selection has probably taken place in the group of children participating in the project. It seems that especially children in whom non-medication treatment at school or at home was insufficiently effective were registered for the joint consultation hour. 
Still, the following clear criteria were applied as to the indication of medication:

Insufficient effect of non-medication interventions - accompanied by: stagnant development of the child - and/or - pressure of suffering in the child and/or his family.

For all the children who were given medication or trial medication, the examination included in the joint consultation was supplemented with the pediatric neurological findings as described before. These were used as baseline values. As part of the procedure, the children came to a joint consultation hour for re-examination 6 to 8 weeks after they started taking the medication. Re-examination also included CBCL and TRF again; neuropsychological assessment was also repeated for evaluation [9].

The first experiences with the joint consultation hour at the Public Health Service have shown that the Youth Health Care Department offers a perfect infrastructure for case-finding based on screening protocols, for longitudinal follow-up through direct or indirect (intermediaries, e.g. schools) monitoring, and for epidemiological registration of risk factors and protective factors in relation to learning and behavioral problems. In this respect, Youth Health Care can play a crucial role in the early detection and diagnosis of learning and behavioral problems as well as in the indication and referral of children for additional neurological, neuropsychological or psychiatric assessment.

Acknowledgements: This study was made possible in part by financial support of the 'Stichting ter Behartiging van de Belangen van het Gebrekkige Kind' [Dutch Association for the Interests of Infirm Children]. 


\section{REFERENCES}

[1] Gezondheidsraad: Diagnostiek en behandeling van ADHD. Gezondheidsraad: Den Haag, 2000; publicatie nr. 2000/24. [Health Council: Diagnosis and Treatment of ADHD]

[2] Kroes M, Hendriksen JGM, Steyaert J, Kalff AC, Feron FJM, van Zeben-van der Aa ThMCB, Jolles J, Troost J en Vles JSH. De Vragenlijst Voorlopers ADHD. Tijdschrift Kind en Adolescent 2001; 22 no. 1, pp. 22-36. [The Questionnaire Early Symptoms of ADHD. Dutch Journal about Children and Adolescents]

[3] Njiokiktjien C. Problemen in de psychomotorische ontwikkeling. Suyi Publicaties Amsterdam 1996. [Problems in psychomotor development]

[4] Vlasveld L, Gunning WB. Klinisch beeld en diagnostiek. In: Gunning WB, red. Behandelingsstrategieën bij kinderen en jeugdigen met ADHD. Bohn, Stafleu \& Van Loghum 1998. [Treatment strategies in children and adolescents with ADHD]

[5] Vos P. Handleiding Bourdon Vos test. Nijmegen: Katholieke Universiteit, 1988.

[6] Jurjens HB \& Hendriksen JGM. De Kaufman Assessment Battery for Children: psychometrische kenmerken en toepasbaarheid. Proceedings van de Najaarsconferentie sectie revalidatiepsychologen. Amsterdam: Nederlands Instituut voor Psychologen, 1991. [Kaufman Assessment Battery for Children: psychometric properties and applications. Proceedings of the Fall Conference, Section Rehabilitation Psychologists]

[7] Beery KE (ed). The developmental test for visual motor integration. Cleveland: Modern Curriculum Press, 1989.

[8] Vles JSH, Smit LME. De neurologie van aandachtsstoonissen en hyperactief gedrag bij kinderen. In: Gunning WB, red. Behandelingsstrategieën bij kinderen en jeugdigen met ADHD. Bohn, Stafleu \& Van Loghum 1998. [Neurology of attention disorders and hyperactive behavior in children, Treatment strategies in children and adolescents with ADHD]

[9] Hendriksen JGM, Feron FJM, Njiokiktjien C, Vles JSH. Het effect van clonidine en methylfenidaat bij kinderen met een aandachtstekort en hyperactiviteit. Tijdschrift voor Kindergeneeskunde 2000; 68 nr.3: 94-99 [The effect of clonidine and methylphenidate in children with attention deficit and hyperactivity]. 
108 CHAPTER 9

CHAPTER 9

\section{A neurodevelopmental model in a learning environment - concluding remarks}


For more than a decade, the Youth Health Care Service in Maastricht participates in a large-scale multidisciplinary research program aimed at detecting the developmental profile of children with Attention Deficit Hyperactivity Disorder (ADHD). This research program is carried out by the joined efforts of the University Hospital in Maastricht (department of Child Neurology), University of Maastricht (department of Psychiatry and Neuropsychology), Child Rehabilitation Center Franciscusoord in Valkenburg a/d Geul, and the Youth Health Care Service in Maastricht. Furthermore, the Youth Health Care Service, the department Child Neurology and Child Neuropsychology, work together in early detection, diagnosis and treatment of children with neurodevelopmental disorders, inclusive aftercare (assignment of experiences and advices to schoolteachers) and follow-up. We want to emphasize that our research interest is not on psychiatric comorbidity and mental retardation, so that these topics are not discussed.

The research program on the one side and the integral interdisciplinary care for children with neurodevelopmental disorders on the other, were the starting point for the studies on several neurodevelopmental issues in children as described in the present thesis. The main objectives within the domain of neurodevelopment in children as presented in this thesis were:

- to assess the relationship between acid-base status at birth and short-term and long-term neurodevelopmental outcome;

- to determine effects of medication treatment in children with ADHD in terms of information-processing and behavioral functioning;

- to monitor medication treatment in children with ADHD, focusing on the neurobiological substrate of ADHD in relation to neurodevelopmental outcome;

- to indicate the practical implications of the multidimensional aspects of neurodevelopmental outcome measures.

- In the next paragraphs these objectives will be discussed and several reflections will be described.

The above mentioned neurodevelopmental issues in children were discussed in the preceding chapters of this thesis, emphasizing the importance of neurodevelopmental research in the wider context of an age dependent perspective. Acidosis at birth was addressed in terms of neurodevelopmental follow-up, in particular motor development, neurocognitive and behavioral outcome in children from birth till four years of age. Attention deficit hyperactivity disorder at school age was studied in terms of neurodevelopmental outcome monitoring medication treatment in children with ADHD in line of the neurobiological approach.

The multidimensional aspects of the neurodevelopmental issues in this thesis were studied on the basis of the multidisciplinary nature of neurodevelopmental outcome. The Maastricht model as visualized an interdisciplinary approach in managing neurodevelopmental disorders in children. According to this concept, the Youth 
Health Care professional is the gatekeeper, gathering structured information on the child's general health, development, school performance and environment.

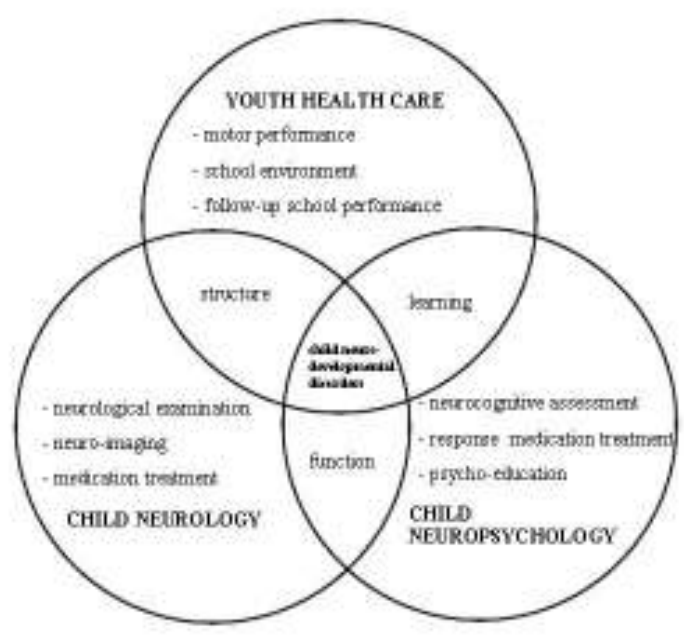

Figure 9.1: Elaboration of the Maastricht model: multidimensional aspects of neurodevelopmental outcome visualized by a Venn-diagram.

According to the Maastricht model, diagnosing neurodevelopmental disorders in children is based on interdisciplinary experiences: physical examination (including vision and hearing), neurocognitive profile, child neurological examination, behavioral functioning and parent interview. After determining diagnosis using DSM-IV criteria, a multi-treatment plan is made and discussed with the parents in relation to potential medication treatment, education and support for parents and children, information support for school and counseling for teachers. Structured follow-up with careful monitoring and psycho-education is standard component in the Maastricht model. In this Maastricht model medical treatment is initiated when the diagnosis has a negative impact on the child's school performance. If emotional and behavioral dysfunction and parental stress prove to be primary problems, the child and his parents are referred to mental health care institutions.

In figure 9.1, which was also presented in chapter one, the multidimensional aspects of neurodevelopmental outcome are now elaborated on the basis of the interdisciplinary approach of Youth Health Care, Child Neurology and Child Neuropsychology in the studies as presented in this thesis. Mutual interdisciplinary interest was formulated by using a neurobiological substrate of child 
neurodevelopmental disorders, describing the overlap of the three disciplines Youth Health Care, Child Neurology and Child Neuropsychology. The studies were by no means intended to be all-inclusive but were selected from a neurodevelopmental perspective (studies described in chapter 2 and 3 ) respectively from a neurobiological and neurocognitive perspective (studies described in chapter 4,5 and 6). A neurobiological perspective was also used to discuss adverse effects of medication treatment in ADHD, based on a case report (chapter 7). The multidimensional aspects of neurodevelopmental issues adduce arguments in support of efforts to fit in treatment in a continuous care chain (described in chapter 8). The final chapter of this thesis provides an outline of the studies as presented and the implications for the future from a theoretical and practical perspective will be discussed.

\subsection{REFLECTIONS ON THE ACID-BASE STUDIES}

The amount of studies on the consequences of acidosis at birth as a potential risk factor for neonatal morbidity is quite considerable. However, the vast majority of these studies have focused on mortality and major neurological sequelae due to hypoxic ischemic encephalopathy. Only a few prospective studies are focused on long-term neurocognitive and behavioral outcome. In the present thesis two prospective studies are reported, concerning the relationship between acid-base status at birth and long-term neurodevelopmental outcome. Both studies on the relationship between acid-base status at birth and long-term neurodevelopmental outcome reached the conclusion that acid-base status at birth in full-term infants, without clinical evidence of perinatal hypoxic-ischemic encephalopathy, is neither predictive for motor milestone achievement [1], nor for neurocognitive and behavioral outcome in preschool and early school-aged children [2]. As such, these findings contribute to the consideration that birth-acidosis on itself cannot be causative of newborn encephalopathy respectively long-term abnormal neurodevelopment. However, the criteria of inclusion and exclusion as chosen in our acid-base studies probably resulted in inclusion of newborns with acute intrapartum acidosis. Neonates who were exposed to chronic antepartum acidosis were excluded.

In general, so-called acute perinatal asphyxia in the clinical context is characterized by a condition of impaired blood gas exchange leading to progressive hypoxemia and hypercapnia with significant metabolic acidosis. In literature the lower level of the normal range of umbilical artery $\mathrm{pH}$ at birth has been lowered in the past two decades from 7.20 to 7.10 and even to 7.00 intending to define damaging acidemia $[3,4,5,6,7]$. After stratification based on acid-base status at birth a causal relation between acid-base status at birth and neurodevelopmental outcome could not be found in our research. A such, umbilical arterial cord $\mathrm{pH}$ and base excess have only moderate predictive value for hypoxic ischemic encephalopathy and none of these 
indicators has good sensitivity, specificity or predictive value for an abnormal neurodevelopment. Consequently, acute acidemia intrapartum in previously normal fetuses is rarely causality of subsequent neurodevelopmental damage. Therefore, causes of neonatal hypoxic encephalopathy are probably more related to risk factors antepartum than intrapartum $[8,9,10,11]$.

The term birth asphyxia is argued to be an imprecise term and a nonspecific diagnosis $[3,11,12,13,14]$. Although the use of the term birth asphyxia is still continued in general medical practice, it is inappropriate to use this term in epidemiological research because of the lack of uniform and specific criteria $[13,14,15]$. Neonates who endure intrapartum or antepartum hypoxia that is severe enough to cause hypoxic-ischemic encephalopathy will develop the following symptoms of hypoxic damage [14]: (1) evidence of metabolic acidosis (umbilical arteria $\mathrm{pH}<7.00$ and base deficit $\geq 12 \mathrm{mmol} / \mathrm{L}$ ); (2) Apgar scores $0-3$ beyond 5 minutes; and (3) neurological sequelae (seizures, coma, hypotonia) and one or more of the following organ or system injuries: cardiovascular, gastrointestinal, hematological, pulmonary, hepatic, or renal system dysfunction. However, it is not clear why a majority of the infants who experienced a severe acidemia at birth do not develop major neurological sequelae. The mechanisms that account for this phenomenon are not yet fully understood. Compensatory mechanisms associated with "beneficial acidemia", providing protection to hypoxic ischemic encephalopathy, might play an important role [16,17]. Another hypothesis is the possible 'repairing' influence of the plasticity of the brain in reducing the genesis of major neurological sequelae in case of hypoxic ischemic brain damage. Multifactorial neurobiological repair mechanisms play a considerable role in recovering from neurocognitive disabilities, a phenomenon known as "growing out of deficit" [18]. A next hypothesis might be the working of possible neurobiological mechanisms that compensate damaged brain areas by generating new neuronal pathways in contiguous undamaged brain areas. And finally, if major neurological signs stay away in case of hypoxic brain damage, the question remains to what extent selective areas of brain damage exist resulting in minor disabilities later in childhood, especially schoolrelated disabilities.

In order to completely elucidate all the factors of fetal hypoxic events in causal relationship with the genesis of infant brain disorders, research into adverse outcome and long-term neurodevelopmental follow-up of these infants require longitudinal studies that include assessment of minor disabilities later in childhood. Such longitudinal studies should include repeated neurological examinations, repeated neuropsychological assessments on neurocognitive and behavioral outcome, regular systemic medical examination of physical growth and maturation and periodical evaluation of school performances. Outcome measures of these repeated assessments should be evaluated in relation with neuropathological, 
electrophysiological or neuroimaging evidence of brain abnormalities. With respect to these recommendations, an integrated interdisciplinary co-operation where neuroscience, child neurology, child neuropsychology and youth health care meet, offers optimal basic potentialities for longitudinal studies on brain-behavior relations and neurodevelopment in children. However, school-aged neurocognitive abilities are determined by various factors such as genetic and environmental variables, which make it difficult to establish a causal relation with subtle hypoxic brain damage.

The first acid-base study as presented in chapter 2 of this thesis indicated that neonatal acidemia is related to subtle and qualitative signs of neuromotor dysfunction as measured with the Hempel-test at the age of four years [1]. In the second acidbase study as described in chapter 3 , a significant positive correlation was found between umbilical arterial $\mathrm{pH}$ at birth and the scores on the motor scale of the Bayley Scales of Infant Development at the age of 18 months [2]. Both findings underline the notion that a perinatal non-reassuring fetal status caused by hypoxia may induce a less optimal function of the central nervous system, a so-called simple form of minor neurological dysfunction (MND) [19,20,21].

The results of both acid-base studies emphasize once more the value of age-related motor performance assessment on behalf of longitudinal studies on neurodevelopment in children. Standardized age-related neuromotor tests contribute to a large extent in assessing neurodevelopment in three ways. First, they contribute in early detecting neurodevelopmental disabilities. Secondly, age-specific neuromotor assessments play a prominent part in longitudinally evaluating neuromotor development in infants, pre-school children and school-aged-children. And thirdly, neuromotor tests contribute to some extent on predicting neurodevelopment.

The notion that motor performance in children is related to other neurodevelopmental aspects brings up the question whether quantitative and qualitative aspects of motor performance also are linked to neurocognitive performance. In a large-scale crosssectional study in 5- to 6- year-old children we recently found that both quantitative and qualitative aspects of motor performance appeared to be related to several aspects of cognition, in particular working memory, verbal fluency, perceptual ability and visual motor integration (Wassenberg, Feron, et al. 2005) [22]. In earlier research we found that qualitative motor performance in 5- to 6-year-old children is related to a later diagnosis of $\mathrm{ADHD}$ and as such assessment of qualitative aspects of motor performance as precursors of ADHD may have an additional value in early detection of children with ADHD [23]. 


\subsection{REFLECTIONS ON ADHD AT SCHOOL AGE: INFORMATION PROCESSING, BEHAVIORAL FUNCTIONING AND MEDICATION MONITORING.}

The diagnosis Attention Deficit Hyperactivity Disorder (ADHD) in children is certainly not a trendy diagnosis of our modern times. As early as 1845 the German physician and psychiatrist Heinrich Hoffmann (1809-1894) has described the typical symptoms of ADHD in the tales of the children's book "Struwwelpeter" ("Slovenly" or "Shockhaired Peter") [24]. "The story of Fidgety Philip" ("Die Geschichte vom Zappel-Phillip") depicts the boy's attention deficit behavior and typical symptoms of hyperactivity [25]. Hoffmann described additional symptoms of ADHD in two other tales: inattention in "The story of Johnny Look-in-the-Air" ("Die Geschichte von Hans Guck-in-die-Luft") and the progression to antisocial behavior in "The Story of Cruel Frederick" ("Die Geschichte vom bösen Friederich"). In 1902 the British pediatrician Still has explained hyperactivity in children as a "defect of moral control". In the thirties hyperactivity was thought to be caused by brain damage resulting from "postencephalitic disorder" and the term "Minimal Brain Damage" (MBD) was used to describe the hyperactivity disorder. In 1937 it was reported for the first time that stimulant medication helped to control hyperactive symptoms. In the sixties the term "Minimal Brain Dysfunction" became the prevalent term for the disorder. In the mid sixties stimulant medication became the common treatment for hyperactivity disorder. In 1968 the American Psychiatric Association (APA) established a diagnostic category for "hyperkinetic reaction of childhood" in the Diagnostic and Statistical Manual of Mental Disorders (DSM-II). In the seventies, impaired attention and impulse control were recognized as primary symptoms in addition to hyperactivity. In 1980 the American Psychiatric Association officially referred to the disorder in the DSM-III for the first time as Attention Deficit Disorder (ADD) with or without Hyperactivity. Over the next two decades, the American Psychiatric Association further defined the disorder, ultimately arriving at today's widely accepted AttentionDeficit/Hyperactivity Disorder (ADHD) as described in the latest version of the diagnostic manual DSM-IV-TR in 2000 [26].

The amount of published studies on ADHD in children is tremendous. Entering the keywords "ADHD" and "children" in an Internet PubMed search (on March $4^{\text {th }}, 2006$ ) provided 8.257 hits on a number of 10.291 hits on the keyword "ADHD" (articles published from 1966 op to now). On the contrary, the number of publications on ADHD-related issues with a direct or indirect contribution by Youth Health Care Services is rather low $(<1 \%)$ with a number of 62 based on PubMed searches. This finding is quite remarkable, taking in account that ADHD is a prevalent ( 3 to $5 \%$ ) and serious condition and that an absolute majority of children attend the Youth Health Care Services for periodical medical assessments from early infancy through adolescence age. 
At present, there is an international consensus on the diagnostic criteria on ADHD as rendered in the Diagnostic Statistical Manual of Mental Disorders IV (DSM-IV-TR) [26 \& appendix 1]. All the diagnostic criteria of the so-called core symptoms of ADHD, inattentiveness - impulsivity - hyperactivity, are based on behavioral symptoms and rely on a rather subjective diagnostic judgment, because there is no objective test to diagnose $A D H D$ in children. Besides criteria on age of onset, situational pervasiveness and differential diagnostics, an obligate criterion for diagnosis concerns the requirement of impairment. According to DSM-IV criteria "there must be clear evidence of clinically significant impairment in social, academic, or occupational functioning". However, the criterion of impaired academic functioning is not made operational by the DSM-IV. Especially the extent of children's impairment in school functioning is to our view a point of great importance in the early detection and diagnosis of ADHD in children. In this respect current information from parents as well as teachers should be involved in diagnosing ADHD in children and in treatment monitoring. It is essential to obtain reports of behavior, learning, and attendance at school, as well as grades and test scores. School-based problems include lower than expected grades, gaps in learned material, poor organizational and study skills, failure to complete or turn in homework assignments or grade retention. Neuropsychological testing of children suspect for ADHD is useful to evaluate specific deficits in neurocognitive functioning, focusing on attentional functioning, executive functioning, working memory and verbal learning. As such, a neuropsychological profile is important in terms of strengths and weaknesses in neurocognitive functioning and the impact on school performance or school failure (see also figure 9.1).

Recognizing and careful diagnosing ADHD in children is a challenge, because this process can be complicated taking in account three points of consideration. Firstly, from a neurodevelopmental point of view the diagnostic ADHD-items have a limited sensitivity and specificity $[27,28]$. Consequently, it is not easy to differentiate ADHDsymptoms from developmentally normal or healthy levels of inattentiveness, impulsivity and hyperactivity [28]. Because of a lack of sensitivity and specificity of diagnostic symptoms, up till now no tests are available with a predictive value that is high enough for use in clinical practice. The lack of sensitivity and specificity may also be demonstrated by different prevalence rates on ADHD in children given by various experts: 3 to $5 \%$ according to Barkley [29] versus 8 to $12 \%$ according to Biedermann [28]. Secondly, seen from an age-related perspective ADHD-symptoms in the same individual child may have various age-related expressions. In other words: character, content, pervasiveness and quantity of ADHD-symptoms manifest differently at various stages of development of the child (intra-individual variability) $[27,29]$. Further research is needed to provide more specific, reliable diagnostic tools that also can be used in an age-dependent perspective. Thirdly, there is a high degree of associated disorders in children with ADHD. Experiences as described in chapter 8 of this thesis are illustrative in this respect. Gillberg and co-authors recently 
(2004) gave an overview of co-existing disorders in ADHD in a review of the empirically based literature [30]. A schematic summary of their study is represented in table 9.1.

\begin{tabular}{|c|c|c|}
\hline Co-existing Disorder in ADHD & $\begin{array}{l}\text { Prevalence } \\
\text { rate }\end{array}$ & Remarks \\
\hline $\begin{array}{l}\text { Oppositional defiant disorder } \\
\text { (ODD) }\end{array}$ & $50-60 \%$ & rate even higher in combined type of ADHD \\
\hline Conduct disorder (CD) & increased & $\begin{array}{l}A D H D, C D \text { and antisocial personality disorder are linked (the role of ODD in } \\
\text { this chain of event not yet confirmed) }\end{array}$ \\
\hline Depression and anxiety disorders & $16-26 \%$ & co-morbidity of anxiety disorder with ADHD debatable \\
\hline Bipolar disorder & unknown & ADHD precursor of a child-onset subtype of bipolar disorder?? \\
\hline $\begin{array}{l}\text { Tic disorders (incl. Tourette } \\
\text { Syndrome) }\end{array}$ & unknown & About $50 \%$ of children with chronic tics or TS have co-existing ADHD \\
\hline $\begin{array}{l}\text { Obsessive Compulsive Disorders } \\
\text { (OCD) }\end{array}$ & unknown & ADHD co-existing in $6-15 \%$ of the OCD-cases \\
\hline Substance use disorders & increased & $\begin{array}{l}\text { 1) } A D H D \text { increases risk of misuse nicotine/alcohol/drugs } \\
\text { 2) Stimulant treatment of } A D H D \text { does not increase of later substance abuse }\end{array}$ \\
\hline $\begin{array}{l}\text { Developmental coordination } \\
\text { disorder }(D C D)\end{array}$ & $50 \%$ & $\begin{array}{l}\text { prevalence of } A D H D \text { and co-existing } D C D \text { and perceptual problems (DAMP) } \\
\text { unknown }\end{array}$ \\
\hline Autism spectrum disorders & increased & $\begin{array}{l}65-80 \% \text { of all clinic children have several symptoms of DSM-IV autism } \\
\text { disorder }\end{array}$ \\
\hline Language disorders & increased & $\begin{array}{l}\text { Early language delay in } 50 \% \text { of the children with } \mathrm{ADHD} \text { or with } \mathrm{ADD} \text { and } \\
\text { concomitant } \mathrm{DCD}\end{array}$ \\
\hline Learning problems & increased & $\begin{array}{l}\text { 1) in children with ADHD: mean IQ reduced by } 3-7 \text { points } \\
\text { 2) increased prevalence for disabilities on reading, spelling and arithmetic }\end{array}$ \\
\hline Reading disorder & $25-40 \%$ & $50-80 \%$ when ADHD combined with DCD \\
\hline $\begin{array}{l}\text { Disorder of written expression / } \\
\text { dysgraphia }\end{array}$ & increased & \\
\hline Mathematics disorder & increased & $10-60 \%$ (more strongly associated with inattentive subtype of ADHD) \\
\hline Neurological disorders & increased & $\begin{array}{l}\text { 1) Epilepsy associated with } A D H D \text { in about } 30 \% \\
\text { 2) } 6 \% \text { of children with } A D H D \text { have evidence of epileptiform abnormalities on } \\
\text { the } E E G \\
\text { 3) } C P \text { associated with } A D H D \text { in } 5-12 \% \text { of all cases } \\
\text { 4) very low birth-weight children (VLBW) } \rightarrow \text { high risk of ADHD } \\
\text { 5) VLBW + parenchymal lesions/ventricular enlargement } \rightarrow \text { extremely high } \\
\text { risk of ADHD }\end{array}$ \\
\hline Non-neurological disorders & unknown & $\begin{array}{l}\text { associated with ADHD: sleep disorders, enuresis, encopresis, height and } \\
\text { weight problems }\end{array}$ \\
\hline Chromosomal-genetic disorders & increased & $\begin{array}{l}\text { 1) fragile } X \text {-syndrome very often associated with } A D H D \\
\text { 2) the } 22 q 11 \text { deletion syndrome often }(43 \%) \text { associated with } A D(H) D\end{array}$ \\
\hline
\end{tabular}

As shown in table 9.1, co-morbidity occurs in a majority of ADHD cases. These coexisting disorders have a considerable impact on processes of early recognizing and diagnosing of ADHD in children. 
Recapitulating, problems in diagnostic process of ADHD in children concern lack of sensitivity and specificity of diagnostic symptoms (inter-individual variability), lack of individual age-dependent consistency of symptoms (intra-individual variability), and complexity of symptoms by co-morbidity. These problems have also an impact on careful evaluation of treatment and medication monitoring. In this respect, experiences during the introductory period of the Maastricht multidimensional approach as described in chapter 8 underline the need for an interdisciplinary approach [31]. These first experiences as reported in chapter 8 are based on a relatively small group of children $(n=66)$ [31]. However, the number of children that are diagnosed and treated in accordance with the Maastricht model of integrated interdisciplinary approach has increased to a large sample of $n=495$. A descriptive study on neuropsychological and behavioral functioning in this sample of children with various subtypes of learning disabilities has been made [32].

The Maastricht model provides also an appropriate procedure in order to evaluate effectiveness of treatment [33]. The contents of chapter 4 demonstrate the added value of a multidimensional procedure in evaluating medical treatment, comparing effects of methylphenidate and clonidine medication on ADHD in children [33]. Baseline school data on behavior and academic performance before starting medication should be available. Neuropsychological testing should be performed to compare neurocognitive functioning of the child before and after medication treatment. As said before, outcome of quantitative and qualitative motor performance is also related to neurocognitive development.

\subsection{REFLECTIONS ON THE NEUROBIOLOGICAL SUBSTRATE OF ADHD}

Combining assessment on neurocognitive outcome, neuromotor performance and neurological diagnostics (neuroimaging) in children treated for ADHD, three dimensions are brought together by integrating the triad 'structure - function learning' (figure 9.1). ADHD in children is known as a heterogeneous neurodevelopmental disorder related to structural and functional abnormalities in specific brain regions. For that reason it is not justified to focus only on behavioral symptoms in diagnosing ADHD and in evaluating treatment response. Consequently, diagnosis and evaluation of the child with ADHD requires a multidimensional approach, relating brain structure, function, neuropsychological dysfunctions, social and school functioning from an age dependent perspective. In other words, the interdisciplinary synergism in assessing various elements in brain-behavior relations in children with ADHD within the context of learning leads to a synthesis of professional competences with a high grade of effectiveness and with a high level of quality control. Using this multidimensional point of view to indicate pharmacological 
treatment options for children with ADHD and subsequently individually dosage titration, high rates of efficacy are attainable. For example, the rate of success in pharmacological treatment of ADHD in children is $90.8 \%$. This beneficial outcome underlines the feasibility of a high degree of effectiveness as a result of an interdisciplinary multidimensional approach (Vles, Hendriksen, Feron; paper presented at the national conference on ADHD, Amsterdam, October 12, 2005). To our experience, high rates of success in treatment of ADHD are attainable looking at a child with ADHD from a neurodevelopmental perspective in a learning environment, and not only evaluating the child's behavioral symptoms during individual contact in the doctor's consulting room. When target outcomes of treatment are focused on improvement of neurodevelopmental outcome of children with ADHD in a learning environment, the use of short-acting methylphenidate $\left(\right.$ Ritalin $\left.^{\circledR}\right)$ is of benefit because short-acting methylphenidate enables clinicians to begin with a low dose of medication and titrate upward to the dose of medication leading to optimal effects with minimal side effects in a given child.

For more than four decades, methylphenidate has been the most widely used stimulant in the treatment of ADHD [34]. Based on neuroimaging studies using SPECT (single-photon emission computed tomography) as described in chapter five and six of the present thesis, the principal mechanism of action of methylphenidate appears to be a down-regulation of dopamine transporter system $[35,36]$. The shortterm response on treatment with methylphenidate is a substantial decrease in dopamine transporter density, with improvement in both neuropsychological tests and behavioral questionnaires [35]. Follow-up with SPECT after withdrawal of methylphenidate medication showed an increase of dopamine transporter activity comparable with pre-treatment values [36]. The observed up-regulation of dopamine transporter activity might support the assumption that methylphenidate does not lead to permanent damage of the nigrostriatal dopaminergic pathways.

ADHD in children has to be considered as a neurodevelopmental disorder and, without doubt, the pathophysiology of ADHD has a biological basis. Recent reviews in literature reinforce the existing evidence for a neurobiological substrate of ADHD $[28,37]$. First of all, genetic studies demonstrate ADHD as a highly heritable disorder of childhood onset $[28,38]$. Furthermore, several studies demonstrate morphological anomalies in brains of ADHD subjects concerning prefrontal volume reduction besides anomalies of the basal ganglia, corpus callosum and cerebellum $[37,39,40]$. The biological basis of ADHD is also underlined by pathological dysregulations in neurotransmission of dopamine and norepinephrine systems respectively the proven effectiveness of medication treatment in ADHD.

The working mechanism of methylphenidate in ADHD treatment is not limited to interfering with the dopaminergic neurotransmission in the striatum. Firstly, 
methylphenidate not only modulates extracellular dopamine concentrations in the striatum, but also in various other brain regions like the prefrontal cortex and nucleus accumbens [41]. Secondly, methylphenidate also influences the noradrenergic system by raising norepinephrine levels, especially in the prefrontal cortex [41]. Thirdly, because both neurotransmitter systems for norepinephrine and dopamine are implicated in the pathophysiology of ADHD it is hypothesized that both systems interact with each other [42]. Fourthly, the degree of involvement of neurotransmission systems for dopamine and norepinephrine in the interaction between left and right hemisphere exerts influence on the expression of ADHD symptoms $[41,42,43]$. Finally, other neurotransmitter systems are also involved in ADHD. The central acetylcholine system modulates arousal and alertness [42]. Furthermore, there is some evidence that ADHD is also associated to the serotonergic system [43]. However, it is not yet clear whether dysregulations in neurotransmitter systems are to some extent due to morphologic anomalies in several brain regions in ADHD children. The complexity of all the neurotransmitter systems involved in ADHD in children contributes to the broad range of inter- and intra-individual variability in the clinical expression of ADHD to a large extent.

The alpha-2-adrenergic agonist clonidine has been used for many years as a second-line treatment in children with ADHD. The effects of clonidine and methylphenidate are described in chapter four of this thesis [33]. Clonidine acts on the norepinephrine system by stimulating both pre- and postsynaptic alpha-2adrenoreceptors. Stimulating the presynaptic alpha-2-adrenoreceptors results in a decrease of norepinephrine, but direct stimulation of the post-synaptic alpha-2adrenoreceptors mimics the effect of norepinephrine [42]. It is not known which of these two effects predominates in the treatment of ADHD [42]. Norepinephrine increases responses to relevant stimuli and/or suppresses responses to irrelevant stimuli. Both low and high levels of norepinephrine probably influence selective attention capacity (i.e. inattention and underreactivity to stimuli respectively overstimulation and disorganizing effects on executive attention). The case study as presented in chapter eight deals with the specific role of the alpha-2-adrenoreceptor related to the working mechanism of clonidine [44]. However, the role of clonidine as second-line treatment for ADHD in children has to be reconsidered, because the side effects give cause for concern. For the future the clinical use of clonidine as secondline treatment for ADHD is expected to be displaced by medication with favorable pharmacological properties in relation to safety, efficacy, duration of action and tolerability. In this respect atomoxetine has become an interesting prospect for the treatment of ADHD. Atomoxetine is a highly selective noradrenaline reuptake inhibitor. Atomoxetine increases the extracellular levels of norepinephrine by inhibiting the norepinephrine transporter. Atomoxetine is the first nonstimulant medication approved for the treatment of ADHD [45,46,47]. However, further research is needed to determine the responsiveness to atomoxetine medication of 
academic performance, social behavior, and neurodevelopmental outcome in children beyond the core symptoms of ADHD $[47,48]$.

\subsection{REFLECTIONS ON NEURODEVELOPMENTAL OUTCOME MEASURES.}

In research into neurodevelopmental issues in children, multiple outcome measures are essential using more than one source, setting, and method of data collection. In the studies on neurodevelopmental issues as presented in this thesis, the instruments used for outcome measures were chosen on methodological considerations focusing on assessment of neuromotor development, neurocognitive development, performance on attention tasks and behavioral functioning.

Several methods of assessing spontaneous motor behavior and standardized tests on motor performance are available to assess quantitative and qualitative aspects of neuromotor development from an age-related perspective. For example, the assessment of the quality of General Movements (GMs) at the age of 2 to 4 months is a sensitive tool to evaluate brain function in young infants and longitudinal series of GM assessment have a good predictive value on developmental outcome $[19,20,21,49,50]$.

The Hempel assessment is a standardized observation technique for spontaneous qualitative motor behavior in children from $1 \frac{1}{2}$ to 4 years old and its performance takes about 30 minutes. The inter-rater reliability of the Hempel is satisfactory varying between 0.63 and 1.00 (mean 0.93) for the various items [51]. However, HaddersAlgra concludes in a recent review-article (2005) that the prognostic significance of the assessment according to Hempel is limited because of lack of information on predictive validity [51]. For further information about specific characteristics of the used tests on neuromotor performance in the acid-base studies is referred to literature and manuals about respectively GMs [19-21,49,50] and the Hempel-test $[52,53]$.

The Movement-ABC test provides an indication of a child's motor performance across gross and fine motor tasks related to motor norms using age-dependent standardized scores $[54,55]$. The Movement-ABC provides norms for children aged 4 to 12 years using four age-related item-sets, each consisting of 8 items measuring motor ability scored between 0 (optimal score) and 5 grouped as three subscores: manual dexterity ( 3 items), ball skills ( 2 items) and static/dynamic balance (3 items). This test has an acceptable validity and reliability: inter-rater reliability for the Movement-ABC test ranges from 0.70 to 0.89 and test/retest reliability is 0.75 [54,55]. The Bayley Scales of Infant Development are used for assessment of the current level of cognitive, language, personal-social, fine and gross motor development. In the Dutch version norms are provided for infants and toddlers in the age range from 2 
months through 30 months of age [56,57]. The Bayley Scales of Infant Development are known to have a high reliability and validity. The coefficients for test-retest reliability of the Bayley's mental and motor scales are high: 0.83 respectively 0.77 $[56,57]$.

Age-related assessment of neuromotor development is proved to be of considerable value in longitudinal evaluating respectively in predicting long-term neurodevelopmental outcome in children with adverse perinatal events. However, aiming at optimizing age-specific assessment of neuromotor development, further research is needed to improve reliability, validity and applicability of tests on this issue.

Neurocognitive development in terms of information processing was measured by using the Kaufman Assessment Battery for children [58]. This battery is designed for testing children aged 2.5 to 12.5 years, and based on eight subscales, two total scales for information processing can be derived: the sequential information processing scale and the simultaneous information processing scale. Sequential processing refers to solving problems in which the emphasis is on the serial or temporal order of the stimuli and to measure the child's ability to tackle and solve problems in turn and with logical consistency. Simultaneous processing is defined as 'using a gestalt-like or holistic approach to integrate many stimuli to solve problems'. The Kaufman-ABC test has proven validity and reliability: test-retest reliability of the two global scales of information processing ranged from 0.77 to 0.97 (median 0.88 ) and the internal-consistency reliability ranged from 0.84 to 0.97 (median 0.93 )

The Developmental Test of Visual-Motor Integration (VMI Beery) was used to measure the integration of visual perception and motor abilities. The child must copy geometric forms that become progressively more difficult and which are presented simultaneously with three forms on one page [59]. The test-retest reliability of the VMI-Beery test is reported as 0.83 for boys and 0.87 for girls; the internal consistency reliability is 0.93 , and a correlation of 0.89 between scores on the VMI and chronological age is reported.

A Continuous Performance Task (CPT) was used to measure sustained visual attention (Bourdon-Vos test for children). Standard scores can be calculated measuring speed of working and accuracy of working [60]. Test-retest reliability was computed as .87 for boys and .84 for girls [61].

Behavioral functioning was measured by using by proxy instruments like the Child Behavior Checklist (CBCL) [62,63] the Teacher's Report Form (TRF) [64,65], and the Precursors of ADHD Questionnaire (PAQ) [27,66]. The Child Behavior Checklist and Teacher's Report Form are well standardized and widely used in both clinical and research settings because of their demonstrated reliability and validity and their 
convenient applicability. The association between attention problems obtained with the $\mathrm{CBCL}$ and ADHD is higher in boys than in girls [67]. The internal consistency of the Precursors of ADHD Questionnaire (PAQ) is reported to be $0.86[27,66]$.

The selection of the above mentioned instruments might suggest a possible drawback to our studies. However, the instruments used for neuropsychological assessment were selected for three purposes: identification of the individual neuropsychological profile of the children included in the studies of this thesis, neuropsychological assessment in monitoring medication treatment, and assessment of the neurocognitive performance and behavioral functioning for both initial evaluation and for measuring changes over time. As such, neuropsychological assessment contributes in an interdisciplinary approach diagnosing neurodevelopmental disorders and supports in the process of diagnosing.

The use of neurobiological markers in measuring dopamine transporter binding by single-photon emission computed tomography (SPECT) does not have any added value for the diagnostic process of ADHD in children [28]. In our studies as described in chapter four and five of this thesis SPECT measurement of dopamine transporter was used as an indicator in monitoring the therapeutic response to medication treatment with methylphenidate. However, the question remains to what extent SPECT scans contribute to measurements in monitoring and evaluating treatment of ADHD in children. Further research is needed to reveal the value of other neuroimaging techniques: high-resolution magnetic resonance imaging (MRI) and functional magnetic resonance imaging (fMRI) scans [68,69]. Combining neuropsychological, structural and functional MRI measures will allow an evaluation of structure-function relationships in children with ADHD with and without co-morbid learning disabilities [69].

In general ADHD in children is diagnosed if clinical symptoms meet the criteria of the DSM-IV [26]. In this respect, clear evidence of clinically significant impairment in social and academic functioning is an obligate criterion of the DSM-IV. However, in the DSM-IV this criterion is not made operational in terms of measuring discrepancy between potential learning ability and acquired learning. Because of this relative shortcoming of the DSM-IV it is important to assess academic performance as an initial evaluation in diagnosing ADHD in children. In our research baseline school data on behavior and achievement scores were collected by the youth health care and the assessment of academic performance in children was primarily used as an input criterion indicating the need of medication treatment in children with ADHD. Secondarily, the level of parenting stress and the current level of the child's personal stress were used as input criteria for the indication of pharmacological treatment. If medication treatment was started, repeated scores on behavioral functioning and school achievement were used as output criteria in evaluating and monitoring the 
effect of medication treatment, completed with repeated neuropsychological assessment. 


\subsection{GENERAL CONCLUSIONS}

The current studies have clearly demonstrated the significance of a multidisciplinary approach in the early detection, diagnosis, treatment and follow-up of neurodevelopmental disorders in children. The youth health care perspective as described in the Maastricht model in relation to neurodevelopmental research in the wider context of an age dependent perspective has up to the present not been reported in literature, and as such the current studies are unique to our knowledge. Within the group of neurodevelopmental disorders, attention-deficit disorders in children have a high prevalence and as such the impact of attention-deficit disorders on learning is considerable and needs to be further elaborated. The influence of neonatal acidosis as a predictive factor for later neurodevelopmental disorders, especially ADHD, has not been confirmed in our studies.

Practical implications of the studies as described in the present thesis are:

[1] The multidisciplinary approach of the Maastricht model needs to be replicated in terms of dissemination, implementation and continuance of this new type of care in other centers. Both the report on diagnosis and treatment of ADHD of the Dutch Health Council (2000) and the Dutch Multidisciplinary Guideline on ADHD (2005) enclose references tot the Maastricht model [70,71].

[2] Further research is needed to evaluate this integrated type of diagnosis and care compared to care as usual i.e. a discipline-oriented approach consisting of miscellaneous elements, assuming that this multidisciplinary approach with a central role of the Youth Health Care will lead to a reduction of false referrals and a decreased intensity of medical interventions. Furthermore, the supposition that continuity in care will lead to a more efficient allocation of services, which is expected to lead to less costs, has to be investigated in the near future.

[3] Early detection, diagnosis, treatment and follow-up of children whose schoolcarreer is threatened by attention problems are important topics for further research. There has been a lot of non-scientific attention to attention-deficit disorders and learning problems in relation with the effect of methylphenidate. However, up to now this subject has not been studied systematically from a multidisciplinary youth health care perspective.

[4] On behalf of medication monitoring of methylphenidate, placebo-controlled studies as reported in literature are not strictly necessary. It has been shown that child neuropsychology offers adequate outcome measures to evaluate the efficacy of methylphenidate treatment. Whenever the effect of methylphenidate is not clear, imaging by single-photon emission computed tomography might contribute in monitoring and evaluating medication treatment of ADHD in children. So, both child neurology and child neuropsychology have dependent 
outcome measures available to evaluate medication treatment of ADHD in children.

[5] Long-term follow-up of children treated for ADHD problems in age dependant learning perspective is necessary, especially as quality of care is a major topic in current health care systems in the Netherlands.

[6] Youth Health Care practitioners should not focus on intrapartum acidosis as the main predictor of high risk for neurodevelopmental disorders in children. Moreover, potential risk factors in the antepartum period need more research to elucidate the influence of the multiple heterogeneous antepartum causes of neurodevelopmental disorders in children. 


\section{CHAPTER 9, APPENDIX:}

\section{Attention-Deficit/Hyperactivity Disorder: DSM-IV-TR criteria}

A.

Either

(1)

or

(2):

(1) Inattention: six (or more) of the following symptoms of inattention have persisted for at least 6 months to a degree that is maladaptive and inconsistent with developmental level:

often fails to give close attention to details or makes careless mistakes in schoolwork, work, or other activities;

often has difficulty sustaining attention in tasks or play activities;

often does not seem to listen when spoken to directly;

often does not follow through on instructions and fails to finish school work, chores, or duties in the workplace (not due to oppositional behavior or failure to understand instructions);

often has difficulty organizing tasks and activities;

often avoids, dislikes, or is reluctant to engage in tasks that require sustained mental effort (such as schoolwork or homework);

often loses things necessary for tasks or activities (e.g., toys, school assignments, pencils, books, or tools);

is often easily distracted by extraneous stimuli;

is often forgetful in daily activities.

(2) Hyperactivity-impulsivity: six (or more) of the following symptoms of hyperactivity-impulsivity have persisted for at least 6 months to a degree that is maladaptive and inconsistent with developmental level:

\section{Hyperactivity}

often fidgets with hands or feet or squirms in seat;

often leaves seat in classroom or in other situations in which remaining seated is expected;

often runs about or climbs excessively in situations in which it is inappropriate (in adolescents or adults, may be limited to subjective feelings of restlessness);

often has difficulty playing or engaging in leisure activities quietly;

is often "on the go" or often acts as if "driven by a motor"; 
often talks excessively.

Impulsivity

often blurts out answers before questions have been completed;

often has difficulty awaiting turn;

often interrupts or intrudes on others (e.g., butts into conversations or games).

B. Some hyperactive-impulsive or inattentive symptoms that caused impairment were present before age 7 years.

C. Some impairment from the symptoms is present in two or more settings (e.g., at school [or work] and at home).

D. There must be clear evidence of clinically significant impairment in social, academic, or occupational functioning.

E. The symptoms do not occur exclusively during the course of a Pervasive Developmental Disorder, Schizophrenia, or other Psychotic Disorder and are not better accounted for by another mental disorder (e.g., Mood Disorder, Anxiety Disorder, Dissociative Disorders, or a Personality Disorder).

Code based on type:

314.01 Attention-Deficit/Hyperactivity Disorder, Combined Type: if both Criteria

A1 and A2 are met for the past 6 months
314.00 Attention-Deficit/Hyperactivity Disorder, Predominantly Inattentive Type: if Criterion $A 1$ is met but Criterion $A 2$ is not met for the past 6 months 314.01 Attention-Deficit/Hyperactivity Disorder, Predominantly HyperactiveImpulsive Type: if Criterion A2 is met but Criterion A1 is not met for the past 6 months

Coding note: For individuals (especially adolescents and adults) who currently have symptoms that no longer meet full criteria, "In Partial Remission" should be specified.

Literature: American Psychiatric Association (2000). Diagnostic and Statistical Manual of Mental Disorders: fourth edition text revision (DSM-IV-TR). $4^{\text {th }}$ ed: Washington DC: American Psychiatric Association [35]. 


\section{REFERENCES:}

[1] Wildschut J, Feron FJM, Hendriksen JGM, van Hall M, Gavilanes-Jiménez DWD, Hadders-Algra M, Vles JSH. Acid-base status at birth, spontaneous motor behaviour at term and 3 months and neurodevelopmental outcome at age 4 years in full-term infants. Early Hum Dev 2005; 81: 535-544.

[2] Feron FJM, Hendriksen JGM, Kessels AGH, Gavilanes-Jiménez, Wildschut J, Vles JSH. Acid-base status at birth and neurocognitive outcome at preschool age. Submitted for publication.

[3] MacLennan A. A template for defining a causal relation between acute intrapartum events and cerebral palsy: international consensus statement (International Cerebral Palsy Task Force). BMJ 1999; 319(7216): 1054-1059.

[4] van den Berg PP, Nelen WLDM, Jongsma HW, Nijland R, Kollée LAA, Nijhuis JG, Eskes TKAB. Neonatal complications in newborns with an umbilical artery pH $<7.00$. Am J Obst Gynecol 1996; 175: 1152-1157.

[5] Goodwin TM, Belai IM, Hernandez P, Durand M, Paul RH. Asphyxial complications in the term newborn with severe umbilical acidemia. Am J Obstet Gynecol 1992; 167: 1506-1512.

[6] Carter BS, Haverkamp AD, Merenstein GB. The definition of acute perinatal asphyxia. Clin Perinatol 1993; 20: 287-304

[7] Sehdev HM, Stamilio DM, Macones GA, Graham E, Morgan MA. Predictive factors for neonatal morbidity in neonates with an umbilical arterial cord pH less than 7.00. Am J Obstet Gynecol 1997; 177: 1030-1034.

[8] Badawi N, Kurinczuk JJ, Keogh JM, Alessandri LM, O'Sullivan F, Burton PR, Pemberton PJ, Stanley FJ. Antepartum risk factors for newborn encephalopathy: the Western Australian case-control study. BMJ 1998; 317: 1549-1553.

[9] Badawi N, Kurinczuk JJ, Keogh JM, Alessandri LM, O'Sullivan F, Burton PR, Pemberton PJ, Stanley FJ. Intrapartum risk factors for newborn encephalopathy: the Western Australian case-control study. BMJ 1998; 317: 1554-1558.

[10] Bobrow CS, Soothill PW. Causes and consequences of fetal acidosis. Arch Dis Child Fetal Neonatal Ed. 1999; 80: 246-249.

[11] Becher JC, Bell JE, Keeling JW, McIntosh N, Wyatt B. The Scottish perinatal neuropathology study: clinicopathological correlation in early neonatal deaths. Arch Dis Child Fetal Neonatal Ed 2004; 89: F399-F407.

[12] Low JA. Intrapartum fetal asphyxia: Definition, diagnosis and classification. Am J Obstet Gynecol 1997; 176: 957-959.

[13] American College of Obstetricians and Gynecologists, Committee on Obstetric Practice. ACOG, Number 326, December 2005. Inappropriate use of the terms fetal distress and birth asphyxia. Obstet Gynecol 2005; 106: 1469-1470.

[14] Stokowski LA. Noteworthy professional news: Reminder to stop using terms "fetal distress" and "birth asphyxia". Advances in Neonatal Care 2005; 5: 62-63.

[15] Fahey J, King TL. Intrauterine asphyxia: clinical implications for providers of intrapartum care. J Midwifery Womens Health 2005; 50: 498-506.

[16] Dennis J, Johnson A, Mutch L, Yudkin P, Johnson P. Acid-base status at birth and neurodevelopmental outcome at four and one-half years. Am J Obstet Gynecol 1989; 161: 213-220.

[17] Hermansen MC. The acidosis paradox: asphyxial brain injury without coincident acidemia. Dev Med Child Neurol 2003; 45: 353-356.

[18] Vles JSH. Growing into deficit. Inaugural lecture [in Dutch], University of Maastricht, 2000; ISBN 90 90143947.

[19] Hadders-Algra M, Groothuis AM. Quality of movements in infancy is related to neurological dysfunction, ADHD, and aggressive behaviour. Dev Med Child Neurol 1999; 41: 381-391.

[20] Hadders-Algra M, Mavinkurve-Groothuis AM, Groen SE, Stremmelaar EF, Martijn A, Butcher PR. Quality of general movements and the development of minor neurological dysfunction at toddler and school age. Clin Rehabil 2004; 18: 287-299. 
[21] Groen SE, de Blecourt AC, Postema K, Hadders-Algra M. General movements in early infancy predict neuromotor development at 9 to 12 years of age. Dev Med Child Neurol 2005; 47: 731-738.

[22] Wassenberg R, Feron FJ, Kessels AG, Hendriksen JG, Kalff AC, Kroes M, Hurks PP, Beeren M, Jolles J, Vles JS. Relation between cognitive and motor performance in 5- to 6-year-old children: results from a large-scale cross-sectional study. Child Dev 2005; 76: 1092-1103.

[23] Kroes M, Kessels GH, Kalff AC, Feron FJM, Vissers YL, Jolles J, Vles JSH. Quality of movement as predictor of Attention Deficit/Hyperactivity Disorder: results from a prospective population study in 5and 6-year-old children. Dev Med Child Neurol. 2002 Nov; 44: 753-760.

[24] Hoffmann H. Der Struwwelpeter. First pseudonymous edition 1845: Lustige Geschichten und drollige Bilder mit 15 schön kolorirten Tafeln für Kinder von 3-6 Jahren. Fifth edition published in 1947under Hoffmann's own name. http://www.fln.vcu.edu/struwwel/struwwel.html. Accessed March 19, 2006

[25] Thome J, Jacobs KA. Attention deficit hyperactivity disorder (ADHD) in the $19^{\text {th }}$ century children's book. European Psychiatry 2004; 19: 303-306.

[26] American Psychiatric Association (2000). Diagnostic and Statistical Manual of Mental Disorders: fourth edition text revision (DSM-IV-TR). $4^{\text {th }}$ ed: Washington DC: American Psychiatric Association.

[27] Kroes M, Hendriksen JGM, Steyaert J, Kalff AC, Feron FJM, van Zeben-van der Aa TMCB, Jolles J, Troost J, Vles JSH. De Vragenlijst Voorlopers ADHD: Ontwikkeling en enkele psychometrische kenmerken [Precursors of ADHD Questionnaire: development and some psychometric features]. Kind en Adolescent, 2000; 22: 22-35.

[28] Biederman J, Faraone SV. Attention-deficit hyperactitiy disorder. Lancet 2005; 366: 237-248

[29] Barkley RA. Attention-Deficit Hyperactivity Disorder, a handbook for diagnosis and treatment. Second edition. New York: The Guilford Press, 1998.

[30] Gillberg C, Gillberg IC, Rasmussen P, Kadesjö B, Söderström H, Råstam M, Johnsons $M$, Rothenberger A, Niklasson L. Co-existing disorders in ADHD-implications for diagnosis and intervention. Eur Child Adolesc Psychiatry [Suppl 1], 2004; 13: I/80-I/92.

[31] Feron FJM, Hendriksen JGM, Vles JSH. Transmural Consultation Hour for ADHD at the Youth Health Care Department. [Article in Dutch]. Tijdschr v Jeugdgezondheidszorg 2002; 34: 46-51.

[32] Hendriksen JGM, Keulers EHH, Feron FJM, Wassenberg R, Jolles J, Vles JSH. Subtypes of learning disabilities: neuropsychological and behavioral functioning of 495 children referred for multidisciplinary assessment. Submitted for publication.

[33] Hendriksen JGM, Feron FJM, Njiokiktjien C, Vles JSH. The Effect of Clonidine and Methylphenidate in Children with Attention Deficit Disorder with Hyperactivity: a Comparison of Neuropsychological and Behavioral Effects in 37 Children. [Article in Dutch]. Tijdschr v Kindergeneeskunde 2000; 68: 94-99.

[34] Conners CK. Forty years of methylphenidate treatment in Attention-Deficit/ Hyperactivity Disorder. J Atten Disord 2002; 6 (Suppl 1): S17-30.

[35] Vles JS, Feron FJ, Hendriksen JG, Jolles J, van Kroonenburgh MJ, Weber WE. Methylphenidate downregulates the dopamine receptor and transporter system in children with attention deficit hyperkinetic disorder (ADHD). Neuropediatrics 2003; 34: 77-80.

[36] Feron FJM, Hendriksen JGM, van Kroonenburgh JPG, Blom-Coenjaerts C, Kessels AGH, Jolles J, Weber WEJ, Vles JSH. Dopamine Transporter in Attention-Deficit Hyperactivity Disorder normalizes after cessation of Methylphenidate. Pediatric Neurology 2005; 33: 179-183.

[37] Krain AL, Castellanos FX, Brain development and ADHD. Clin Psychological Review 2006; 26 : 433 444.

[38] Waldman ID, Gizer IR. The genetics of attention deficit hyperactivity disorder. Clin Psychological Review 2006; 26: 396-432.

[39] Miller SR, Miller CJ, Bloom JS, Hynd GW, Craggs JG. Right hemisphere Brain Morphology, AttentionDeficit Hyperactivity Disorder (ADHD) subtype and social comprehension. J Child Neurol 2006; 21: 139-144.

[40] Toga AW, Thompson PM, Sowell ER. Mapping brain maturation. Trends in neurosciences 2006; 29:148-159.

[41] Madras BK, Miller GM, Fischman AJ. The Dopamine Transporter and Attention-Deficit/Hyperactivity Disorder. Biol Psychiatry 2005; 57: 1397-1409.

[42] Pliszka SR. The Neuropsychopharmacology of Attention-Deficit/Hyperactivity Disorder. Biol Psychiatry 2005; 57: 1385-1390. 
[43] Smoller JW, Biederman J, Arbeitman L, Doyle AE, Fagerness J, Perlis RH, Sklar P, Faraone SV. Association Between the 5HT1B Receptor Gene (HTR1B) and the Inattentive Subtype of ADHD. Biol Psychiatry 2006; 59: 460-467.

[44] Feron FJM, Hendriksen JGM, Nicolai J, Vles JSH. Status Epilepticus in a child with CP and ADHD: a possible proconvulsant effect of Clonidine? The role of alpha-2-adrenoreceptors. Submitted.

[45] Kelsey DA, Summer CR, Casat CD, Coury DL, Quintana H, Saylor KE, Sutton VK, Gonzales J, Malcolm SK, Schuh KJ, Allen AJ. Once-daily Atomoxetine treatment for children with AttentionDeficit/Hyperactivity Disorder, including an assessment of evening and morning behavior: a doubleblind, placebo-controlled trial. Pediatrics 2004; 114: e1-e8.

[46] Kratochvil CJ, Vaughan BS, Daughton JM, Mayfield-Jorgensen ML, Burke WJ. Atomoxetine in the treatment of attention deficit hyperactivity disorder. Expert Rev Neurotherapeutics 2004; 4: 601-611.

[47] Weiss M, Tannock R, Kratochvil C, Dunn D, Velez-Borras J, Thomason C, Tamura R, Kelsey D, Stevens L, Allen AJ. A randomized, placebo-controlled study of once-daily Atomoxetine in the school setting in children with ADHD. J Am Acad Child Adolesc Pschychiatry 2005; 44: 647-655.

[48] Wilens TE, Kratochvil C, Newcorn JH, Gao H. Do children and adolescents with ADHD respond differently to Atomoxetine? J Am Acad Child Adolesc Psychiatry 2006; 45: 149-157.

[49] Hadders-Algra, M. General Movements: a window for early identification of children at high risk for developmental disorders. J Pediatr, 2004; 145: S12-S18.

[50] Hadders-Algra, M, Mavinkurve-Groothuis AM, Groen SE, Stremmelaar EF, Martijn A, Butcher PR. Quality of general movements and the development of minor neurological dysfunction at toddler and school age. Clin Rehabil 2004; 18: 287-299.

[51] Hadders-Algra, M. The neuromotor examination of the preschool child and its prognostic significance. MRDD Research Reviews, 2005; 11: 180-188.

[52] Hempel MS. The neurological examination for toddler-age. Groningen: Rijksuniversiteit Groningen; 1993 [232 p].

[53] Hempel MS. Neurological development during toddling age in normal children and children at risk of developmental disorders. Early Hum Dev 1993; 34: 47-57.

[54] Henderson SE, Sugden DA. Movement assessment battery for children; manual. London: The Psychological; 1992

[55] Smits-Engelsman BCM. Handleiding movement assessment battery for children, Nederlandse bewerking [Manual; Dutch version]. Lisse: Swets \& Zeitlinger; 1998.

[56] Bayley N. Manual for the Bayley Scales of Infant Development. San Antonio, TX: The Psychological Corporation; 1969

[57] van der Meulen BF, Smrkovsky M. Handleiding bij de Bayley Ontwikkelingsschalen BOS 2-30. [Manual]. Lisse: Swets \& Zeitlinger; 1983.

[58] Kaufman AS, Kaufman NL. Kaufman assessment battery for children. Interpretive manual. Circle Pines, Minnesota: American Guide Service; 1983.

[59] Beery KE. The Beery-Buktenica Developmental Test of Visual-motor integration (VMI). Pasipanny, New Jersey: Modern Curriculum Press; 1997.

[60] Vos PG. Bourdon-Vos test: handleiding (3de herziene uitgave)-Manual for the Bourdon-Vos test. Lisse, Netherlands: Swets en Zeitlinger; 1998.

[61] De Zeeuw J. Algemene psychodiagnostiek L-testmethoden. Lisse: Swets \& Zeitlinger; 1995

[62] Achenbach TM. Manual for the Child Behavior Checklist / 4-18 and 1991 profile. Burlington University of Vermont Department of Psychiatry, 1991.

[63] Verhulst FC, Koot JM, Van der Ende J. Handleiding voor de CBCL (Child Behavior Checklist) [Manual for the CBCL]. Afd. Kinder- en Jeugdpsychiatrie, Sophia Kinderziekenhuis / Academisch Ziekenhuis Rotterdam / Erasmus Universiteit Rotterdam, the Netherlands, 1996.

[64] Achenbach, TM (1991). Manual of the Teacher's Report Form and 1991 profile. Burlington, VT: University of Vermont, Department of Psychiatry.

[65] Verhulst FC, Van der Ende J, Koot HM. Handleiding voor de Teacher's Report Form (TRF) [Manual for the TRF]. Afd. Kinder- en Jeugdpsychiatrie, Sophia Kinderziekenhuis / Academisch Ziekenhuis Rotterdam / Erasmus Universiteit Rotterdam, the Netherlands, 1997.

[66] Hendriksen JGM, Steyaert J, Kroes M, Vles JSH. VVA: Vragenlijst Voorlopers ADHD [PAQ: Precursors of ADHD Questionnaire]. Dutch questionnaire; Manual. Leiden: PITS 2002 
[67] Derks EM, Hudziak JJ, Dolan CV, Ferdinand RF, Boomsma DI. The relations between DISC-IV DSM diagnoses of ADHD and multi-informant CBCL-AP syndrome scores. Comprehensive Psychiatry 2006; 47: $116-122$

[68] Seidman LJ, Valera EM, Makris M. Structural brain imaging of Attention-Deficit/Hyperactivity Disorder. Biol Psychiatry 2005; 57: 1263-1272

[69] Seidman LJ. Neuropsychological functioning in people with ADHD across the life-span. Clin Psychological Review 2006; 26: 466-486.

[70] Health Council of the Netherlands: Diagnosis and treatment of ADHD. Health Council of the Netherlands: The Hague, 2000; publication no. 2000/24.

[71] Multidisciplinaire richtlijn ADHD. Richtlijn voor de diagnostiek en behandeling van ADHD bij kinderen en jeugdigen. [Multidisciplinary Guideline ADHD 2005] Trimbos-instituut Utrecht, 2005. ISBN 90-5253525-6. Website: www.ggzrichtlijnen.nl 
132 CHAPTER 9 


\section{Summary}

Preventive Youth Health Care in the Netherlands has a history of more than a century. As part of the Youth Health Care system, all children living in the Netherlands receive free preventive medical assessments, from birth through adolescence. Research on neurodevelopmental issues in children in the field of the Youth Health Care is not quite common. However, research on brain-behavioral relations and neurodevelopment in children does have large potentialities using the infrastructure of Youth Health Care, especially regarding longitudinal cohort studies. In this respect it has become quite a challenge for Youth Health Care to contribute to research on neurodevelopmental issues in children, taking into account the achievements of neurosciences in the last decades. First, it is important to gain deeper understanding of the complex processes underlying normal development in children in relation with the ratio of risk-bearing factors and protective factors of the child and his environment. Secondly, research on neurodevelopmental delays or disorders in children is important in elucidating the prevalence, etiology, course and potential therapeutic interventions. Thirdly, more research on neurodevelopmental disorders is needed focused on the interference with respectively the impact on learning and social functioning of the child. Finally, research on neurodevelopmental issues in children is of great importance for the field of the Youth Health Care in attaining evidence based methods for early detection and preventive measures in case of developmental delays or disorders.

The present thesis contemplates to contribute in the knowledge on neurodevelopmental issues in children and to elucidate the added value of interdisciplinary co-operation within the context of research and care in the domain of neurodevelopmental disorders in children. Therefore, the general objective of this thesis was to emphasize the connection between neurodevelopmental research and Youth Health Care. In the context of this general intention, this thesis was focused on the following specific objectives within the domain of neurodevelopment in children: 
(1) to assess the relationship between acid-base status at birth and short-term and long-term neurodevelopmental outcome, in terms of general movements at birth respectively at age of 3 months, mental and motor development at age of 9 months respectively 18 months, and neurological, cognitive and behavioral functioning at age of 4 years;

(2) to determine effects of medication treatment in children with ADHD in terms of information processing and behavioral functioning;

(3) to monitor medication treatment in children with ADHD, focusing on the neurobiological substrate of ADHD in relation to neurodevelopmental outcome; and

(4) to indicate the practical implications of the multidimensional aspects of neurodevelopmental issues. Two studies of this thesis deal with the predictive value of acid-base status at birth on later cognitive development at pre-school age. As such it concentrates on the first four years of development and the possible role of acidosis for development of later attention problems and cognition. Subsequently, three studies are presented on the effects of medication in a group of school-aged children with ADHD. The specific aim of these three studies was to demonstrate the influence of medication on the brain mechanism of $A D H D$ respectively on learning and behavioral outcome: the neurobiological substratum of ADHD is discussed. A case study on the risks of medication for ADHD in a child with cerebral palsy is described. Finally, the multidimensional aspects of neurodevelopmental issues are discussed in an article where Youth Health Care, Child Neurology and Child Neuropsychology are brought together.

In chapter 1 the background, the general objective and the aims of the thesis are described in terms of neurodevelopment and health of children. Introductory remarks enclose a description of the preventive Youth Heath Care in the Netherlands, in particular assignment, function and working methods of Youth Health Care practice. Brain-behavior relations are supposed to be the most important theoretical frameworks in children with neurodevelopmental disorders. As such Child Neurology and Child Neuropsychology are closely allied disciplines, which are brought together with Youth Health Care in a field of action for the studies in this thesis.

Chapter 2 describes a study on the relationship between acid base status and quality and quantity of General Movements (GMs) at birth and quality of GMs at age three months and motor, cognitive and behavioral functioning at the age of four years. Quality and quantity of general movements were assessed in full-term infants at birth and at the age of three months. At the age of four years in a group of 44 children outcome on motor, cognitive and behavioral functioning was measured, with a main focus on evaluation of neuromotor behavior. In this sample of infants with a large variation in umbilical artery $\mathrm{pH}$ and without severe neonatal neurological 
abnormalities, acid-base status at birth and quality of GMs at three months of age is not predictive for motor milestone achievement, cognitive and behavioral functioning at four years, but these parameters are related to a less optimal condition of the nervous system. The latter finding has, however, limited clinical significance. The results of this study are discussed from a clinical point of view, especially with concern to the prognosis for development in children with a history of perinatal acidosis of different degree.

The aim of the study presented in chapter 3 was to further investigate the relationship between acid-base status at birth and long-term neurocognitive and behavioral outcome using an extended sample size. Based on analysis of data collected at the age of nine months, 18 months and four years, a group of 66 children was prospectively evaluated, with special reference to information processing capacities at the age of four years. In particular this study was focused on the values of initial umbilical artery $\mathrm{pH}$ and base excess as predictors of neurocognitive and behavioral outcome at early school age as well as possible gender differences. This study revealed only significant positive correlations between initial umbilical artery $\mathrm{pH}$ and mental and motor development at the age of 18 months. At the age of four years no significant correlations could be found between initial umbilical artery $\mathrm{pH}$ values and mental processing, language reasoning and visual motor integration on the age of four years. Finally no relation was found between $\mathrm{pH}$ values at birth and behavioral outcome at four years. In conclusion, acid-base status at birth in full-term infants, without clinical evidence of perinatal hypoxic-ischemic encephalopathy, is a poor predictor of long-term neurocognitive and behavioral outcome in children.

Chapter 4 reports on a prospective study on the effects of medication treatment in a group of 37 children with ADHD, comparing clonidine to methylphenidate medication. Information processing and behavioral functioning were systematically assessed before and eight weeks after medication was started. The results of medication monitoring comparing clonidine to methylphenidate showed significant different effects as well as similar effects on information processing and inhibition control in behavior. It was found that methylphenidate had significant positive effects on spatial reasoning and aggressive behavior. The difference in effect on aggressive behavior between methylphenidate and clonidine was statistically significant. Both types of medication in children with ADHD without neurological dysfunction can effectively improve information processing and inhibition control in behavior. This study also demonstrated that neuropsychological assessment is not only an important tool to establish the treatment diagnosis of ADHD, but it is also a useful instrument to objectively evaluate the effect of medication.

Chapter 5 presents a study on imaging of brain dopamine transporter and receptor activity in six boys with ADHD. Single-photon emission computed tomography 
(SPECT) was used to monitor methylphenidate treatment. Imaging by SPECT was performed before starting treatment with methylphenidate and SPECT was repeated after three months. An extensive neuropsychological assessment was also performed before and three months after treatment. The results on SPECT were studied in relation to baseline and follow-up neuropsychological findings. Three months after initiation of treatment with methylphenidate a down-regulation of the post-synaptic dopamine receptor was found with a maximum of $20 \%$ and a downregulation of the dopamine transporter with a maximum of $74.7 \%$ in the striatal system. This corresponded with a positive clinical response evaluated by neuropsychological questionnaires and tests. These findings indicated that dopamine transporter imaging by SPECT might be used to monitor psychostimulant treatment in children suffering from ADHD.

Chapter 6 deals with the potential long-term effects of chronic methylphenidate treatment. In this study, single-photon emission computed tomography (SPECT) was used to investigate possible long-term alterations in the cerebral dopamine system after cessation of treatment with methylphenidate in five children with ADHD. Three months after initiation of treatment with methylphenidate, a reduction of the dopamine transporter in the striatal system was observed. Methylphenidate was administered for a period of 9 to 20 months. Follow-up with single-photon emission computed tomography after withdrawal of methylphenidate medication showed an increase of dopamine transporter activity comparable with pretreatment values. The observed up-regulation of dopamine transporter activity might support the assumption that methylphenidate does not lead to permanent damage of the nigrostriatal dopaminergic pathways. Single-photon emission computed tomography (SPECT) was used to investigate possible long-term alterations in the cerebral dopamine system after cessation of treatment with methylphenidate in five children with ADHD.

Chapter 7 describes a case report in order to discuss the possible proconvulsant effect the role of clonidine, focusing on the role of the alpha-2-adrenoreceptors. Clonidine is used as second line medication for the treatment of attention deficit hyperactivity disorder in children. Clonidine is an imidazoline derivate and acts as an agonist on alpha-2 adrenergic receptors. Product information concerning clonidine reports seizures only after overdosage of clonidine and prescription of clonidine is up till now not contraindicated in patients with known epilepsy. Attention deficit hyperactivity disorder in 9-year-old girl with cerebral palsy was treated with clonidine. Two weeks after initializing treatment with clonidine, the girl was transferred to emergency room because of a secondarily generalized convulsive status epilepticus. Within the spectrum of pharmacological interventions for the management of ADHD in school-aged children the role of clonidine is changing. Special caution is warranted in administration of clonidine for the treatment of attention deficit hyperactivity 
disorder in children with a prior history of seizures or with electroencephalographic abnormalities in absence of seizures.

Chapter 8 reports the experiences on a transmural consultation hour for children with behavioral-neurological developmental disorders, in particular ADHD. In this project the lines between the finding place (school or family) and secondary health care are very short for case finding by the youth health care physician. Children have already been pre-examined according to a standard protocol before they are presented to secondary health care consultants at the joint consultation. In addition, the consultants can consult directly with the youth health care physician if necessary. The examination results are discussed not only directly with the parents, but the youth health care physician will always also pass on the information (with the parents' permission) to the school. This implies that the immediate consequences of the examination results for educational support at school are discussed and that tailored advice is provided. Once treatment has started, the same short lines of communication are used to include the school's experiences with the child in the evaluation. This procedure appeared to be extremely pragmatic in practice, especially due to the 'bridging function' of the youth health care physician between secondary health care and schools, and the youth health care physician's intermediate position in the health care chain both at the start and the end of secondary health care.

Finally, in Chapter 9 the findings as presented in the preceding chapters are combined and discussed. Recommendations for further research and implications on future course of action are presented in this chapter. The presented studies have clearly demonstrated the significance of an interdisciplinary approach in neurodevelopmental disorders, relating brain structure, function, neuropsychological dysfunctions, social and school functioning from an age dependent perspective. Combining assessment on neurological diagnostics (neuroimaging), neurocognitive outcome, and follow-up by Youth Health Care in children treated for ADHD, three dimensions are brought together by integrating the triad 'structure - function learning'. Youth Health Care services play a key role in the network of numerous professionals and institutions concerning early detection, referral and prompting interventions in children with developmental disorders. 


\section{Samenvatting}

De preventieve Jeugdgezondheidszorg in Nederland heeft een voorgeschiedenis van meer dan honderd jaar. Een belangrijk element in de uitvoering van de Jeugdgezondheidszorg is het programma van geneeskundige preventieve gezondheidsonderzoeken dat aangeboden wordt aan alle kinderen van 0-19 jaar in Nederland. Binnen het vakgebied van de Jeugdgezondheidszorg wordt nog maar weinig wetenschappelijk onderzoek verricht op het terrein van de ontwikkeling van het zenuwstelsel bij kinderen. Toch biedt de infrastructuur van de Jeugdgezondheidszorg ruime mogelijkheden voor wetenschappelijk onderzoek naar de relatie tussen hersenen en gedrag respectievelijk de hersenontwikkeling bij kinderen, in het bijzonder via longitudinale studies. In dit opzicht ligt er een grote uitdaging voor de Jeugdgezondheidszorg om een bijdrage te leveren aan onderzoek binnen het domein van de ontwikkeling van het zenuwstelsel bij kinderen, zeker gelet op de verworvenheden van de neurowetenschappen in de laatste decennia. Op de eerste plaats is het belangrijk om meer inzicht te krijgen in de complexe processen die ten grondslag liggen aan de normale ontwikkeling bij kinderen in relatie tot risicofactoren en protectieve factoren van het kind en zijn omgeving. Op de tweede plaats is wetenschappelijk onderzoek naar achterstanden of stoornissen in de ontwikkeling van het zenuwstelsel bij kinderen belangrijk voor aspecten als prevalentie, etiologie, verloop en mogelijke therapeutische interventies. Op de derde plaats is er meer onderzoek nodig naar ontwikkelingsstoornissen in de hersenfuncties, toegespitst op de interferentie met het leren en de sociale ontwikkeling van het kind. Ten slotte is wetenschappelijk onderzoek op het gebied van de hersenfuncties bij kinderen belangrijk voor het vakgebied van de Jeugdgezondheidszorg waar het gaat om het ontwikkelen van evidence-based methoden voor de vroegtijdige onderkenning van ontwikkelingsvertragingen of ontwikkelingsstoornissen respectievelijk het nemen van preventieve maatregelen. 
Met dit proefschrift wordt beoogd om een wetenschappelijke bijdrage te leveren binnen het domein van de ontwikkeling van het zenuwstelsel bij kinderen en daarnaast om de toegevoegde waarde van interdisciplinaire samenwerking in het kader van research en zorg te benadrukken op het gebied van hersenfunctiestoornissen bij kinderen. De algemene doelstelling van dit proefschrift was het accentueren van het belang van de koppeling tussen neurowetenschappelijk ontwikkelingsonderzoek bij kinderen en de Jeugdgezondheidszorg. Binnen de context van deze algemene intentie richt dit proefschrift zich vooral op de volgende onderwerpen in het domein van de ontwikkeling van hersenfuncties bij kinderen:

(1) onderzoek naar de relatie tussen zuur-base-evenwicht bij de geboorte en de korte en lange termijn gevolgen van de hersenfunctieontwikkeling in termen van 'general movements' bij de geboorte respectievelijk op de leeftijd van drie maanden, verstandelijke en motorische ontwikkeling op de leeftijd van negen maanden en achttien maanden en het neurologisch, cognitief en gedragsmatig functioneren op de leeftijd van vier jaar;

(2) het determineren van de effecten van medicamenteuze behandeling van kinderen met $A D H D$ in termen van informatie verwerking en gedragsmatig functioneren;

(3) het monitoren van medicamenteuze behandeling van kinderen met ADHD, gericht op het neurobiologische substraat van ADHD in relatie tot de 'outcome' op het gebied van de ontwikkeling van de hersenfuncties;

(4) het aangeven van de praktische implicaties van de meerdimensionale aspecten van vraagstukken op het gebied van de hersenfunctieontwikkeling.

Twee studies van dit proefschrift behandelen de predictieve waarde van het zuurbase-evenwicht bij de geboorte voor de latere cognitieve ontwikkeling op de voorschoolse leeftijd. Hiertoe zijn in het bijzonder de eerste vier jaar van de ontwikkeling gevolgd wat betreft de relatie tussen acidose bij de geboorte en het later ontstaan van problemen op het gebied van aandacht en cognitie. Vervolgens zijn drie studies gepresenteerd over de effecten van medicatie bij kinderen met ADHD op de basisschoolleeftijd. Deze drie studies zijn specifiek gericht op het aantonen van de invloed van medicatie op de het zenuwstelsel bij ADHD respectievelijk het meten van leerprestaties en gedrag, met een bespreking van het neurobiologische substraat van ADHD. Verder is een case-study beschreven over de risico's van medicamenteuze behandeling van ADHD bij een kind met cerebral palsy. Ten slotte volgt nog een bespreking van de meerdimensionale aspecten van de ontwikkeling van het zenuwstelsel in een artikel waarin Jeugdgezondheidszorg, Kinderneurologie en Kinderneuropsychologie worden samengebracht.

In hoofdstuk 1 wordt ingegaan op de achtergrond, de algemene doelstelling en de specifieke doelstellingen van het proefschrift in termen van hersenfunctieontwikkeling bij kinderen en hun gezondheid. De inleiding bevat een algemene beschrijving van de preventieve Jeugdgezondheidszorg in Nederland en meer in het bijzonder een 
beschrijving van taak, functie en werkwijze van de praktijk van de Jeugdgezondheidszorg. De relatie hersenen en gedrag wordt beschouwd als het meest belangrijke theoretische kader bij kinderen met stoornissen op het gebied van de hersenfunctieontwikkeling. In dit opzicht zijn Kinderneurologie en Kinderneuropsychologie nauw verwante disciplines die samengebracht zijn in één werkterrein ten behoeve van de studies in dit proefschrift.

In hoofdstuk 2 wordt een studie gepresenteerd over de relatie tussen het zuur-baseevenwicht bij de geboorte en: (a) de postnatale kwantiteit en kwaliteit van de grote lichaamsbewegingen (General Movements); (b) de kwaliteit van de grote lichaamsbewegingen op de leeftijd van drie maanden; en (c) motorisch, cognitief en gedragsmatig functioneren op de leeftijd van vier jaar.

Kwaliteit en kwantiteit van spontaan motorisch gedrag aan de hand van observatie van de grote lichaambewegingen werden bestudeerd bij à terme pasgeborenen respectievelijk op de leeftijd van drie maanden. Op de leeftijd van vier jaar werd bij een groep van 44 kinderen het motorisch, cognitief en gedragsmatig functioneren beoordeeld, met het belangrijkste accent op de evaluatie van het neuromotorische gedrag. In deze steekproef van kinderen met een brede spreiding in arteriële navelstreng-pH en zonder ernstige neonatale neurologische afwijkingen blijkt dat het zuur-base-evenwicht bij de pasgeborene en de kwaliteit van de geobserveerde spontane grote lichaamsbewegingen op de leeftijd van drie maanden, geen voorspellende waarde hebben voor het bereiken van de motorische ontwikkelingsmijlpalen respectievelijk voor het cognitieve en gedragsmatige functioneren op de leeftijd van vier jaar, maar dat deze parameters gerelateerd zijn aan een minder optimale conditie van het zenuwstelsel. Deze laatste bevinding heeft echter een beperkte klinische betekenis. De discussie over de resultaten van deze studie is geschreven vanuit een klinisch gezichtspunt met betrekking tot de ontwikkelingsprognose van kinderen met een voorgeschiedenis van verschillende graden van perinatale acidose.

Het doel van de studie in hoofdstuk 3 was om aan de hand van een grotere steekproef de relatie tussen zuur-base-evenwicht bij de pasgeborene verder te bestuderen in relatie tot de beoordeling van het neurocognitieve en gedragsmatig functioneren op de lange termijn. Aan de hand van analyse van data die verzameld zijn op de leeftijd van negen maanden, achttien maanden en vier jaar, werd een groep van 66 kinderen prospectief geëvalueerd, in het bijzonder wat betreft het niveau van informatieverwerking op de leeftijd van vier jaar. Deze studie was speciaal gericht op de waarden van initiële arteriële navelstreng-pH en base excess als voorspellende factoren van neurocognitief en gedragsmatig niveau van functioneren op de vroege schoolgaande leeftijd respectievelijk mogelijke verschillen tussen jongens en meisjes in dit verband. Deze studie leverde alleen significante 
positieve correlaties tussen initiële arteriële navelstreng-pH en de verstandelijke en motorische ontwikkeling op de leeftijd van 18 maanden. Op de leeftijd van vier jaar werden geen significante correlaties gevonden tussen initiële arteriële navelstreng$\mathrm{pH}$ en respectievelijk informatieverwerking, redeneren met taal en visuomotorische integratie. Ten slotte werd er ook geen relatie gevonden tussen de waarden van de arteriële navelstreng-pH bij de pasgeborene en het gedragsmatig functioneren op de leeftijd van vier jaar. Concluderend kan worden gesteld dat het zuur-base-evenwicht bij de à terme pasgeborene, zonder klinische verschijnselen van hypoxischischemische encefalopathie, een slechte voorspeller is van het niveau van neurocognitief en gedragsmatig functioneren.

Hoofdstuk 4 beschrijft een prospectieve studie over de effecten van medicamenteuze behandeling van 37 kinderen met ADHD, waarbij clonidine vergeleken werd met methylfenidaat. Het niveau van informatieverwerking en gedragsmatig functioneren werden systematisch onderzocht vóór aanvang van de medicamenteuze behandeling en na acht weken medicatiegebruik. De bij medicatiemonitoring gevonden effecten van clonidine respectievelijk methylfenidaat gaven zowel significant verschillende als vergelijkbare effecten op informatieverwerking en controle van gedragsinhibitie. Methylfenidaat en clonidine lieten beide een significant positief effect zien op volgehouden aandacht, aspecten van informatieverwerking en hyperactief gedrag. Alleen voor methylfenidaat werd een significant positief effect gevonden op ruimtelijk denken en agressief gedrag. Het verschil in effect op agressief gedrag tussen beide vormen van medicatie was statistisch significant. Geconcludeerd werd dat beide vormen van medicatie voor kinderen met ADHD zonder neurologische afwijkingen effectief kunnen zijn voor informatieverwerking en inhibitiecontrole van gedrag. Neuropsychologisch onderzoek is niet alleen een belangrijk instrument voor het opstellen van de behandeldiagnose $A D H D$, maar bovendien een objectief middel voor effectevaluatie van medicatie.

In hoofdstuk 5 wordt een studie beschreven over beeldvorming van de dopamine transporter en receptor activiteit in het brein bij zes jongens met ADHD. Singlephoton emission computed tomography (SPECT) werd gebruikt om behandeling met methylfenidaat te monitoren. Beeldvorming met SPECT werd uitgevoerd voordat met methylfenidaat als medicatie werd gestart en herhaald na drie maanden. Tevens werd uitgebreid neuropsychologisch onderzoek verricht voor de start met methylfenidaat en drie maanden later. De resultaten van de SPECT werden bestudeerd in relatie tot de uitgangswaarden en neuropsychologische bevindingen bij follow-up. Drie maanden na het starten van de behandeling met methylfenidaat werd in het striatum een down-regulatie van de postsynaptische dopamine receptor gevonden met een maximum van $20 \%$ en een down-regulatie van de dopamine transporter met een maximum van $74,7 \%$. Deze resultaten kwamen overeen met een positieve klinische respons zoals bepaald aan de hand van neuropsychologische 
vragenlijsten en testen. Verder zijn deze bevindingen indicatief voor de mogelijkheid om imaging van de dopamine transporter met behulp van SPECT te gebruiken voor het monitoren van kinderen met ADHD die behandeld worden met psychostimulantia.

Hoofdstuk 6 gaat in op de potentiële lange termijn effecten van chronische behandeling met methylfenidaat. In deze studie werd aan de hand van single-photon emission computed tomography (SPECT) nagegaan wat de mogelijke veranderingen op langere termijn zijn in het dopaminerge systeem in de hersenen na stoppen met de behandeling met methylfenidaat bij vijf kinderen met ADHD. Drie maanden na de start van de behandeling met methylfenidaat werd de down-regulatie van de dopamine transporter in het striatum onderzocht. Methylfenidaat was toegediend gedurende een periode tussen 9 en 20 maanden. Bij follow-up met single-photon emission computed tomography na het stopzetten van methylfenidaat, werd een toename van de dopamine transporter activiteit gevonden vergelijkbaar met de uitgangswaarden voordat de medicamenteuze behandeling werd gestart. De waargenomen up-regulatie van de dopamine transporter activiteit zou de veronderstelling kunnen bevestigen dat methylfenidaat niet leidt tot blijvende schade aan de nigrostriatale dopaminerge neurale banen.

In hoofdstuk 7 wordt aan de hand van een case-study het mogelijke proconvulsieve effect van clonidine besproken, met het accent op de rol van de alfa-2adrenoreceptoren. Clonidine wordt voorgeschreven als middel van tweede keuze bij de behandeling van ADHD. Clonidine is een imidazoline derivaat en werkt als een agonist op de alfa-2 adrenerge receptoren. De productinformatie over clonidine vermeldt alleen epilepsie als complicatie na overdosering en het voorschrijven van clonidine is tot nu toe niet gecontraïndiceerd bij patiënten bekend met epilepsie. Bij een 9-jarig meisje met cerebral palsy werd ADHD behandeld met clonidine. Twee weken na start met de clonidine medicatie werd het meisje overgebracht naar de spoedeisende eerste hulp vanwege een secundair gegeneraliseerde convulsieve status epilepticus. De rol van clonidine in het spectrum van farmacotherapeutische interventies bij de behandeling van ADHD bij kinderen wijzigt. Voorzichtigheid is in het bijzonder gerechtvaardigd bij toediening van clonidine in het kader van behandeling van ADHD bij kinderen met een epilepsie of EEG-afwijkingen zonder epilepsie in de voorgeschiedenis.

In hoofdstuk 8 wordt gerapporteerd over de ervaringen met een transmuraal spreekuur voor kinderen met gedragsneurologische ontwikkelingsstoornissen, in het bijzonder ADHD. In dit project zorgt case-finding door de jeugdarts voor heel korte lijnen tussen de vindplaats (school of gezin) en de tweedelijns. Kinderen werden op het gemeenschappelijk spreekuur voorgesteld aan de tweedelijns specialisten nadat vooronderzoek had plaatsgevonden volgens een standaard protocol. Bovendien konden de tweedelijns consulenten tijdens het gemeenschappelijk spreekuur 
desgewenst direct overleg hebben met de jeugdarts. De bevindingen van onderzoek werden vervolgens niet alleen in een direct contact met de ouders besproken, maar via de jeugdarts vond standaard ook een terugkoppeling naar de school plaats (met toestemming van de ouders), waarbij de directe consequenties van de bevindingen van onderzoek voor de pedagogisch-didactische begeleiding op school werden besproken en advisering "op maat" plaatsvond. Wanneer behandeling eenmaal was ingesteld, werden via dezelfde korte lijnen ook de ervaringen met het kind op school in de evaluaties meegenomen. Deze werkwijze bleek in de praktijk uitermate pragmatisch te zijn, vooral door de "brugfunctie" van de jeugdarts tussen tweede lijn en de school en door de plaats van de jeugdarts in de zorgketen: zowel het functionele voorportaal als het achterportaal van de tweedelijns zorg.

Het afsluitende hoofdstuk 9 is een inhoudelijke beschouwing van de samenhang tussen de bevindingen in de voorgaande hoofdstukken. Verder worden in dit hoofdstuk aanbevelingen gedaan voor verder onderzoek en de implicaties voor toekomstig beleid besproken. De beschreven studies tonen duidelijk het belang aan van een interdisciplinaire benadering bij ontwikkelingsstoornissen van het zenuwstelsel, waarbij op breinniveau een relatie gelegd wordt tussen structuur, functie, neuropsychologische disfuncties, sociaal functioneren en leren vanuit een leeftijdsafhankelijk perspectief. Door de samenhang tussen neurologische diagnostiek (inclusief neuroimaging), neurocognitief onderzoek, en sociaalgeneeskundige follow-up bij kinderen die behandeld werden voor ADHD, zijn drie dimensies bijeen gebracht door het integreren van de triade "structuur - functie leren". De Jeugdgezondheidszorg speelt een sleutelrol in het netwerk van een groot aantal professionals en instellingen die zich bezig houden met vroegtijdig onderkennen, verwijzen en behandelen van kinderen met ontwikkelingsstoornissen. 


\section{Dankwoord}

"Finis coronat opus, parvum non parvae amicitiae pignus": het einde kroont het werk, een klein bewijs van een niet geringe vriendschap. Een hechte vriendschap, voortgekomen uit een collegiale samenwerking, waarbij bevlogenheid en betrokkenheid centraal stonden, vormde de basisconditie om dit proefschrift te kunnen realiseren. In het bijzonder de support van mijn goede vrienden en collega's maakte het voor mij haalbaar om te promoveren, vanwege een context waarin mijn promotietraject doorlopen moest worden naast een drukke fulltime baan. Met voldoening kijk ik terug op de afgelopen jaren die voor mij bijzonder leerzaam waren en gaarne richt ik mijn welgemeende woorden van dank en waardering tot degenen die direct of indirect hebben bijgedragen aan de totstandkoming van dit proefschrift.

Prof. Dr. Vles, beste Hans, als promotor heb jij prachtige kansen voor mij gecreëerd en ik ben je dan ook zeer veel dank hiervoor verschuldigd. Mijn erkentelijkheid geldt ook je bevlogen inzet, de bijzondere manier waarop je mijn promotietraject wetenschappelijk hebt begeleid en de onvoorwaardelijke steun die ik van je heb mogen ervaren. Je expertise op het gebied van de kinderneurologie en de hoge mate van professionaliteit waarmee jij inhoudelijk invulling geeft aan je vak hebben diepe indruk op mij gemaakt. Dank ook voor je beschikbaarheid, voornamelijk in avonduren en weekenden: de warme gastvrijheid van jou en je gezin maakten het altijd weer een genoegen om in huize Vles te vertoeven. Mijn waardering en respect voor jou zijn groot en ik beschouw het als een voorrecht om jou als vriend te hebben. Immers, goede vrienden zijn familieleden zonder bloedverwantschap.

Dr. Hendriksen, beste Jos, de wijze waarop jij de rol van co-promotor hebt ingevuld, is in diverse opzichten bijzonder. De combinatie van je enthousiasme voor de wetenschap en je grote deskundigheid op het gebied van de neuropsychologie van het kind was voor mij een bron van inspiratie. Je betrokkenheid bij het realiseren van mijn proefschrift was groot en je gaf me daarbij het gevoel dat je continu bereikbaar en beschikbaar was voor advies en begeleiding, mede door het feit dat je structureel oproepsein, semafoon én mobiele telefoon op zak had. Met plezier kijk ik terug op onze samenwerking, waarin jij blijk gaf van gedrevenheid en inzet, ook al ging dat vaak ten koste van je eigen vrije tijd. De vanzelfsprekendheid waarmee jij me gesteund hebt, kenmerkt onze hechte vriendschap. Heel veel dank voor alles. 
Prof. Dr. Troost, beste Jaap, als emeritus hoogleraar klinische neurologie bleef jij warme interesse houden voor de ontwikkelingen binnen de kinderneurologie, het vakgebied dat jij zo vaak benoemde als je "oude liefde". Het gezegde "oude liefde roest niet" ligt mijns inziens dan ook ten grondslag aan de constatering dat jij geen enkele van onze ontmoetingen voorbij liet gaan zonder met oprechte belangstelling te informeren naar de lopende onderzoekstrajecten in het algemeen en de vorderingen van mijn proefschrift in het bijzonder. Daarom beschouw ik het als een eer dat jij de bereidheid had om op te treden als voorzitter van de beoordelingscommissie van mijn manuscript. Gaarne wil ik ook dankzeggen aan de overige leden van de beoordelingscommissie, Prof. Dr. Aldenkamp, Prof. Dr. Korebrits, Prof. Dr. Swaab-Barneveld en Prof. Dr. Zimmermann.

Een speciaal woord van dank gaat uit naar alle kinderen en hun ouders die het mogelijk hebben gemaakt voor onze onderzoeksgroep om de gewenste data te verzamelen en tot onderzoeksresultaten te komen. Zonder hun medewerking zou het onmogelijk geweest zijn om de gepresenteerde studies te realiseren en ik ben al die ouders en kinderen daar zeer erkentelijk voor.

Prof. Dr. Jolles, beste Jelle, binnen de context van de vigerende jarenlange samenwerking op het gebied van neurowetenschappelijk onderzoek was het vanzelfsprekend dat jij mijn tweede promotor zou zijn. Jouw persoonlijke website geeft een indrukwekkend overzicht van al je wetenschappelijke verdiensten en toont tevens dat ik als $51^{\mathrm{e}}$ promovendus mocht aansluiten in de reeks dissertaties die onder jouw promotorschap succesvol zijn afgerond. Dank voor het in mij gestelde vertrouwen.

Fons Kessels, een groot aantal publicaties en proefschriften is tot stand gekomen met de inbreng van jouw expertise op het gebied van de klinische statistiek en methodologie. Zelf behoor ik ook tot degenen die het genoegen hadden om met jou samen te werken. Veel dank voor de degelijkheid en betrouwbaarheid die zo basaal aanwezig waren in je adviezen, afgewisseld met subtiele humor, bijvoorbeeld je Daltonse vergelijking.

De studies als beschreven in dit proefschrift zijn tot stand gekomen dankzij de medewerking van Prof. Dr. Marinus van Kroonenburgh, Dr. Wim Weber, Dr. Mariëtte van Hall, Janny Wildschut, Dr. Danilo Gavilanes, Prof. Dr. Mijna Hadders-Algra, Drs. Joost Nicolai, Dr. Charles Njiokiktjien en Ciska Blom-Coenjaerts. Mijn welgemeende dank voor jullie bijdragen.

In de afgelopen jaren heb ik in een prettige sfeer mogen samenwerken met een aantal jonge onderzoekers. Een aantal van hen wil ik graag hier noemen uit dank 
voor die samenwerking en het vertrouwen dat ik heb mogen ervaren: Dr. Mariëlle Kroes, Dr. Ariane Tjeenk-Kalff, Dr. Petra Hurks, Femke Dings, Renske Wassenberg en Esther Keulers.

Desiree Serpenti-Breuer, een beroep doen op jouw secretariële ondersteuning was nooit tevergeefs en mijn contacten met jou in dat verband waren altijd uiterst plezierig. Graag wil ik je op deze plaats hartelijk danken voor je inzet.

Beste collega's van "mijn" afdeling Jeugdgezondheidszorg in Maastricht, het collectieve vertrouwen en de fantastische loyaliteit die ik door de jaren heen van jullie heb mogen ervaren, waardeer ik enorm. Het was voor mij een voorrecht om zoveel jaren jullie afdelingsleider te mogen zijn. Daarom een oprecht woord van dank voor jullie allemaal: collegae jeugdartsen, jeugdverpleegkundigen, GVO-ers, logopedisten, doktersassistenten en administratief medewerker van onze afdeling. Ook voor de Jeugdgezondheidszorg geldt: "in het verleden behaalde resultaten bieden geen garantie voor de toekomst". Toch wil ik hier het gedenkwaardige feit benoemen van jullie verdienste om in 2003 als beste JGZ van Nederland te scoren in het GGDonderzoek van de Inspectie voor de Gezondheidszorg. Daarmee hebben jullie bewezen wat de kracht is van zelfsturende teams in onze organisatie. Marion, kompleminte veur al dien höllep um in benkelikke drökde alle werrek op tied aof te kriege.

Aan mijn ouders heb ik heel veel te danken omdat zij natuurtalenten waren: opvoeden deden mijn ouders heel basaal, gewoon vanuit hun hart. Mijn vader heeft de mijlpaal van mijn promotie helaas niet meer mogen meemaken. Daarom speciaal voor mijn moeder: dank je wel mam, samen met pa heb je mij fantastische jeugdjaren bezorgd en optimale ontwikkelingsmogelijkheden gecreëerd.

Erik en Martijn, het was voor mij een fantastische ervaring om als vader jullie groei naar volwassenheid en zelfstandigheid mee te maken. Al op jonge leeftijd bleek jullie grote belangstelling voor techniek. Een uit de hand gelopen automotive hobby en jullie studie Mechanical Engineering aan de TU/e maakten de "bèta-invloeden" binnen ons gezin nadrukkelijk merkbaar. Opmerkelijk dat jullie beiden dezelfde afstudeerrichting hebben gekozen: Computational and Experimental Mechanics. Met veel plezier denk ik terug aan al onze interessante discussies, waarbij ik dankzij jullie op inspirerende wijze kennis kon maken met de boeiende wereld van de technologie. Blijkbaar hebben jullie ook iets van mij geleerd, gelet op jullie voornemen om jullie eigen promotie niet uit te stellen tot na je vijftigste. Tijdens mijn promotie treden jullie op als mijn paranimfen, een blijk van de bijzonder fijne band die we samen hebben. Als tegenprestatie ben ik gaarne bereid om te zijner tijd te opponeren bij gelegenheid van jullie promotie. 
Jolien, als ik de unieke band die ik met jou voel in één woord zou moeten weergeven, dan kies ik voor "harmonisch", niet toevallig een woord dat ook in de muziekterminologie wordt gebruikt. Muziek is onze gemeenschappelijke passie, muziek is het dagelijkse genoegen om jouw vioolspel te begeleiden tijdens ons vaste muziekuurtje, muziek is onze manier van communiceren zonder woorden, muziek is ons alles. "Harmonisch" is ook kenmerkend voor jouw aard, jouw persoonlijkheid en misschien is de harmonie tussen ons tweeën ook de basis geweest voor jouw buitengewone interesse voor mijn vakgebied. Fantastisch voor jou (en voor mij!) dat je aan de UM kon starten met je studie geneeskunde.

Lieve Josien, alles wat ik aan jou te danken heb, is eigenlijk niet in woorden uit te drukken. Al meer dan 30 jaar ben jij mijn trouwe maatje in voor- en tegenspoed. Je hebt mij altijd maximale ruimte gegeven om optimaal te kunnen functioneren in mijn werk en je steun daarbij was onvoorwaardelijk. De warme, gezellige sfeer bij ons thuis is te danken aan jouw zorgzaamheid en aan jouw intrinsieke kracht als spil van ons gezin. Onze kinderen dragen jou op handen, onze zonen doen dat soms zelfs letterlijk door huis en tuin. Dank voor je steun en begrip in moeilijke tijden. Mijn proefschrift draag ik op aan jou en onze kinderen.

"Labor omnia vincit improbus" (Vergilius). 


\section{Curriculum Vitae}

Frans J.M. Feron werd geboren op 3 augustus 1953 in het Zuid-Limburgse dorpje Ulestraten. In 1972 behaalde hij het einddiploma Gymnasium- $\beta$ aan het toenmalige Henric van Veldeke College te Maastricht. Vervolgens studeerde hij Geneeskunde aan de Katholieke Universiteit van Nijmegen, alwaar hij in 1980 zijn artsexamen behaalde. Sinds 1 september 1980 is hij werkzaam in de Jeugdgezondheidszorg voor kinderen en jeugdigen vanaf 4 jaar, gecombineerd met forensisch geneeskundige taken, bij de GGD in Maastricht. Van 1981 tot 1984 was hij op basis van detachering eveneens werkzaam in de Jeugdgezondheidszorg voor kinderen van 0-4 jaar bij een consultatiebureau in Maastricht. Zijn postacademische opleiding tot Sociaal Geneeskundige volgde hij aan het Instituut voor Sociale Geneeskunde van de Katholieke Universiteit in Nijmegen en hij verkreeg zijn registratie als Sociaal Geneeskundige op 22 november 1984. In 1983 werd hij benoemd tot Vertrouwensarts inzake Kindermishandeling voor de provincie Limburg en deze functie heeft hij tot 1996 vervuld op basis van detachering bij het toenmalige Bureau Vertrouwensarts te Maastricht. Van februari 1987 tot juli 2006 was hij naast zijn werkzaamheden als uitvoerend jeugdarts tevens hoofd van de afdeling Jeugdgezondheidszorg. Door de combinatie van uitvoering van zorg en afdelingsmanagement kreeg hij de mogelijkheid om de samenwerking met het Academisch Ziekenhuis Maastricht, de Universiteit Maastricht en Franciscusoord te intensiveren op het gebied van zorg, onderwijs en onderzoek. Van 1994 tot 1998 participeerde hij in het door Prof. Vles geïnitieerde ADHD-team Zuid-Limburg en vanaf 1998 was hij namens de Jeugdgezondheidszorg teamlid van het transmuraal ADHD-spreekuur. Toen het transmuraal gemeenschappelijk spreekuur in 2002 werd geïntegreerd in de Poli Leerstoornissen van het azM, zette hij deze werkzaamheden voort bij de kinderneurologie. Op het gebied van onderwijs verrichtte hij vanaf het curriculumjaar 1982/1983 activiteiten als gastdocent bij de faculteit der Geneeskunde van de Universiteit Maastricht. Zijn onderwijsactiviteiten kregen vanaf 1996 een structurele inbedding in het curriculum Geneeskunde, met als speciaal aandachtsgebied de Sociale Geneeskunde, in het bijzonder de Jeugdgezondheidszorg en Kindermishandeling. Op het gebied van wetenschappelijk onderzoek leverde hij, met de infrastructuur van zijn afdeling Jeugdgezondheidszorg als basis, een substantiële bijdrage aan 14 promotietrajecten, waarvan inmiddels 9 promoties succesvol zijn afgerond. Frans Feron is getrouwd met Josien Roosen en vader van drie kinderen: Erik (1981), Martijn (1983) en Jolien (1987). 


\section{List of publications}




\section{PRESENT THESIS}

\section{Chapter 2:}

Wildschut J, Feron FJM, Hendriksen JGM, van Hall M, Gavilanes-Jiminez DWD, Hadders-Algra M, Vles JSH. Acid-base status at birth, spontaneous motor behaviour at term and 3 months and neurodevelopmental outcome at age 4 years in full-term infants. Early Human Development 2005; 81 (6): 535-544.

\section{Chapter 3:}

Feron FJM, Hendriksen JGM, Kessels AGH, AWD Gavilanes, Wildschut J, Vles JSH. Acid-base status at birth and neurocognitive outcome at preschool age. Pediatric Neurology, under revision.

\section{Chapter 4:}

Hendriksen JGM, Feron FJM, Njiokiktjien C, Vles JSH. Het effect van clonidine en methylfenidaat bij kinderen met een aandachtstekortstoornis en hyperactiviteit. [The effect of Clonidine and Methylphenidate in children with Attention Deficit Hyperactivity Disorder: a comparison of neuropsychological and behavioral effects in 37 children]. Tijdschrift voor Kindergeneeskunde 2000; 68: 94-99.

\section{Chapter 5:}

Vles JSH, Feron FJM, Hendriksen JGM, Jolles J, van Kroonenburgh MJPG, Weber WEJ. Methylphenidate down-regulates the dopamine receptor and transporter system in children with Attention Deficit Hyperkinetic Disorder (ADHD). Neuropediatrics 2003; 34 (2): 77-80.

\section{Chapter 6:}

Feron FJM, Hendriksen JGM, van Kroonenburgh JPG, Blom-Coenjaerts C, Kessels AGH, Jolles J, Weber WEJ, Vles JSH. Dopamine Transporter in Attention-Deficit Hyperactivity Disorder normalizes after cessation of Methylphenidate. Pediatric Neurology 2005; 33 (3): 179-183.

\section{Chapter 7:}

Feron FJM, Hendriksen JGM, Nicolai J, Vles JSH. Status Epilepticus in a child with Cerebral Palsy and ADHD: a possible proconvulsant effect of Clonidine? Neuropediatrics, under revision.

\section{Chapter 8:}

Feron FJM, Hendriksen JGM, Vles JSH, Transmuraal ADHD-spreekuur jeugdgezondheidszorg - een samenwerkingsmodel in de regio Zuidelijk ZuidLimburg. [Transmural Consultation Hour for $\mathrm{AHDH}$ at the Youth Health Care Department]. Tijdschrift voor Jeugdgezondheidszorg 2002; 34 nr. 3: 46-51 


\section{PUBLICATIONS OUTSIDE THIS THESIS}

Kroes M, Hendriksen JGM, Steyaert J, Kalff AC, Feron FJM, van Zeben-van der Aa TMCB, Jolles J, Troost J, Vles JSH. De Vragenlijst Voorlopers ADHD: Ontwikkeling en enkele psychometrische kenmerken [Precursors of ADHD questionnaire: development and some psychometric features]. Kind en Adolescent 2000; 22: 22-35.

Bandell-Hoekstra IE, Abu-Saad HH, PasschierJ, Frederiks CM, Feron FJM, Knipschild P. Prevalence and characteristics of headache in Dutch schoolchildren. Eur J Pain 2001; 5(2): 145-153.

Kalff AC, Kroes M, Vles JSH, Bosma H, Feron FJM, Hendriksen JGM, Steyaert J, van Zeben TM, Crolla IF, Jolles J. Factors affecting the relation between parental education as well as occupation and problem behaviour in Dutch 5- to 6-year-old children. Soc Psychiatry and Psychiatric Epidemiology 2001; 36 (7): 324-331.

Kroes M, Kalff AC, Steyaert J, Kessels AGH, Feron FJM, v.Someren AJWGM, Hurks PPM, Hendriksen JGM, v.Zeben TM, Rozendaal N, Crolla IF, Troost J, Jolles J, Vles JSH. Child psychiatric diagnoses in a population of Dutch school children aged 6 to 8 years. J Am Acad Child Adolesc Psychiatry 2001; 40 (12): 1401-1409.

Kalff AC, Kroes M, Vles JSH, Hendriksen JGM, Feron FJM, Steyaert J, Zeben, TMCB van, Jolles J, Os J van. Neighbourhood level and individual level SES effects on child problem behaviour: a multilevel analysis. J Epidemiol Community Health. 2001; 55 (4): 246-250.

Bandell-Hoekstra IE, Abu-Saad HH, Passchier J, Frederiks CM, Feron FJM, Knipschild P. Coping en Quality of Life in relation to headache in Dutch schoolchildren. Eur J Pain 2002; 6(4) : 315-321.

Kroes M, Kessels GH, Kalff AC, Feron FJM, Vissers YL, Jolles J, Vles JSH. Quality of movement as predictor of Attention Deficit/Hyperactivity Disorder: results from a prospective population study in 5-and 6-year-old children. Dev Med Child Neurol 2002; 44(11): 753-760.

Kroes M, Kalff AC, Steyaert J, Kessels AGH, Feron FJM, Hendriksen JGM, van Zeben TMCB, Jolles J, Troost J, Vles JSH. A longitudinal community study: do psychosocial risk factors and $\mathrm{CBCL}$ scores at 5 years of age predict psychiatric diagnoses at a later age? J Am Acad Child Adolesc Psychiatry 2002; 41(8): 955-963.

Kalff AC, Hendriksen JGM, Kroes M, Vles JSH, Steyaert J, Feron FJM, van Zeben TMCB, Jolles J. Neurocognitive performance of 5- and 6-year-old children who met 
criteria for attention deficit/hyperactivity disorder at 18 months follow-up: results from a prospective population study. Journal of Abnorm Child Psychol 2002; 30(6): 589598.

Drukker M, Kaplan CD, Feron FJM, van Os J, Children's health-related quality of life, neighbourhood socio-economic deprivation and social capital. A contextual analysis. Social Science and Medicine 2003; 57(5): 825-841.

Kalff AC, de Sonneville LMJ, Hurks PPM, Hendriksen JGM, Kroes M, Feron FJM, Steyaert J, van Zeben TMCB, Vles JSH, Jolles J. Low- and high-level controlled processing in executive motor control tasks in 5-6-year-old children at risk of ADHD. J Child Psychol Psychiatry 2003; 44(7): 1049-1057.

Drukker M, Gunther N, Feron FJM, van Os J. Social Capital and mental health v. objective measures of health in the Netherlands. Br J Psychiatry 2003; 183: 174.

Gunther N, Slavenburg B, Feron F, van Os J. Childhood social and early developmental factors associated with mental health service use. Soc Psychiatry and Psychiatric Epidemiology 2003; 38 (3): 101-108.

van der Linden J, Drukker M, Gunther N, Feron F, van Os J. Children's mental health use, neighbourhood socioeconomic deprivation and social capital. Soc Psychiatry and Psychiatric Epidemiology 2003; 38(9): 507-514.

Hurks PP, Hendriksen JG, Vles JS, Kalff AC, Feron FJM, Kroes M, Van Zeben TM, Steyaert $\mathrm{J}$, Jolles $\mathrm{J}$. Verbal fluency over time as a measure of automatic and controlled processing in children with ADHD. Brain \& Cognition 2004; 55(3): 535-544.

Kroes M, Vissers Y, Sleijpen FA, Feron FJM, Kessels AG, Bakker E, Kalff AC, Hendriksen JG, Troost J, Jolles J, Vles JS. Reliability and validity of a qualitative and quantitative motor test for 5-to 6-year-old children. Eur J Paediatr Neurol 2004; 8(3): 135-143.

Drukker M, Feron FJM, van Os J. Income inequality at neighbourhood level and quality of life - a contextual analysis. Soc Psychiatry Psychiatr Epidemiol 2004; 39(6): 457-463.

Hurks PP, Adam JJ, Hendriksen JG, Vles JS, Feron FJM, Kalff AC, Kroes M, Steyaert J, Crolla IF, van Zeben TM, Jolles J. Controlled visuomotor preparation deficits in attention-deficit/hyperactivity disorder. Neuropsychology 2005; 19(1): 6676. 
Kalff AC, de Sonneville LMJ, Hurks PPM, Hendriksen JGM, Kroes M, Feron FJM, Steyaert J, van Zeben TMCB, Vles JSH, Jolles J. Speed, speed variability, and accuracy of information processing in 5 to 6 -year-old children at risk of ADHD. J Int Neuropsychol Soc 2005; 11(2): 173-183.

Leurs MTW, Mur-Veeman IM, Schaalma HP, Feron FJM, Vries NK de. Integrale ketenzorg biedt mogelijkheden om de zorgkracht in het onderwijs te versterken. Tijdschrift voor Jeugdgezondheidszorg 2005; 37(4): 77-82.

Gunther N, Drukker M, Feron F, Korebrits A, van Os J. The combination of shared family environment and individual-specific developmental deviance as a cause for treated psychiatric morbidity in children. Acta Psychiatrica Scandinavica 2005; 112: 376-384.

Wassenberg R, Feron FJM, Kessels AGH, Hendriksen JGM, Kalff AC, Kroes M, Hurks PPM, Beeren M, Jolles J, Vles JSH. Relation between cognitive and motor performance in 5- to 6-year-old children: results from a large-scale cross-sectional study. Child Dev 2005; 76 (5): 1092-1103.

Gunther N, Drukker M, Feron F, van Os J. Association of mental health problems in childhood with prenatal and postnatal physical growth. European Psychiatry 2005; 20: 277-286.

Schneiders J, Nicolson NA, Berkhof J, Feron FJ, van Os J, and deVries MW. Mood reactivity to daily negative events in early adolescence: relationship to risk for psychopathology. Developmental Psychology 2006; 42(3): 543-554

Lataster T, van Os J, Drukker M, Henquet C, Feron F, Gunther N, Myin-Germeys I. Childhood victimisation and developmental expression of non-clinical delusional ideation and hallucinatory experiences: Victimisation and non-clinical psychotic experiences. Soc Psychiatry Psychiatr Epidemiol 2006; 41(6): 423-428.

Drukker M, Kaplan CD, Schneiders J, Feron FJM, and van Os J. The wider social environment and changes in self-reported quality of life in the transition from late childhood to early adolescence: a cohort study. BMC Public Health. 2006; 6:133.

Hurks PP, Vles JS, Hendriksen JG, Kalff AC, Feron FJ, Kroes M, van Zeben TM, Steyaert J, Jolles J. Semantic category fluency versus initial letter fluency over 60 seconds as a measure of automatic and controlled processing in healthy school-aged children. J Clin Exp Neuropsychol 2006; 28(5): 684-695. 
de Haen M, Spigt MG, van Uden CJ, van Neer P, Feron FJ, Knottnerus JA. Efficacy of duct tape vs placebo in the treatment of verruca vulgaris (warts) in primary school children. Arch Pediatr Adolesc Med 2006; 160(11): 1121-1125.

Kroes M, Vles JSH, Feron FJM, Sleijpen FAM. De Maastrichtse Motoriek Test. Tijdschrift Kinderfysiotherapie 2006. Article in press.

Thush C, Wiers RW, Theunissen N, Van den Bosch J, Opdenacker J, van Empelen $P$, Moerbeek M, Feron FJM. A randomized clinical trial of a targeted intervention to moderate alcohol use and alcohol- related problems in adolescents at risk for alcoholism. Pharmacology, Biochemistry \& Behavior special issue on Adolescence: Alcohol, Drugs \& Mental Disorders. Submitted for publication.

Schneiders J, Nicolson NA, Berkhof J, Feron FJ, deVries MW, van Os J. Mood in Daily Contexts: Relationship to Risk in Early Adolescence. Journal of Research on Adolescence. Under revision.

Schneiders J, Nicolson NA, Berkhof J, Sulon J, Feron FJ, van Os J, and deVries MW. Salivary cortisol secretion in relation to daily experience in early adolescence. Child Development. Submitted for publication.

Hurks PPM, Hendriksen JGM, Kalff AC, Feron FJM, Vles JSH, van Zeben TMCB, Steyaert $\mathrm{J}$, Kroes $\mathrm{M}$, Jolles $\mathrm{J}$. A three year longitudinal follow-up on the cognitive performance of children with ADHD: A controlled study. Submitted for publication.

Hurks PPM, Hendriksen JGM, Vles JSH, Feron FJM, Kalff AC, van Zeben TMCB, Steyaert J, Kroes M, Jolles J. Executive functioning and behavioral problems (ADHD, $\mathrm{CD} / \mathrm{ODD}$ ) in school-aged children. Neuropsychology. Under revision.

Hurks PPM, Hendriksen JGM, Feron FJM, Jolles J, Vles JSH. Sequential and simulateous information processes in children with ADHD and children with comorbid ADHD and Learning Disabilities. Journal of Clinical Child and Adolescent Psychology. Under revision.

Keulers EHH, Hendriksen JGM, Feron FJM, Wassenberg R, Boschma I, Dings F, Jolles J, Vles JSH. Non-verbale leerstoornissten: spectrum of één syndroom? Tijdschrift voor Neuropsychologie. Under revision.

Tremmery S, Buitelaar JK, Steyaert J, Molenberghs G, Feron FJM, Kalff AC, Hurks PPM, Hendriksen JGM, van Zeben TMCB, Vles JSH, Jolles J. Diagnostic Continuity of ADHD in a community sample of primary school children: A three-year-follow-up. American Journal of Child Psychiatry. Submitted for publication. 
Hurks PPM, Vles JSH, Hendriksen JGM, Crolla IFAM, Feron FJM, Kroes M, Kalff AC, Bruckers L, Van Zeben TMCB, Steyaert J, Jolles J. Quantity and quality of sleep in school-aged children and the influence of behavioral and environmental factors on it: a longitudinal design. Submitted for publication.

Wassenberg R, Hendriksen JGM, Hurks PPM, Feron FJM, Keulers EHH, Vles JSH, Jolles J. Development of time awareness in school-aged children and the influence of sex, verbal ability, and parental education. Submitted for publication.

Keulers EHH, Hendriksen JGM, Feron FJM, Jolles J, Vles JSH. The effect of methylphenidate on reading performances in children with both Dyslexia and Attention Deficit/ Hyperactivity Disorder: A pilot study. Submitted for publication.

Wassenberg R, Hendriksen JGM, Hurks PPM, Feron FJM, Keulers EHH, Vles JSH, Jolles J. Development of time awareness in school-aged children and the influence of sex, verbal ability, and parental education. Submitted for publication.

Wassenberg R, Hendriksen JGM, Feron FJM, Hurks PPM, Jolles J, Vles JSH. Predictive value of cognitive and behavioural aspects of attention for academic outcome. Submitted for publication.

Hendriksen JGM, Keulers EHH, Feron FJM, Wassenberg R, Jolles J, Vles JSH. Subtypes of learning disabilities: neuropsychological and behavioral functioning of 495 children referred for multidisciplinary assessment. Submitted for publication.

Lataster T, Myin-Germeys I, Drukker M, Feron FJM, Gunther N, Van Os J. Sexual abuse, bullying and sub-clinical psychosis-like experiences in young adolescents. In preparation. 


\section{MISCELLANEOUS}

Vles JSH, Kroes M, Feron FJM. Maastrichtse Motoriek Test. Uitgeverij PITS, 2004. Handleiding, CD-rom, opdrachtlijsten, scorelijsten. Doelgroep: 5-6 jarige kinderen of oudere kinderen met motorische problemen. Informatie: www.pits-online.nl

\section{GENERAL PUBLICATIONS}

Feron FJM. Kindermishandeling. Werkboek Nascholing voor de huisarts, deel 3 van het thema traumata. Bureau PAOG van de Rijksuniversiteit Limburg, 1989.

Drukker M, Van der Linden J, Feron FJM, Van Os J. Sociale cohesie en sociaaleconomische status bevorderen gezondheid kinderen. Vitale Stad 2002; 5: 20-23.

Drukker M, Feron FJM, van Os J. Buurtkenmerken en Kwaliteit van Leven bij kinderen en volwassenen, een contextuele analyse. Tijdschr. V. Gezondheidswetenschappen 2003; 81(1): 9-18.

Leurs M, Kleijnen R, Consten K, Pennartz A, Feron F. Integrale ketenzorg binnen het onderwijscontinuüm van zorg. Remediaal 2003; 4(2): 16-22.

Thush C, Wiers RW, van den Bosch J, Opdenacker J, Theunissen N, en Feron FJM. "Leren drinken" Opzet en eerste resultaten van een preventieprogramma gericht op overmatig drinkende jongeren. Gedrag \& Gezondheid 2004; 32(3): 193-203.

Leurs M, Jansen M, Feron F. From school health promotion to integrated school health care - Schoolbeat in the Netherlands. Network News, the European network of health promoting schools, 2004, 8th issue, 22

Drukker M, Feron FJM, Van Os J. De buurt doet ertoe. Maastricht Kwaliteit van Leven Studie, eindrapportage. Maastricht: Universiteit Maastricht, 2005

Drukker M, Hardy C, Heurman L, Feron FJM. Overgewicht en obesitas bij Maastrichtse kinderen. Tijdschrift voor Jeugdgezondheidszorg. Submitted for publication. 